DR. 2555

LA-7455-MS

Informal Report

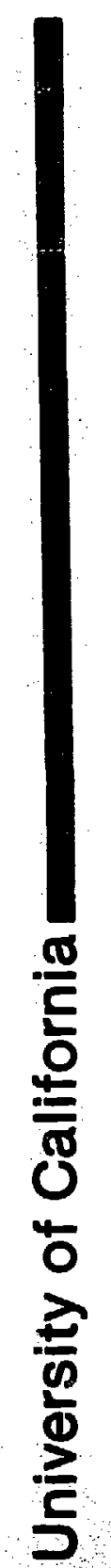

Sorption-Desorption Studies on Argillite

I. Initial Studies of Strontium, Technetium, Cesium,

Barium, Corium, and Europium

MASTER

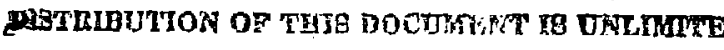

LOS ALAMOS SCIENTIFIC LABORATORY 
LA-7455-MS

Informal Report

UC.11 and UC-70

Issued: March 1979

\title{
Sorption-Desorption Studies on Argillite
}

\section{Initial Studies of Strontium, Technetium, Cesium, \\ Barium, Cerium, and Europium}

\author{
B. R. Erdal \\ R. D. Aguilar \\ B. P. Bayhurst \\ P. Q. Oliver \\ K. Wolfsberg
}

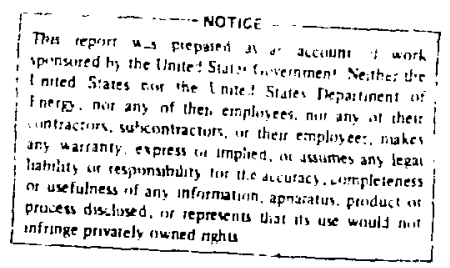




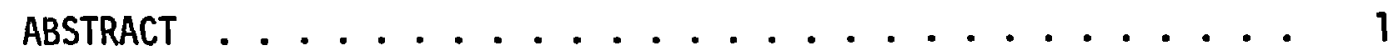

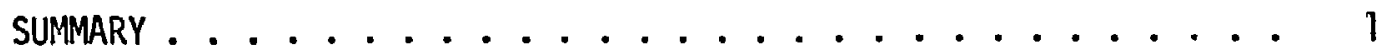

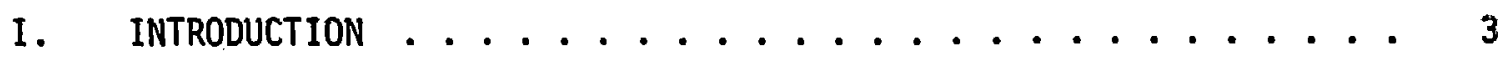

II. GEOLOGIC MATERIAL PROPERTIES .............. 3

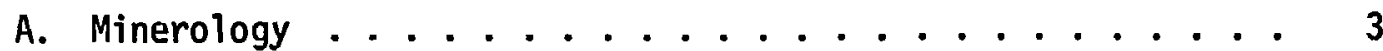

B. Cation Exchange Capacity .............. 4

C. Size Distribution Analysis ............ 5

D. Surface Area ................ 6

E. Groundwater Properties ............ 7

III. SORPTION OF STRONTIUM, CESIUM, BARIUM, CERIUM, AND EUROPIUM

A. Measurement Techniques ............. 8

1. Preparation of Tagged Solutions .......... 8

2. Sorption Measurements .............. 11

3. Desorption Measurements ............ 13

4. Assay of Radioactivity .............. 14

5. Calculations .................. 14

B. Results and Conclusions.............. 17

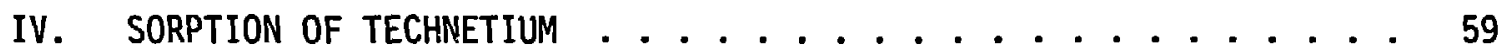

A. Measurement Technique .............. 59

B. Results and Conclusions ............. 62

V. SUMMARY .................... . . . 70

ACKNOWLEDGMENTS ......................... 70

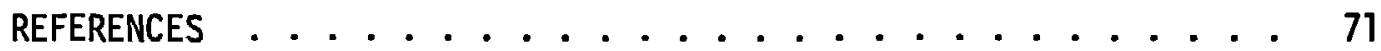




\title{
SORPTION-DESORPTION STUDIES ON ARGILLITE
}

\author{
1. Initial Studies of Strontium, Technetium, \\ Cesium, Barium, Cerium, and Europium
}

by

B. R. Erda1, R. D. Aguilar, B. P. Bayhurst,

P. Q. 01 iver, and K. Wolfsberg

\begin{abstract}
Distribution ratios were determined for sorptiondesorption of radioactive tracers between Eleana argillite available from the Nevada Test Site and a water prepared to be representative of the natural groundwater composition. The measurements were preformed at $22^{\circ} \mathrm{C}$ and $70^{\circ} \mathrm{C}$ under atmospheric oxygen conditions. The order of increasing distribution coefficient by element at both temperatures is Tc(VII), Sr, Cs, Ba, Eu, and Ce. The effects of surface area and mineralogy were also investigated.
\end{abstract}

\section{SUMMARY}

The most important barpier to the movement of dissolved radionuclides in geologic systems is retardation due to the interaction between the radionuclides and the geologic medium. This report sumarizes initial investigations on the behavior of various radionuclides using Eleana argillite fror: the Nevada Test Site (NTS).

A batch technique has been developed for all sorption and desorption measurements. One-gram quantities of the crushed and sieved rock were pre-equilibrated for a minimum of 2 weeks with a water having a composition similar to the natural water. The spiked water was prepared by a similar pre-equilibration with ground but unsieved material. The evaporated radionuclides were then dissolved in this pre-equilibrated water. Twenty-ml portions of the spiked water were shaken with the pre-equilibrated rock for various contact times, the mixture was separated by four separate centrifugations at $16000 \mathrm{rpm}$, and the solution was assayed for radioactivity. Due to the removal of some radionuclides by the container in which the measurements were performed, it was 
necessary to sample all or part of the solid fraction in order to obtain accurate values. Techniques and caloulational methods were developed for this purpose. The residue from the sorption measuremenis were employed for the desorption experiments using the same technique.

Various particle sizes ranging from 106 to $850 \mu \mathrm{m}$, and both ambient and elevated $\left(70^{\circ} \mathrm{C}\right)$ temperatures were used. Changes in the sorption-desorption behavior with time were examined for intervals of 1, 2, 4, and 8 weeks. The elements studied were $S r$, Tc(VII), Cs, Ba, Ce(III), Eu(III), U(VI), Pu, and Am. The measurements were performed under atmospheric oxygen conditions.

The sorption ratio ( $R_{d}=$ activity per $g$ of solid/astivity per ml of water) increases slowly with time presumably due to the slow interaction of the rock surface with the groundwatex. Surface alteration presumably is also the reason for the observation that it is more difficult to remove $\mathrm{Cs}, \mathrm{Sr}, \mathrm{Ba}, \mathrm{Ce}$, and $\mathrm{Eu}$ from the rock than it was to sorb these elements (desorption ratio greater than sorption ratio). Because there was little change in the surface area for the various particle size fractions studied, the sorption ratios did not vary strongly with paricle size. The sorption ratio for Cs did not change with temperature, while the $R_{d}$ values for $\dot{S} r$ and $B a$ increased with increasing temperature and those for $\mathrm{Ce}$ and Eu decreased. Tc(VII) did not sorb appreciably. 


\section{INTRODUCTION}

A major requirement for the evaluation of the long-term safety of nuclear waste disposal in a geologic storage environment is a thorough understanding of the mechanisms and phenomenology of the sorption-desorption behavior of the various radionuclides that are biologically hazardous. This knowledge will help in the prediction of the fate of the radionuclides during the length of time required for radioactive decay to reduce the waste to safe levels.

This report presents the results of laboratory investigations of the sorption behavior of various radionuclides with the Eleana argillite found at the Nevada Test Site (NTS). The investigation was intended to satisfy two functions. First, site specific information on this medium was needed in order to help make a decision as to the feasibility of using the Eleana formation as a waste repository. Second, this work contributes to the large general data base of sorption information for a variety of representative geologic media.

The parameter most commonly used for describing equilibrium sorptiondesorption ion-exchange reactions is the distribution coefficient, $k_{d}$ (see for example, Ref. 1). The $K_{d}$ is defined as the concentration per gram of a species on a solid phase divided by its concentration per ml in the liquid phase at equilibrium. This parameter currently is being used to describe the behavior of radionuclides in geologic systems (see, for example, Refs. 2-4) even though equilibrium may not have been established.

\section{GEOLOGIC MATERIAL PROPERTIES}

A. Mineralogy

Four different samples of the Eleana argillite were obtained from hole UEl7e at the Nevada Test Site by A. R. Lappin, Sandia Laboratories, Albuquerque (SLA). The samples had all been wrapped in aluminum foil and waxed when they were origina11y taken. The depths from which they were removed were 121.8-122.2 $\mathrm{m}, 364.8-$ $365.2 \mathrm{~m}, 548.2-548.4 \mathrm{~m}$, and $717.2-717.3 \mathrm{~m}$. They were labelled $\mathrm{CN} 3, \mathrm{CN} 4, \mathrm{CN} 1$, and CN2, respectively. Thin sections of this material were prepared and examined by optical microscopy to determine grain size and original mineralogy. The following were obtained by R. M. Vidale, Los Alamos Scientific Laboratory (LASL).

Major minerals - detrital

Quartz - angular, detrital in appearance
Approx. Average

Grain Diameter
0.01 min 
Major minerals - metamorphic

These are very fine grained and approach

the limit of microscope resolution

$0.001 \mathrm{~mm}$

Sericite

Chlorite, Opaques

Probable albite

Carbonate (siderite)

Pyrophyzlite (by $x$-ray powder diffraction)

Opaques

After unwrapping the samples, CN1 and CN2 were reduced in size with hammers, with a Braun Chipmunk apparatus, and finally with a puiverizer having the plates set to produce a maximum grain size of about $1 \mathrm{~mm}$. Each material was graded by use of Tyler sieves (ASTM E-11 specification) into the following size fractions: $>850 \mu \mathrm{m}, 500-850 \mu \mathrm{m}, 355-500 \mu \mathrm{m}, 250-355 \mu \mathrm{m}, 180-250 \mu \mathrm{m}$, 150-180 $\mu \mathrm{m}_{2}, 106-150 \mu \mathrm{m}_{3}$, and $<106 \mu \mathrm{m}$.

The 106-150 $\mu \mathrm{m}$ and 355-500 $\mu \mathrm{m}$ fractions of samples CN1 and CN2 were selected for subsequent use in some of the sorption studies. The fractions were washed briefly with deionized water to remove dust, and they were then dried in air, pumped in a vacuum desiccator containing Drierite for one hour, and dried in the desiccator for two days.

About $100 \mathrm{~g}$ of each of the original samples (CST-4) were also pulverized in a ball mill, using tool-steel components, until the entire quantity passed through a 75- $\mu \mathrm{m}$ sieve. They were then washed and dried as above.

A fourth set of samples was prepared by simply taking a few pieces of the original sample from the Braun Chipmunk from cores CN3 and CN4. These pieces, which had an approximate diameter of $2-5 \mathrm{~mm}$, were simply washed and dried as before. These are hereafter named "chunk" samples.

A petrographic description of the fractions from one core is given in Table I (as determined by J. R. Smyth, LASL).

B. Cation Exchange Capacity

The cation exchange capacity (CEC) of each of the 106-150 $\mu \mathrm{m}$ and 355-500 um fractions selected for study was measured using both cesium and strontium. The measurement was made ${ }^{5}$ by shaking weighed $100-\mathrm{mg}$ portions of the solids 
TABLE I

PETROGRAPHIC ANALYSIS OF CN1 FRACTIONS

\begin{tabular}{|c|c|c|c|}
\hline & \multicolumn{3}{|c|}{ Percent in Sieve Fraction ( $\mu \mathrm{m})$} \\
\hline & $106-150$ & $250-355$ & $355-500$ \\
\hline Detrital Quartz & $3 ?$ & 28 & 25 \\
\hline Other Detrital & 2 & 3 & 4 \\
\hline Hematite & 6 & 5 & 9 \\
\hline Clay Groundmass & 60 & 64 & 62 \\
\hline
\end{tabular}

with $20 \mathrm{ml}$ of $\approx 0.5 \mathrm{M} \mathrm{CsCl}(\mathrm{pH}=8.2)$ or $\approx 0.5 \mathrm{M} \mathrm{SrAc}_{2}(\mathrm{pH}=8.5)$ in deionized water for 8-14 days. The solutions were spiked with ${ }^{137} \mathrm{Cs}$ and ${ }^{85} \mathrm{Sr}$, respectively, and the cation concentrations were determined by atomic absorption. spectrophotometry. After the appropriate contact iime, the phases were separated by centrifugation, the solids were washed briefly with water, and they were counted with a $\mathrm{NaI}(\mathrm{Tl})$ detector to ascertain the amount of strontium or cesium that had exchanged. The resuits from these measurements are given in Table II. The values indicate that samples from CN1 have a higher CEC than those from CN2. The CEC values determined using strontium tend to be higher than those obtained from cesium. However, due to the uncertainties in the technique, the differences may not be significant.

C. Size Distribution Analysis

The size distributions of the particles in the selected fractions were measured by screening techniques by R. E. Honne11, LASL. For the range data, the sizes of the smallest screens through which $100 \%$ of the material passed were not recorded. However, the screen size listed in Table II as the upper bound for each sample is the size immediately larger than the size recorded as having collected the largest particles in a sample. The median values in Table II were calculated by linear interpolation between screen size data that most closely bracketed the median mass. Similarly, the upper and lower quartile values were calculated by linear interpolation between the screen data that immediately bracketed the $75 \%$ and $25 \%$ mass values, respectively. The semi-interquartile range as defined by cramer $^{6}$ is a measure of the dispersion of the particle size distribution. 
TABLE II

CATION EXCHANGE CAPACITY AND SIEVE ANALYSIS

\begin{tabular}{|c|c|c|c|c|c|c|}
\hline \multirow[b]{2}{*}{ Sample } & \multirow[b]{2}{*}{$\begin{array}{l}\text { Mesh Size } \\
(\mu \mathrm{m}) \\
\end{array}$} & \multicolumn{2}{|c|}{$\begin{array}{c}\text { Cation Exchange } \\
\text { Capacity } \\
\text { (meg/100g) }\end{array}$} & \multicolumn{3}{|c|}{$\begin{array}{c}\text { Particle Size } \\
\text { Distribution }(\mu \mathrm{m})\end{array}$} \\
\hline & & $\underline{\text { Cs }}$ & $\underline{s r}$ & Range & Median & $\begin{array}{c}\text { Semi-inter- } \\
\text { Quartile Range } \\
\end{array}$ \\
\hline \multirow[t]{2}{*}{$\mathrm{CN} 1$} & $106-150$ & 14 & 17 & $75-177$ & 107 & 12 \\
\hline & $355-500$ & 14 & 16 & $300-595$ & 415 & 39 \\
\hline \multirow[t]{2}{*}{$\mathrm{CN}^{*}$} & $106-150$ & & & $45-210$ & 122 & 16 \\
\hline & $355-500$ & & & $250-595$ & 426 & 38 \\
\hline \multirow[t]{2}{*}{ CN2 } & $106-150$ & 8 & 10 & & & \\
\hline & $106-150$ & 8 & 10 & & & \\
\hline
\end{tabular}

*These samples were not treated by the washing and drying procedure before use; they were simply dried in the vacuum desiccator.

\section{Surface Area}

The surface area of the fractions has been determined by two different techniques, the BET method ${ }^{7}$ and the ethylene glycol method. ${ }^{8-10}$ The values are summarized in Table 111. The BET method employed nitrogen as the absorbate. A portion of the ground and pulverized 106-150 $\mu \mathrm{m}$ unwashed material from CN1 was also used as an intercomparison of BET values determined at LASL and Sandia (A. W. Lynch and R. G. Dosch) laboratories. The values were 12.5 and 9.9 $\mathrm{m}^{2} / \mathrm{g}$ from LASL and 10.2 and 9.1 from SLA, which indicates satisfactory agreement. Briefly the equilibrium ethylene glycol procedure ${ }^{8,9}$ consists of wetting a dried and weighed sample of calcium saturated material with glycol. This is then followed by equilibration in an evacuated desiccator containing an anhydrous calcium chloride-ethylene glycol solvate. The equilibration is repeated until the weights become constant. This presumably indicates that only a monolayer remains. The results obtained using the standard procedure are shown in the fourth column of Table III. 
TABLE III

SURFACE AREA $\left(\mathrm{m}^{2} / \mathrm{g}\right)$ MEASUREMENTS

\begin{tabular}{|c|c|c|c|c|}
\hline \multirow[b]{2}{*}{ Sample } & \multirow[b]{2}{*}{$\begin{array}{l}\text { Mesh Size } \\
(\text { (um) }\end{array}$} & \multirow[b]{2}{*}{ BET } & \multicolumn{2}{|c|}{ Ethylene Glycol } \\
\hline & & & $\begin{array}{c}\mathrm{CaCl}_{2} \\
\text { Pretreaqment }\end{array}$ & $\begin{array}{l}\text { No } \mathrm{CaCl}_{2} \\
\text { Pretreatment }\end{array}$ \\
\hline \multirow[t]{2}{*}{ CN1 } & $106-150$ & 5.22 & 50,47 & 53 \\
\hline & $355-500$ & 7.61 & 45,64 & $\sim 57$ \\
\hline \multirow[t]{2}{*}{$\mathrm{CNI}$ * } & $105-150$ & 12.5 & 51,48 & \\
\hline & $355-500$ & 9.9 & 64,49 & \\
\hline CN2 & $<75$ & & 75 & \\
\hline
\end{tabular}

*These samples were not treated by the washing and drying procedure before use; they were simply dried in the vacuum desiccator.

The equilibrium ethylene glycol method ${ }^{8,9}$ requires that the samples be saturated with calcium prior to treatment with the glycol. This is needed in order to make the systems homoionic. ${ }^{10}$ In order to verify this requirement, some surface areas were also determined without this pretreatment. This was also done to see if the prior treatment had degraded the samples. These data (see Table III) would seem to indicate that the pretreatment is necessary for argillite samples. This is not surprising since the clay content in the argillite is significant.

E. Groundwater Properties

The water used in these studies was made up in the laboratory to simulate the composition of a natural groundwater from hole UE16d at the NTS. The natural water composition represents an average sample taken by $A$. R. Lappin, SLA, from the depth interval $24.7-645.9 \mathrm{~m}$. This water is not strictly an Eleana water since virtually all of the production was from the Tippipah formation and only a small amount of production was from the uppermost quartzites within the Eleana argillite in this hole. This water is therefore representative of waters that would enter the Eleana from above. The analysis of this water was performed 
by R. L. McAvay, U. S. Geological Survey (see Table IV).

The composition of this natural water was simulated in the laboratory according to a prescription developed by Dosch, SLA. In this procedure, 187.1 $\mathrm{mg} \mathrm{CaCO} 3,32 \mathrm{mg} \mathrm{MgCO}_{3}$ was dissolved in $800 \mathrm{~m} \ell$ deionized water saturated with carbon dioxide. Then $1 \mathrm{ml} \mathrm{NaF}$ solution $\left(1.26 \mathrm{mg} / \mathrm{ml}\right.$ ), $1.347 \mathrm{~g} \mathrm{Na}_{2} \mathrm{SiO}_{3} \cdot 5 \mathrm{H}_{2} \mathrm{O}$, and $0.35 \mathrm{~g} \mathrm{H}_{2} \mathrm{SiO}_{3}$ were dissolved in $20 \mathrm{ml}$ deionized water, and $10 \mathrm{ml}$ was added to the first solution. Similariy, 50 ml of a solution containing $\mathrm{KCl}(0.25$ $\mathrm{mg} / \mathrm{ml}), \mathrm{CaCl}_{2}(0.22 \mathrm{mg} / \mathrm{ml})$, and $\mathrm{MgSO}_{4}(1.56 \mathrm{mg} / \mathrm{ml})$ was added to the first solution, as were $1 \mathrm{ml} \mathrm{FeCl}_{3} \cdot 6 \mathrm{H}_{2} \mathrm{O}$ solution $(0.14 \mathrm{mg} / \mathrm{ml})$, and $1 \mathrm{ml} \mathrm{SrCl}_{2} \cdot 6 \mathrm{H}_{2} \mathrm{O}$ solution $(1.28 \mathrm{mg} / \mathrm{ml})$. The solution was then diluted to $1.0 \ell$ with deionized water, followed by sparging with carbon dioxide for at least $12 \mathrm{~h}$. After sparging the solution with nitrogen until a pH of about 8 was reached, it was allowed to air-equilibrate for at least one week prior to use. The typical atmospheric pressure at Los Alamos is $\sim 580 \mathrm{~mm} \mathrm{Hg}$.

Rock pre-equilibrated water was used in all the sorption measurements given in this report. This was prepared by contacting batches of the "synthetic" water with ground material that had not been sieved. The contact time was at least two weeks with a solution volume to solid ratio of $20 \mathrm{ml} / \mathrm{g}$. The phases were separated by centrifugation at $7000 \mathrm{rpm}$ followed by filtration through a $0.45 \mu \mathrm{m}$ Nuclepore filter paper. This procedure was used for preparation of waters pre-equilibrated at ambient temperature $\left(22 \pm 2^{\circ} \mathrm{C}\right)$ and at elevated temperature $\left(70 \pm 1^{\circ} \mathrm{C}\right)$. The same rock phase with fresh "artificial" water was used in all subsequent batches. Table IV summarizes the results of atomic absorption spectrophotometric analysis of these waters. The composition of the $70^{\circ} \mathrm{C}$ waters may be approaching steady state, but this is not true for the $20^{\circ} \mathrm{C}$ waters. Selected batches of these waters were also sent to the U. S. Geological Survey (R. L. McAvay) for analysis and these results are given in Table $\mathrm{V}$. The $\mathrm{pH}$ of each of the waters was measured using glass electrodes, and standard reference electrodes.

III. SORPTION OF STRONTIUM, CESIUM, BARIUM, CERIUM, AND EUPOPIUM A. Measurement Techniques 1. Preparation of Tagged Solutions

A11 traced waters used in these studies were prepared using the pre-equilibrated waters described previously and the following commercially available carrier-free or high sp r.ific activity radionuclides: ${ }^{85} \mathrm{Sr},{ }^{137} \mathrm{Cs},{ }^{133} \mathrm{Ba}$, 


\section{TABLE IV}

ANALYSIS OF WATERS BY ATOMIC ABSORPTION SPECTROPHOTOMETRY

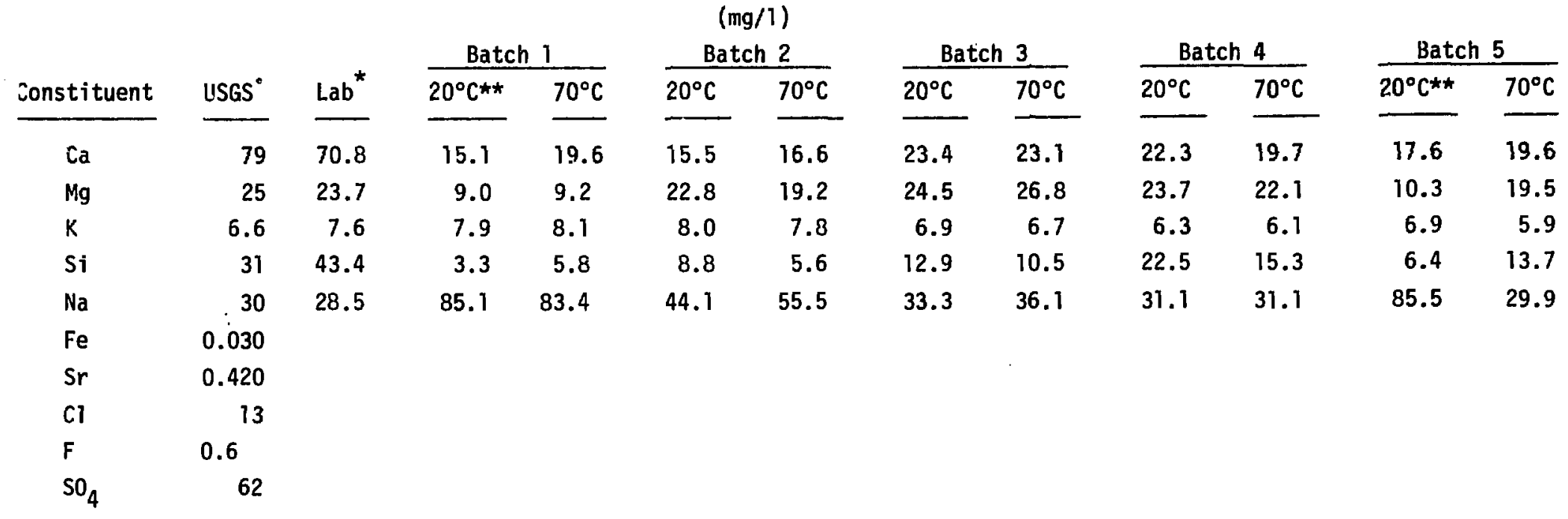

- Composition of water obtained in the field (R. L. MCAvay, USGS).

* Composition before equilibration

** Started with a fresh portion of rock 
TABLE V

USGS WATER ANALYSES

\begin{tabular}{|c|c|c|c|}
\hline & & & Batch 5 \\
\hline & $22^{\circ} \mathrm{C}$ & $\begin{array}{c}70^{\circ} \mathrm{C} \\
(\mathrm{mg} / \ell)\end{array}$ & $22^{\circ} \mathrm{C}$ \\
\hline Barium (Ba) & 0.3 & 0.3 & 0.3 \\
\hline Calcium (Ca) & 38 & 21 & 18 \\
\hline Iron (Fe) & 0.02 & 0.02 & 0.02 \\
\hline Lithium (Li) & 0.01 & 0.01 & 0.02 \\
\hline Magnesium (Mg) & 23 & 21 & 9.8 \\
\hline Potassium (K) & 6.9 & 6.6 & 7.7 \\
\hline Silicon (Si) & 16 & 11 & 4.3 \\
\hline Sodium (Na) & 32 & 33 & 96 \\
\hline Strontium (Sr) & 0.60 & 0.40 & 0.57 \\
\hline Bicarbonate & 190 & 130 & 260 \\
\hline Carbonate & 0 & 0 & 0 \\
\hline Chloride & 15 & 15 & 15 \\
\hline Fluoride & 0.7 & 0.6 & 0.9 \\
\hline Sulfate & 70 & $\begin{array}{c}78 \\
(\text { meq } / \ell)\end{array}$ & 74 \\
\hline Total Cations & 5.357 & 4.380 & 6.077 \\
\hline Total Anions & 5.031 & 4.209 & 6.273 \\
\hline
\end{tabular}


${ }^{141} \mathrm{Ce}$, and ${ }^{152} \mathrm{Eu}$. The concentrations for these tracers are given in Table VI. The specific activities given are those provided by the manufacturer. The activities $(\mu \mathrm{Ci} / \mathrm{ml}$ ) were measured on a calibrated $\mathrm{Ge}(L i)$ detector system (see below). The element coricentrations given in Table VI only include that consciously added with the tracer. The appropriate volumes of tracers needed for a set of measurements were evaporated to dryness in a washed polyethylene tube overnight on a steam bath. Concentrated hydrochloric acid was added, and the mixture was taken dry again in order to convert the salts to chlorides. The appropriate volume of pre-equilibrated groundwater was added, and the mixture was stirred for $\sim 24 \mathrm{~h}$. The mixture was centrifuged for one hour at $16000 \mathrm{rpm}$, followed by filtration through a $0.45-\mu \mathrm{m}$ Nuclepore filter paper. The resulting tracer solution was used for the sorption measurements within about 0.5 day. An aliquot of the final solution was also removed for assay of the initial activity of each of the tracers in the solution. This aliquot was acidified with hydrochloric acid before assaying in order to stabilize the solution. The density of the final solution was also measured. During the tracer preparation, no cesium, strontium, or barium was lost, but about $50 \%$ of the cerium and europium was lost onto the filter paper.

One should note that the pre-equilibrated water itself may have considerable concentration of the carriers for each of these tracers. This concentration will be measured in the future when neutron activation analyses are made on each of the batches of water used in this study.

\section{Sorption Measurements}

Batch sorption experiments were performed by shaking weighed one-gram quantities of the crushed rock with $20 \mathrm{ml}$ untraced pre-equilibrated water for a period of about two weeks. The samples were contained in stoppered $40 \mathrm{~m} \ell$ polyethylene centrifuge tubes at ambient temperature or in sealed polypropylene tubes at elevated temperature. All tubes were washed with deionized water prior to use. The phase were then separated by centrifuging at 16000 rpm for one hour. The weight of the wash solution remaining with the solid phase was obtained by weighing the tube and solid before and after the preequilibration. A $20-m \ell$ volume of the tagged pre-equilibrated water was then added to the tube, the solid sample was dispersed with vigorous shaking, and the mixture wus agitated gently for a given time. Typically, 1, 2, 4, and 8 
TABLE VI

ELEMENT CONCENTRATIONS

Tracer

\begin{tabular}{ll}
\hline Specific & \\
Activity & Activity \\
$\left(\mathrm{mC}(\mathrm{g} / \mathrm{g})^{*}\right.$ & $(\mu \mathrm{C} \mathrm{C} / \mathrm{m} \ell)$ \\
\hline
\end{tabular}

${ }^{85} \mathrm{Sr}$

${ }^{137} \mathrm{Cs}$

$133 \mathrm{Ba}$

${ }^{141} \mathrm{Ce}$

$152 \mathrm{Eu}$
300

CF

8120

600

2638
21

34

51

110

32
Traced Water

$\begin{array}{ccc}\begin{array}{c}\text { Tracer } \\ \begin{array}{c}\text { Concentration } \\ (\mu \ell / \mathrm{ml})\end{array}\end{array} & \begin{array}{c}\text { Element } \\ \text { Concentration } \\ \text { (molar) }\end{array} \\ 1.5 & & 1.2 \times 10^{-6} \\ 0.5 & & 1.4 \times 10^{-9} \\ 0.3 & & 2.4 \times 10^{-8} \\ 1 . & & 1.3 \times 10^{-6} \\ 1 . & & 8.0 \times 10^{-8}\end{array}$

${ }^{\star}$ CF means carrier-free.

week contact times were used. The shaking rates were 200 oscillations per minute for the ambient temperature studies, and 80 ocillations per minute for the $70^{\circ} \mathrm{C}$ samples. A water bath shaker was used for the latter studies. At the end of the shaking period, the aqueous phase was separated from the solids by four centrifugings, each in a new polyethylene centrifuge tube, for one hour at $16000 \mathrm{rpm}$. An aliquot of the final solution was then remioved and placed in a standard scintillation counting polyvial. This solution was acidified with hydrochloric acid, and it was then assayed for the remaining activities. The $\mathrm{pH}$ of the solutions before and after contact with the rock were also recorded.

All solutions remaining from the sorption measurements, including the solution used for radioactivity assay, have been stored for future measurement of the final concentration of the major cations in these solutions. The procedures for these analyses are currently being developed on a Spectrametrics, Inc., model 3 spectrograph.

The same sorption procedure was also performed using a tube that did not have a solid phase present. This "control" sample was used to indicate if any of the radionuclides were likely to be removed by the container. In all cases (see below), the cesium, remained completely in solution. However, this was not 
the case for barium, cerium, and europium, and for strontium at $70^{\circ} \mathrm{C}$. It was felt that the amount of sorption on the container would vary, depending on whether or not solid material was present, since elements appear to adsorb on any available surface. Therefore, the presence of a solid phase would tend to reduce the fraction of the activity adsorbed on the container. This effect would be especially large when crushed rock solid phase are used since they have an appreciable surface area (see Table III).

In order to determine the amount of activity remaining with the solid phase, whether due to sorption, precipitation, centrifugation of a colloid with the solid, or by some other mechanism, a fraction $(\sim 25 \%)$ of the solid was removed for radioactivity assay. The solid phase was well mixed prior to removal of the fraction. The fraction of the solid removed was determined from the activity of ${ }^{137} \mathrm{Cs}$ in the solid aliquot, in the solution, and in the initial activity. This method is reasonable since cesium did not adsorb on the container walls. A check was made by weighing the tube before and after removing the sample. Of course, the limitation in this method is how representative the fraction remained is of the entire solid.

The two selected sieve fractions from cores CN1 and CN2 were used for studies at ambient $\left(22 \pm 2^{\circ} \mathrm{C}\right)$ and elevated $\left(70 \pm 1^{\circ} \mathrm{C}\right)$ temperatures. The waters from the first pre-equilibration (Table IV) were used.

The $<75-\mu \mathrm{m}$ samples from ail four cores (CN1-CN4) and the chunk samples from $\mathrm{CN} 3$ and $\mathrm{CN} 4$ were treated in a similar manner using waters from the second pre-equilibration (Table IV).

\section{Desorption Measurements}

Desorption measurements were made for all samples previously used for the sorption measurements, except for the eight week sorption samples. The assay of activity on the solid sample was done as described earlier. A 15-mL volume of untagged pre-equilibrated water was used for each measurement in order to keep the volume to solid ratio $\approx 20$. Contact times of 2,4 , and 8 weeks were used for the 4,2 , and 1 week sorption measurements, respectively. The same procedure was used for separation of the phases and for radioactivity assay as was used in the sorption measurements. This includes the assay of the radioactivity on a fraction of the solid material. 


\section{Assay of Radioactivity}

The solution samples were all counted on a calibrated, 14\%, coaxial Ge(Li) detector. An $11 \% \mathrm{Ge}(\mathrm{Li})$ detector system was used for the solid fractions. The two different detector systems were carefully intercalibrated. The 4096 channel spectra were recorded in multichannel analyzers that are connected to a common PDP-9 computer, where they were analyzed on-line by RAYGUN, our in-house gammaray spectroscopy program. This program is designed for use on a minicomputer and it includes spectral interpretation. Its operation involves: 1) a search for background and peak (nonbackground) regions; 2) a preliminary peak search in the nonbackground regions; 3 ) construction of a step function under the peak(s) in each region; 4) construction of an underlying continuum by smoothing the background together with the step functions; 5) a search for peak regions and peaks with stricter criteria; 6; determination of peak positions and areas and correction for photopeak efficiency; if a multiplet is encountered, separation of the peaks by using peak shape information; 7) a search of the appropriate gamma-ray branching ratio library to find those nuclides and gamma-rays that appear to be in the spectrum, eliminating those that are not plausible; 8 ) set up an interference matrix, $\left[A_{i j}\right]$, where $A_{i j}=$ branching ratio for the $i^{\text {th }}$ peak identified corresponding to the $j^{\text {th }}$ nuclide identified; 9 ) by a least-squares iteration, determine a solution to

$$
Y_{i}=\Sigma_{j} A_{i j} X_{j}
$$

where $Y_{i}=$ observed intensity of the $i^{\text {th }}$ peak and $X_{j}=$ disintegration rate for the $j^{\text {th }}$ nuclide; 10) correction of the disintegration rate observed for each radionuclide at the counting time to a specified time; 11 ) performance of an error analysis and output of the results in suitable form. A minimum of two counts, separated by at least one day were taken for each sample. The results from the RAYGUN analyses for each count were simply averaged prior to use.

\section{Calculations}

The equilibrium distribution coefficient, $k_{d}$, for the distribution of activity between two phases is conventionally defined as:

$$
K_{d}=\frac{\text { activity in solid phase per unit mass of solid }}{\text { activity in solution per unit volume of solution }} .
$$


It is not known whether equilibrium is achieved for the types of measurements reported here. However, the distribution of activities between the phases was measured, and throughout this report the resulting value is called the sorption ratio, $R_{d}$, which is otherwise identical to $k_{d}$, but does not imply equilibrium. The following equation was used to calculate the sorption ratios for all cesium analyses and for strontium at ambient temperature:

$$
R_{d}=\frac{R \cdot A_{f}-A_{t}}{A_{f}} \cdot \frac{V}{W} \text {, }
$$

where

$A_{f}=$ the activity per $m \ell$ of a given radionuclide in the tagged water (feed) added to the sample

$A_{t}=$ the activity per ml in the supernatant solution after the required contact time

$W=$ the weight (grams) of solid material used

$V$ = the total final volume of supernatant solution

$R$ = the dilution factor to take into account the residual solution from the wash.

The amount of residual solution $\left(V_{r}\right)$ left with the solid material was calculated from the weight increase of the sample plus container $\left(g_{r}\right)$ after the prewashed, and the measured density $\left(\rho_{r}\right)$ of the solutions used:

$$
v_{r}=g_{r} / \rho_{r}
$$

Therefore, for these measurements (20.0 ml spiked water volume)

$$
v=20.0+v_{r}
$$

and

$$
R=20.0 /\left(20.0+v_{r}\right)
$$

The activities in the control samples were not used in the calculations. However, the results would not be changed since no container effect was observed in these experiments.

The standard deviation for each measurement was obtained from the errors associated with the activity measurements (generally less than $2 \%$ ), the $3 \%$ uncertainty assumed for $g_{r}$, a $0.5 \mathrm{mg}$ uncertainty in $W$, and a $0.5 \%$ uncertainty in the volumes. The errors were propagated using the rule for change of variables in a moment matrix assuming independence of the variables and using Eq. 1. 
For the barium, cerium, and europium cases and the strontium at $70^{\circ} \mathrm{C}$, a different calculational method was used. Since a contailler problem has never been observed for cesium, the sorption ratio for cesium was used as an iniernal monitor. The activity of the element of interest and of cesium in the solid and liquid samples was measured. The sorption ratio is

$$
R_{d}=\frac{A_{s}}{A_{t}} \cdot \frac{V}{W},
$$

where $A_{S}=$ activity on the solid. If a ratio of $R_{d}$ values is calculated using Eq. 2 one has, after rearrangement,

$$
R_{d x}=\frac{\left(\frac{A_{s x}}{A_{s m}}\right)}{\left(\frac{A_{t x}}{A_{t m}}\right)} R_{d m},
$$

where the $x$ and $m$ refer to the element of interest and cesium, respectively. This equation was used to calculate sorption ratio for the element of interest since the $R_{d}$ for cesium was calculated using Eq. 1, in the same experiment.

The standard deviation was calculated using the same procedure as previously given but with Eq. 3 .

For the desorption measurements, the sorption ratio was again calculated assuming that the cesium did not sorb on the container. The activity, $A_{\mathrm{sm}}^{0}$, of ${ }^{137} \mathrm{Cs}$ on the solid at the beginning of a desorption measurement was calculated using

$$
A_{s m}^{0}=A_{m}^{0}\left(1-f_{m}\right)\left(1-f_{d}\right)
$$

where

$$
\begin{aligned}
A_{m}^{0}= & \text { the initial }{ }^{137} \text { Cs activity at the beginning of the sorption } \\
& \text { measurement, } \\
f_{m}= & \text { the fraction of }{ }^{137} \text { Cs activity remaining in solution after the } \\
& \text { sorption measurement, and } \\
f_{d}= & \text { the fraction of the solid removed from the sample prior to } \\
& \text { beginning the desorption measurement. }
\end{aligned}
$$


The cesium sorption ratio was then calculated by

where

$$
R_{d m}=\frac{A_{s m}^{0}-A_{t m} \cdot V}{A_{t m} \cdot V} \frac{V}{\left(1-f_{d}\right) W} .
$$

$$
v=15.0+v_{r} .
$$

The sorption ratios for all other species in the desorption measurement were then calculated using the sorption ratio for cesium and Eq. 3. An error analysis similar to that described earlier was also performed.

B. Results and Conclusions

The results for the sorption ratio measurements for ambient temperature conditions are given in Tables VII- $X$, while those obtained at elevated temperature are given in Tables XI-XIV. If no sorption ratio is listed in these tables for a given contact time, this is due to the difficulty of measuring the activity in the solution. This means that aither the sorption ratio is too large or that the decay time was too long (particularly important for ${ }^{141} \mathrm{Ce}$ ). Limits for the $R_{d}$ values have not been estimated.

The initial $\mathrm{pH}$ values of the tagged pre-equilibrated water used for the measurements involving the 106-150 $\mu \mathrm{m}$ and 355-500 $\mu \mathrm{m}$ fractions from CN1 and CN2 were 8.65 and 8.70 for the ambient and elevated temperature measurements, respectively. The final $\mathrm{pH}$ values for these samples are given in Tables XV and XVI. The initial $\mathrm{pH}$ values of the tagged pre-equilibrated water used for the measurements for the $<75 \mu \mathrm{m}$ fractions and the "chunk" samples were $\approx 8.6$ and 8.63 for the $20^{\circ} \mathrm{C}$ and $70^{\circ} \mathrm{C}$ conditions, respectively, and the final $\mathrm{pH}$ values for these experiments are given in Tables XVII-XVIII. The tables also include a parameter, $L / S$, which is simply the ratio of the $R_{d}$ value calculated using Eq. 1 (i.e., no correction for container effects) to the $R_{d}$ calculated using Eq. 3 (i.e., corrected for container effects). The observation that few of the $L / S$ values are less than one indicates that the sampling of the solid phase was satisfactory for these measurements. Table XIX gives the final $\mathrm{pH}$ values for all control samples and also the percentage of the activity of each of the nuclides that remained in solution. The $R_{d}$ values are shown graphically in Figs. 1-30.

Equation 1 was used to calculate the sorption ratios for cesium under all conditions employed since the container effect was very low. This equation was 
TABLE VII

SORPTION RATIOS, SAMPLE CN1, AMBIENT TEMPERATURE

\begin{tabular}{|c|c|c|c|c|c|c|c|}
\hline \multirow{2}{*}{$\begin{array}{l}\text { Fraction } \\
(\mu \mathrm{m}) \\
\end{array}$} & \multirow{2}{*}{$\begin{array}{c}\text { Sorption } \\
\text { Time } \\
\text { (days) } \\
\end{array}$} & \multirow{2}{*}{$\begin{array}{c}\text { Desorption } \\
\text { Time } \\
\text { (days) } \\
\end{array}$} & \multicolumn{5}{|c|}{ Sorption Ratio, $R_{d}(m \ell / g)^{\star}$} \\
\hline & & & $\underline{\text { Cs }}$ & $\underline{s r}$ & $\underline{\mathrm{Ba}}$ & $\underline{\mathrm{Ce}(\mathrm{III})}$ & EU(III) \\
\hline \multirow[t]{7}{*}{$106-150$} & 6.75 & & $590(2.1)$ & $69.4(2.6)$ & $413(3.6)$ & $4410(4.1)$ & $4340(4.4)$ \\
\hline & & 55.65 & $2810(7.3)$ & $50.0(6.8)$ & $831(5.9)$ & & $43400(8.9)$ \\
\hline & 13.74 & & $864(2.3)$ & $76.0(2.6)$ & $507(3.9)$ & $8290(4.7)$ & $6310(4.4)$ \\
\hline & & 27.61 & $2130(7.2)$ & $46.8(6.3)$ & $732(5.7)$ & & $58400(.11)$ \\
\hline & 26.94 & & $992(2.5)$ & $77.2(2.4)$ & $629(4.1)$ & $22500(6.2)$ & $18600(6.2)$ \\
\hline & & 13.63 & $2460(7.3)$ & $49.2(6.3)$ & $773(5.8)$ & & $121000(15)$ \\
\hline & 55.73 & & $1540(2.4)$ & $82.8(2.6)$ & $866(3.6)$ & $43100(9.6)$ & $43100(7.0)$ \\
\hline \multirow[t]{7}{*}{$355-500$} & 6.74 & & $823(2.3)$ & $74.2(2.6)$ & $365(4.2)$ & $5780(5.0)$ & $7340(5.6)$ \\
\hline & & 55.65 & $2940(7.2)$ & $48.2(6.1)$ & $615(5.5)$ & & $159000(21)$ \\
\hline & 13.73 & & $854(2.4)$ & $74.3(2.6)$ & $441 \quad(3.9)$ & $6690(5.0)$ & $4920(4.4)$ \\
\hline & & 2761 & $2270(7.2)$ & $50.9(6.4)$ & $503(5.7)$ & & $61000(12)$ \\
\hline & 26.94 & & $1090(2.5)$ & $79.0(2.4)$ & $661(4.1)$ & $24700(8.2)$ & $20200(7.9)$ \\
\hline & & 13.63 & $2270(7.2)$ & $48.0(6.0)$ & $516(5.6)$ & & $61200(9.9)$ \\
\hline & 55.72 & & $2410(2.5)$ & $80.3(2.5)$ & $1000(3.7)$ & $47900(12)$ & $49200(8.5)$ \\
\hline
\end{tabular}

\footnotetext{
ॠThe values in parentheses are the standard deviations for a single measurement of the $R_{\text {f }}$ values expressed in percent; these were obtained from the errors associated with the activity measurements and estimated uncertainties for the various parameters entering into the calculation; these estimated uncertainties were propagated using the ivi?e for change of variables in a moment matrix assuming independence of the variables.
} 
TABLE VIII

SORPIION RATIOS, SAMPLE CN2, AMBIENT TEMPERATURE

\begin{tabular}{|c|c|c|c|c|c|c|c|}
\hline \multirow{2}{*}{$\begin{array}{c}\text { Fraction } \\
(\mu \mathrm{m}) \\
\end{array}$} & \multirow{2}{*}{$\begin{array}{c}\text { Sorption } \\
\text { Time } \\
\text { (days) } \\
\end{array}$} & \multirow{2}{*}{$\begin{array}{c}\text { Desorption } \\
\text { Time } \\
\text { (days) } \\
\end{array}$} & \multicolumn{5}{|c|}{ Sorption Ratio, $R_{d}(m l / g)^{\star}$} \\
\hline & & & $\underline{\mathrm{CS}}$ & $\underline{s r}$ & $\underline{B a}$ & $\underline{\mathrm{Ce}}$ (III) & EU(III) \\
\hline \multirow[t]{7}{*}{$106-150$} & 6.74 & & $606(2.2)$ & $.07(2.5)$ & $773(3.8)$ & $2860(4.1)$ & $2250(3.3)$ \\
\hline & & 55.65 & $4920(7.3)$ & $97.3(6.7)$ & $1770(6.2)$ & & $60200(9.6)$ \\
\hline & 13.70 & & $981(2.5)$ & $127(2.4)$ & $1160(4.1)$ & $3490(4.4)$ & $2580(4.1)$ \\
\hline & & 27.61 & $3020(7.3)$ & $90.1 \quad(6.8)$ & $1560(6.3)$ & & $67200(11)$ \\
\hline & 26.90 & & $2280(2.8)$ & $137(2.3)$ & $2190(4.7)$ & $55400(10)$ & $44600(9.7)$ \\
\hline & & 13.63 & $4070(7.3)$ & $76.7(6.3)$ & $1660(6.1)$ & & \\
\hline & 55.69 & & $2510(2.7)$ & $147(2.4)$ & $24100(4.1)$ & $71600(12)$ & $68400(8.7)$ \\
\hline \multirow[t]{7}{*}{$355-500$} & 6.70 & & $671(2.2)$ & $96.9(2.3)$ & $527(4.0)$ & $3930(4.5)$ & $4520(4.4)$ \\
\hline & & 55.65 & $4210(7.3)$ & $73.5(6.5)$ & $882(5.9)$ & & $89100(13)$ \\
\hline & 13.69 & & 991 (2.5) & $111(2.4)$ & $730(4.0)$ & $6720(4.7)$ & $5780(4.5)$ \\
\hline & & 27.61 & $3050(7.3)$ & $84.1(6.4)$ & $10000(6.0)$ & $43700(18)$ & $39000(11)$ \\
\hline & 26.89 & & $1320(2.2)$ & $118(2.2)$ & $1010(3.7)$ & $22300(5.6)$ & $18700(5.2)$ \\
\hline & & 13.63 & $3560(7.2)$ & $63.8 \quad 5.6)$ & $860(5.4)$ & & $102000(12)$ \\
\hline & 55.68 & & $2570(2.8)$ & $118(2.4)$ & $1320(4.2)$ & $80200(19)$ & $50200(11)$ \\
\hline
\end{tabular}

\footnotetext{
* See footnote to Table VII.
} 
TABLE IX

SORPTION RATIOS, < 75- $1 \mathrm{~m}$ FRACTIONS, AMBIENT TEMPERATURE

\begin{tabular}{|c|c|c|c|c|c|c|c|}
\hline \multirow[b]{2}{*}{ Core } & \multirow{2}{*}{$\begin{array}{c}\text { Sorption } \\
\text { Time } \\
\text { (days) } \\
\end{array}$} & \multirow{2}{*}{$\begin{array}{c}\text { Desorption } \\
\text { Time } \\
\text { (days) } \\
\end{array}$} & \multicolumn{5}{|c|}{ Sorption Ratio, $R_{d}(m / g){ }^{\star}$} \\
\hline & & & $\underline{\mathbf{C s}}$ & $\underline{s r}$ & Ba & Ce(III) & Eu(III) \\
\hline \multirow[t]{14}{*}{ CNI } & 7.11 & & $2630(2.6)$ & $163(2.2)$ & $6490(4.8)$ & $48000(6.2)$ & $39500(6.5)$ \\
\hline & & 57.56 & $3640(7.2)$ & $208(6.1)$ & $10100(6.0)$ & & $116000(9.5)$ \\
\hline & 7.08 & & $2480(3.2)$ & $169(2.4)$ & $6770(5.9)$ & $39600(7.2)$ & $32800(7.2)$ \\
\hline & & 57.56 & $4010(7.3)$ & $218(6.9)$ & $10600(6.7)$ & & $101000(9.0)$ \\
\hline & 13.96 & & $2750(2.5)$ & $177(2.2)$ & $7410(4.5)$ & $53800(5.8)$ & $47900(5.4)$ \\
\hline & & 27.58 & $3930(7.3)$ & $212(6.0)$ & $9920(6.6)$ & & $101000(11)$ \\
\hline & 13.93 & & $2300(2.7)$ & $191(2.3)$ & $6460(5.0)$ & $36200(5.8)$ & $30600(5.4)$ \\
\hline & & 27.58 & $3870(7.3)$ & $215(6.0)$ & $10300(6.3)$ & $129000(26)$ & $93000(10)$ \\
\hline & 27.91 & & $2600(3.2)$ & $220(2.4)$ & $8310(6.0)$ & $54800(8.0)$ & $46100(7.6)$ \\
\hline & & 13.54 & $3550(7.3)$ & $222(5.9)$ & $11600(6.3)$ & & $158000(12)$ \\
\hline & 27.88 & & $2500(3.3)$ & $208(2.5)$ & $8670(6.5)$ & $90700(13)$ & $83600(11)$ \\
\hline & & 13.54 & $3470(7.2)$ & $225(11)$ & $9900(9.9)$ & & $109000(12)$ \\
\hline & 56.19 & & $2400(2.3)$ & $246(2.1)$ & $9990(4.3)$ & $127000(16)$ & $113000(8.6)$ \\
\hline & 56.17 & & $2430(2.3)$ & $226(2.2)$ & $9720(4.3)$ & $146000(22)$ & $97600(8.6)$ \\
\hline \multirow[t]{7}{*}{ CN2 } & 7.10 & & $805(2.2)$ & $768(2.1)$ & $1480(3.7)$ & $2240(3.9)$ & $1870(3.6)$ \\
\hline & & 57.56 & $3600(7.2)$ & $206(6.6)$ & $10700(6.4)$ & & $118000(10)$ \\
\hline & 13.95 & & $2700(2.9)$ & $234(2.3)$ & $7760(5.4)$ & $19600(5.3)$ & $16100(4.8)$ \\
\hline & & 27.58 & $4220(7.4)$ & 233 (E. 4 ) & $11700(7.2)$ & & $90400(12)$ \\
\hline & 27.90 & & $1850(2.9)$ & $245(2.4)$ & UT & $23300(6.2)$ & $18400(5.4)$ \\
\hline & & 13.54 & $3610(7.3)$ & $247(6.3)$ & $11700(6.5)$ & $100000(19)$ & $86900(8.7)$ \\
\hline & 56.19 & & $2550(2.4)$ & $257(2.1)$ & $11600(4.7)$ & (15) & $88600(7.3)$ \\
\hline
\end{tabular}


TABLE IX (cont'd)

SORPTION RATIOS, <75- $\mu \mathrm{m}$ FRACTIONS, AMBIENT TEMPERATURE

\begin{tabular}{|c|c|c|c|c|c|c|c|}
\hline \multirow[b]{2}{*}{ Core } & \multirow{2}{*}{$\begin{array}{c}\text { Sorption } \\
\text { Time } \\
\text { (days) } \\
\end{array}$} & \multirow{2}{*}{$\begin{array}{c}\text { Desorption } \\
\text { Time } \\
\text { (days) } \\
\end{array}$} & \multicolumn{5}{|c|}{ Sorption Ratio, $R_{d}(m l / g) \star$} \\
\hline & & & $\underline{\mathrm{CS}}$ & $\underline{\underline{S r}}$ & $\underline{B a}$ & Ce(III) & EU(III) \\
\hline \multirow[t]{7}{*}{ CN3 } & 7.10 & & $2840(2.7)$ & $147(22)$ & $4850(4.7)$ & $34300(5.6)$ & $30500(5.6)$ \\
\hline & & 57.56 & $4200(7.2)$ & $169(6.4)$ & $7320<6.1$ & & $94500(9.3)$ \\
\hline & 13.95 & & $2030(2.6)$ & $147(2.3)$ & $3390(4.3)$ & $11800(4.6)$ & $10600(4.2)$ \\
\hline & & 27.58 & $4930(7.4)$ & $167(6.3)$ & $7340(6.6)$ & & $97400(12)$ \\
\hline & 27.90 & & $2460(3.2)$ & $162(2.4)$ & $4260(5.5)$ & $32200(7.2)$ & $20600(6.5)$ \\
\hline & & 13.54 & $3890(7.3)$ & $167(6.3)$ & $6760(6.4)$ & & $73900(8.7)$ \\
\hline & 56.18 & & $2940(2.4)$ & $180(2.1)$ & $6410(4.1)$ & $77000(12)$ & $82400(6.7)$ \\
\hline \multirow[t]{7}{*}{ CN4 } & 7.09 & & $961(2.5)$ & $163(2.4)$ & $1690(4.5)$ & $3060(4.5)$ & $2740(4.3)$ \\
\hline & & 57.56 & $3400(7.2)$ & $208(6.0)$ & $8420(6.9)$ & & $98 \quad 100(8.2)$ \\
\hline & 13.94 & & $2520(2.7)$ & $212(2.3)$ & $6590(4.9)$ & $15800(5.0)$ & $14500(4.6)$ \\
\hline & & 27.58 & $4190(7.3)$ & $192(5.4)$ & $8950(5.8)$ & $84300(22)$ & $60700(8.0)$ \\
\hline & 27.90 & & $1840(2.9)$ & $194(2.4)$ & $5460(5.4)$ & $22800(9.9)$ & $19500(9.3)$ \\
\hline & & 13.54 & $3310(7.2)$ & $213(514)$ & $9780(5.8)$ & $75000(19)$ & $59100(12)$ \\
\hline & 56.18 & & $2440(2.4)$ & $238(2.1)$ & $9910(4.6)$ & $82900(13)$ & $83000(7.3)$ \\
\hline
\end{tabular}


TABLE $X$

SORPTION RATIOS, CHUCK SAMPLES, AMBIENT TEMPERATURE

\begin{tabular}{|c|c|c|c|c|c|c|c|}
\hline \multirow[b]{2}{*}{ Core } & \multirow{2}{*}{$\begin{array}{c}\text { Sorption } \\
\text { Time } \\
\text { (days) } \\
\end{array}$} & \multirow{2}{*}{$\begin{array}{c}\text { Desorption } \\
\text { Time } \\
\text { (days) } \\
\end{array}$} & \multicolumn{5}{|c|}{ Sorption Ratio, $R_{d}(m \ell / g)^{\star}$} \\
\hline & & & $\underline{\mathrm{Cs}}$ & $\underline{S r}$ & $\mathrm{Ba}$ & $\mathrm{Ce}(\mathrm{III})$ & Eu(III) \\
\hline \multirow[t]{7}{*}{$\mathrm{CN} 3$} & 7.08 & & $2150(2.6)$ & $53.3(2.7)$ & $295(4.2)$ & $35800(20)$ & $53800(25)$ \\
\hline & & 57.56 & $8410(7.3)$ & $47.8(7.0)$ & $939(6.1)$ & & \\
\hline & 13.93 & & $3430(3.8)$ & $56.4(2.7)$ & $380(5.7)$ & $155000(31)$ & $113000(15)$ \\
\hline & & 27.58 & $7700(7.4)$ & $46.8(7.1)$ & $700(6.3)$ & & \\
\hline & 27.88 & & $2790(3.3)$ & $56.4(2.7)$ & $334(5.0)$ & & \\
\hline & & 13.54 & $6480(7.3)$ & $53.3(7.8)$ & $632(6.8)$ & & \\
\hline & 56.16 & & $4090(2.7)$ & $56.6(2.5)$ & $515(4.1)$ & & \\
\hline \multirow[t]{7}{*}{ CN4 } & 7.07 & & $521(2.1)$ & $42.5(2.9)$ & $212(3.7)$ & $15200(4.6)$ & $13000(4.3)$ \\
\hline & & 57.56 & $3540(7.2)$ & $44.4(6.2)$ & $580(5.3)$ & & \\
\hline & 13.92 & & $1090(2.8)$ & $47.1(2.9)$ & $279(4.4)$ & $21500(8.2)$ & $19500(11)$ \\
\hline & & 27.58 & $3990(7.3)$ & $47.3(6.4)$ & $3640(6.1)$ & & \\
\hline & 27.88 & & $1710(2.5)$ & $46.1(2.9)$ & $295(3.9)$ & & \\
\hline & & 13.54 & $3030(7.2)$ & $44.9(9.5)$ & $554(7.7)$ & & \\
\hline & 56.16 & & $4970(2.9)$ & $51.5(2.5)$ & $565(4.3)$ & & \\
\hline
\end{tabular}

\footnotetext{
* See the footnote to Table VII.
} 
TABLE XI

SORPTION RATIOS, SAMPLE CN $1,70^{\circ} \mathrm{C}$

\begin{tabular}{|c|c|c|c|c|c|c|c|}
\hline \multirow{2}{*}{$\begin{array}{l}\text { Fraction } \\
(\mu \mathrm{m})\end{array}$} & \multirow{2}{*}{$\begin{array}{c}\text { Sorption } \\
\text { Time } \\
\text { (days) } \\
\end{array}$} & \multirow{2}{*}{$\begin{array}{c}\text { Desorption } \\
\text { Time } \\
\text { (days) } \\
\end{array}$} & \multicolumn{5}{|c|}{ Sorption Ratio, $R_{d}(m l / g)^{*}$} \\
\hline & & & $\underline{C S}$ & $\underline{s r}$ & $\underline{B a}$ & Ce(III) & $\underline{E \text { UIII) }}$ \\
\hline \multirow[t]{7}{*}{$106-150$} & 7.06 & & $663(2.3)$ & $108(4.4)$ & $1160(4.0)$ & $3790(4.5)$ & $4070(4.0)$ \\
\hline & & 55.65 & $2000(7.2)$ & $133(6.8)$ & $14500(7.1)$ & & $29900(7.6)$ \\
\hline & 13.87 & & $708(2.5)$ & $137(5.3)$ & $2170(4.8)$ & $1260(4.9)$ & $1850(4.4)$ \\
\hline & & 27.65 & $2430(7.2)$ & $110(6.3)$ & $9020(6.4)$ & $13900(19)$ & $18900\langle 6.3\rangle$ \\
\hline & 27.94 & & $879(2.1)$ & $136(3.9)$ & $5460(4.4)$ & $9930(5.4)$ & $9630(4.4)$ \\
\hline & & 13.63 & $1810(7.2)$ & $131(5.1)$ & $10600(5.7)$ & $17700(18)$ & $21100(5.5)$ \\
\hline & 55.80 & & $983(2.2)$ & $200(3.9)$ & $8550(4.2)$ & $1360(4.2)$ & $2050(3.4)$ \\
\hline \multirow[t]{7}{*}{$355-500$} & 7.05 & & $859(2.4)$ & $119(4.4)$ & $1220(4.0)$ & $5530(4.5)$ & $5830(4.0)$ \\
\hline & & 55.65 & $1870(7.2)$ & $95.4(7.0)$ & $12700(6.7)$ & $8110(22)$ & $10300(6.4)$ \\
\hline & 13.86 & & $1080(2.2)$ & $118(4.2)$ & $1780(3.8)$ & $3420(4.2)$ & $3810(3.6)$ \\
\hline & & 27.65 & $2240(7.2)$ & $82.9(6.7)$ & $8150(6.8)$ & $5450(12)$ & $6050(6.4)$ \\
\hline & 27.93 & & $1172(2.1)$ & $129(3.8)$ & $4730(4.2)$ & $4020(4.2)$ & $3790(3.6)$ \\
\hline & & 13.63 & $1880(7 ?)$ & $119(6.0)$ & $8370(6.5)$ & $18000(15)$ & $24700(6.3)$ \\
\hline & 55.84 & & $1250(2.0)$ & $150(4.0)$ & $8780(4.7)$ & $2700(4.6)$ & $3390(3.7)$ \\
\hline
\end{tabular}

\footnotetext{
ॠee the footnote to Table VII.
} 
TABLE XII

SORPTION RATIOS, SAMPLE CN2, $70^{\circ} \mathrm{C}$

\begin{tabular}{|c|c|c|}
\hline $\begin{array}{c}\text { Fraction } \\
\text { (um) }\end{array}$ & $\begin{array}{c}\text { Sorption } \\
\text { Time } \\
\text { (days) } \\
\end{array}$ & $\begin{array}{c}\text { Desorptior } \\
\text { Time } \\
\text { (days) } \\
\end{array}$ \\
\hline \multirow[t]{7}{*}{$106-150$} & 7.01 & \\
\hline & & 55.65 \\
\hline & 13.82 & \\
\hline & & 27.65 \\
\hline & 27.88 & \\
\hline & & 13.63 \\
\hline & 55.80 & \\
\hline \multirow[t]{7}{*}{$355-500$} & 7.00 & \\
\hline & & 55.65 \\
\hline & 13.81 & \\
\hline & & 27.65 \\
\hline & 27.88 & \\
\hline & & 13.63 \\
\hline & 55.80 & \\
\hline
\end{tabular}

\begin{tabular}{|c|c|c|c|c|}
\hline \multicolumn{5}{|c|}{ Sorption Ratio, $R_{d}(m \ell / g)^{\star}$} \\
\hline Cs & $\underline{S r}$ & $\underline{B a}$ & Ce(III) & Eu(III) \\
\hline $0(2.5)$ & $172(4.5)$ & $1390(4.2)$ & $1270(5.1)$ & $805(4.2)$ \\
\hline$(7.2)$ & $114(6.3)$ & $3040(5.8)$ & $11900(18)$ & $12000(5.9)$ \\
\hline $0(2.5)$ & $208(4.5)$ & $2790(4.4)$ & $1380(5.1)$ & $1210(4.4)$ \\
\hline $0(7.3)$ & $145(7.2)$ & $3520(6.8)$ & $8290(15)$ & $8390(6.9)$ \\
\hline$(2.4)$ & $204(4.2)$ & $3040(4.2)$ & $1080(4.8)$ & $1050(4.0)$ \\
\hline $0(7.3)$ & $184(6.1)$ & $4460(6.2)$ & & $57700(7.1)$ \\
\hline$(3.1)$ & $242(4.9)$ & $5300(5.8)$ & $15300(19)$ & $13100(7.4)$ \\
\hline$(2.5)$ & $197(5.2)$ & $1720(4.4)$ & $7880(5.0)$ & $9000(4.0)$ \\
\hline $20(7.2)$ & $85.1(6.4)$ & $1590(5.7)$ & $4650(18)$ & $6500(5.8)$ \\
\hline $80(2.4)$ & $181(4.3)$ & $1230(4.1)$ & $2340(4.8)$ & $2500(4.2)$ \\
\hline $0(7.3)$ & $107(6.8)$ & $1810(6.2)$ & & $14500(6.9)$ \\
\hline $20(2.4)$ & $166(4.4)$ & $1610(4.1)$ & $1510(4.6)$ & $1760(4.0)$ \\
\hline $40(7.2)$ & $130(5.9)$ & $2170(5.6)$ & & $59500(6.8)$ \\
\hline $30(3.1)$ & $185(5.1)$ & $2950(5.1)$ & $5000(11)$ & $5800(5.6)$ \\
\hline
\end{tabular}

ॠ See the footnote to Table VII. 
TABLE XIII

SORPTION RATIOS, <75- $\mu \mathrm{m}$ FRACTIONS, $70^{\circ} \mathrm{C}$

\begin{tabular}{|c|c|c|c|c|c|c|c|}
\hline \multirow[b]{2}{*}{ Core } & \multirow{2}{*}{$\begin{array}{c}\text { Sorption } \\
\text { Time } \\
\text { (days) } \\
\end{array}$} & \multirow{2}{*}{$\begin{array}{c}\text { Desorption } \\
\text { Time } \\
\text { (days) } \\
\end{array}$} & \multicolumn{5}{|c|}{ Sorption Ratio, $R_{d}(m \ell / g)$} \\
\hline & & & $\underline{\underline{C s}}$ & $\underline{s r}$ & $\underline{B a}$ & Ce(III) & Eu(III) \\
\hline \multirow[t]{7}{*}{ CN1 } & 8.02 & & $1320(2.2)$ & $420(4.0)$ & $5460(4.3)$ & $2100(4.1)$ & $2320(3.7)$ \\
\hline & & 57.70 & $3040(7.2)$ & $567(6.6)$ & $58300(9.4)$ & & $39500(6.6)$ \\
\hline & 17.84 & & $1250(2.3)$ & $453(4.3)$ & $17500(5.7)$ & $20500(5.1)$ & $22300(4.7)$ \\
\hline & & 28.56 & $2360(7.3)$ & $504(6.6)$ & $81900(15)$ & & $95400(11)$ \\
\hline & 33.01 & & $2120(2.5)$ & $507(4.1)$ & $31900(7.0)$ & $16500(6.2)$ & $20400(4.9)$ \\
\hline & & 14.60 & $2070(7.2)$ & $562(6.2)$ & $62700(11)$ & $40200(14)$ & $46400(7.2)$ \\
\hline & 59.94 & & $1780(2.2)$ & $767(4.3)$ & $73700(10)$ & $66800(13)$ & $58700(7.1)$ \\
\hline \multirow[t]{7}{*}{ CN2 } & 8.02 & & $1810(2.6)$ & $5 i 4(4.7)$ & $3100(4.5)$ & $2600(4.6)$ & $2600(4.2)$ \\
\hline & & 57.70 & $4750(7.3)$ & $423(8.1)$ & $69800(11)$ & & $50000(8.7)$ \\
\hline & 17.84 & & $2027(2.8)$ & $585(4.9)$ & $12500(5.8)$ & $4700(5.0)$ & $5800(4.6)$ \\
\hline & & 28.56 & $3470(7.3)$ & $430(7.0)$ & $56300(12)$ & $40800(24)$ & $92700(11)$ \\
\hline & 33.01 & & $2810(2.7)$ & $575(4.5)$ & $34800(7.7)$ & $24500(7.5)$ & $27800(6.0)$ \\
\hline & & 14.60 & $3140(7.3)$ & $503(6.7)$ & $55600(11)$ & $49900(20)$ & $74400(9.3)$ \\
\hline & 59.94 & & $3200(2.5)$ & $666(4.5)$ & $52000(8.0)$ & $29000(9.2)$ & $32800(5.3)$ \\
\hline
\end{tabular}


TABLE XIII (cont'd)

SORPTION RATIOS, $<75-\mu \mathrm{m}$ FRACTIONS, $70^{\circ} \mathrm{C}$

\begin{tabular}{|c|c|c|c|c|c|c|c|}
\hline \multirow[b]{2}{*}{ Core } & \multirow{2}{*}{$\begin{array}{c}\text { Sorption } \\
\text { Time } \\
\text { (days) } \\
\end{array}$} & \multirow{2}{*}{$\begin{array}{c}\text { Desorption } \\
\text { Time } \\
\text { (days) } \\
\end{array}$} & \multicolumn{5}{|c|}{ Sorption Ratio, $R_{d}(m / / g)^{\star}$} \\
\hline & & & $\underline{C s}$ & $\underline{s r}$ & $\underline{3 a}$ & Ce(III) & Eu(III) \\
\hline \multirow[t]{7}{*}{ CN3 } & 8.02 & & $1970(3.0)$ & $411(5.2)$ & $7720(5.4)$ & $3060(5.0)$ & $3680(4.7)$ \\
\hline & & 57.70 & $4960(7.3)$ & $454(7.1)$ & $63200(11)$ & & $63000(9.4)$ \\
\hline & 17.83 & & $2250(2.8)$ & $543(4.9)$ & $19600(6.5)$ & $17800(5.8)$ & $19000(5.0)$ \\
\hline & & 28.56 & $3730(7.3)$ & $479(6.0)$ & $44400(9.4)$ & & $72000(12)$ \\
\hline & 33.01 & & $2990(2.8)$ & $655(4.7)$ & $27300(6.8)$ & $17200(6.1)$ & $20500(5.3)$ \\
\hline & & 14.60 & $3630(7.3)$ & $489(6.8)$ & $38100(9.6)$ & $35300(16)$ & $41500(8.1)$ \\
\hline & 59.93 & & $4020(2.7)$ & $881(4.5)$ & $45100(8.1)$ & $32300(16)$ & $32500(7.8)$ \\
\hline \multirow[t]{7}{*}{ CN4 } & 8.01 & & $1760(2.9)$ & $369(5.0)$ & $6360(5.6)$ & $1900(4.9)$ & $2090(4.6)$ \\
\hline & & 57.70 & $4610(7.3)$ & $543(6.7)$ & $10200(15)$ & & $141000(14)$ \\
\hline & 17.83 & & $1730(2.6)$ & $439(5.2)$ & $21100(6.7)$ & $8230(5.6)$ & $10000(4.8)$ \\
\hline & & 28.56 & $3590(7.4)$ & $527(6.5)$ & $13100(23)$ & & $143000(15)$ \\
\hline & 33.01 & & $2490(2.6)$ & $577(4.5)$ & $64300(10)$ & $72200(11)$ & $64300(7.2)$ \\
\hline & & 14.60 & $3020(7.2)$ & $553(6.2)$ & $87100(12)$ & & $105000(10)$ \\
\hline & 59.93 & & $3000(2.5)$ & $882(4.4)$ & $41700(8.2)$ & $21700(9.1)$ & $21800(5.2)$ \\
\hline
\end{tabular}

See the footnote to Table VII. 
TABLE XIV

SORPTION RATIOS, CHUNK SAMPLES, $70^{\circ} \mathrm{C}$

\begin{tabular}{|c|c|c|c|c|c|c|c|}
\hline \multirow[b]{2}{*}{ Core } & \multirow{2}{*}{$\begin{array}{c}\text { Sorption } \\
\text { Time } \\
\text { (days) } \\
\end{array}$} & \multirow{2}{*}{$\begin{array}{c}\text { Desorption } \\
\text { Time } \\
\text { (days) } \\
\end{array}$} & \multicolumn{5}{|c|}{ Sorption Ratio, $R_{d}(\mathrm{ml} / \mathrm{g})^{\star}$} \\
\hline & & & $\underline{\text { Cs }}$ & $\underline{\mathbf{s r}}$ & Ba & Ce(III) & Eu(III) \\
\hline \multirow[t]{7}{*}{ CN3 } & 8.01 & & $1610(2.6)$ & $123(4.6)$ & $469(4.2)$ & $806(4.4)$ & $1630(4.2)$ \\
\hline & & 57.70 & $3230(7.3)$ & $104(6.6)$ & $730(5.8)$ & & $9130(6.4)$ \\
\hline & 17.82 & & $1780(2.9)$ & $151(4.8)$ & $654(4.5)$ & $1130(5.1)$ & $1750(4.7)$ \\
\hline & & 28.56 & $2730(7.3)$ & $100(6.1)$ & $536(5.6)$ & $14500(16)$ & $14400(6.6)$ \\
\hline & 33.00 & & $1750(2.6)$ & $124(4.1)$ & $1177(4.0)$ & $2680(4.9)$ & $6470(4.6)$ \\
\hline & & 14.60 & $2260(7.2)$ & $93.0(6.1)$ & $852(5.7)$ & $3020(6.3)$ & $4720(5.7)$ \\
\hline & 59.92 & & $1840(2.2)$ & $142(3.6)$ & $1320(3.4)$ & $2710(5.0)$ & $5650(3.9)$ \\
\hline \multirow[t]{7}{*}{ CN4 } & 8.00 & & $1410(2.7)$ & $99.2(4.7)$ & $433(4.4)$ & $1680(4.8)$ & $2200(4.4)$ \\
\hline & & 57.70 & $2980(7.3)$ & $100(6.7)$ & $2950(5.9)$ & & $9030(6.3)$ \\
\hline & 17.82 & & $1290(2.5)$ & $98.9(4.3)$ & $752(3.9)$ & $631(4.4)$ & $1150(4.1)$ \\
\hline & & 28.56 & $2150(7.3)$ & $86.4(6.0)$ & $2430(5.7)$ & $4300(8.6)$ & $6430(5.9)$ \\
\hline & 33.00 & & $1440(2.5)$ & $105(4.0)$ & $1280(3.9)$ & $6570(6.0)$ & $10600(5.2)$ \\
\hline & & 14.60 & $1960(7.2)$ & $84.6(6.3)$ & $1730(5.8)$ & $2810(6.9)$ & $4050(5.8)$ \\
\hline & 59.92 & & $1550(2.3)$ & $134(3.7)$ & $2090(3.7)$ & $6520(9.2)$ & $11370(5.3)$ \\
\hline
\end{tabular}

\footnotetext{
* See the footnote to Table VII.
} 
TABLE XV

PH AND L/S VALUES, AMBIENT TEMPERATURE

\begin{tabular}{|c|c|c|c|c|c|c|c|}
\hline Core & $\begin{array}{c}\text { Fraction } \\
\langle\mu m\}\end{array}$ & $\begin{array}{c}\text { Sorption } \\
\text { Time } \\
\text { (days) } \\
\end{array}$ & $\begin{array}{l}\text { Final } \\
\mathrm{pH}\end{array}$ & $\underline{B a}$ & $\frac{\mathrm{L} / \mathrm{S}}{\mathrm{Ce}}$ & EU & $\begin{array}{c}\text { Final } \\
\text { Desorption } \\
\text { pH } \\
\end{array}$ \\
\hline \multirow[t]{8}{*}{ CN1 } & $106-150$ & 6.75 & 8.93 & 1.02 & 2.12 & 2.27 & 8.58 \\
\hline & & 13.74 & 8.88 & 1.05 & 1.17 & 1.16 & 8.70 \\
\hline & & 26.94 & 8.73 & 1.08 & 1.03 & 0.98 & 8.76 \\
\hline & & 55.73 & 9.06 & 1.01 & 1.08 & 1.07 & \\
\hline & $355-500$ & 6.74 & 8.93 & 1.18 & 1.41 & 1.39 & 8.60 \\
\hline & & 13.73 & 8.92 & 1.03 & 1.58 & 1.50 & 8.76 \\
\hline & & 26.94 & 8.83 & 0.93 & 1.57 & 1.48 & 8.76 \\
\hline & & 55.72 & 8.79 & 0.99 & 1.19 & 1.16 & \\
\hline \multirow[t]{8}{*}{$\mathrm{CN} 2$} & $106-150$ & 6.74 & 9.02 & 0.97 & 1.24 & 1.17 & 8.64 \\
\hline & & 13.70 & 8.89 & 1.00 & 1.44 & 1.35 & 8.85 \\
\hline & & 26.90 & 8.86 & 0.86 & 1.19 & 1.16 & 8.81 \\
\hline & & 55.69 & 8.82 & 0.90 & 1.32 & 1.28 & \\
\hline & $355-500$ & 6.70 & 8.98 & 1.03 & 1.68 & 1.54 & 8.68 \\
\hline & & 13.69 & 8.93 & 1.06 & 1.45 & 1.37 & 8.87 \\
\hline & & 26.89 & 8.93 & 1.00 & 1.24 & 1.19 & 8.81 \\
\hline & & 55.68 & 9.04 & 0.98 & 1.59 & 1.66 & \\
\hline \multirow[t]{4}{*}{ CN3 } & Chunk & 7.08 & 8.52 & 1.04 & 1.36 & 1.42 & 8.66 \\
\hline & & 13.93 & 8.56 & 0.97 & 1.29 & 1.25 & 8.83 \\
\hline & & 27.88 & & 1.06 & & & 8.83 \\
\hline & & 56.16 & & 1.02 & & & \\
\hline \multirow[t]{4}{*}{$\mathrm{CN} 4$} & Chunk & 7.07 & 8.58 & 1.09 & 0.88 & 0.90 & 8.63 \\
\hline & & 13.92 & 8.56 & 1.11 & 1.21 & 1.24 & 8.86 \\
\hline & & 27.88 & & 1.10 & & & 8.86 \\
\hline & & 56.16 & & 1.03 & & & \\
\hline
\end{tabular}


TABLE XVI

PH AND L/S VALUES, $70^{\circ} \mathrm{C}$

\begin{tabular}{|c|c|c|c|c|c|c|c|c|}
\hline \multirow[b]{2}{*}{ Core } & \multirow{2}{*}{$\begin{array}{c}\text { Fraction } \\
(\mu \mathrm{m}) \\
\end{array}$} & \multirow{2}{*}{$\begin{array}{c}\text { Sorption } \\
\text { Time } \\
\text { (days) } \\
\end{array}$} & \multirow{2}{*}{$\begin{array}{l}\text { Final } \\
\mathrm{pH} \\
\end{array}$} & \multicolumn{4}{|c|}{$\mathrm{L} / \mathrm{S}$} & \multirow{2}{*}{$\begin{array}{c}\text { Final } \\
\text { Desorption } \\
\mathrm{pH}\end{array}$} \\
\hline & & & & $\underline{S r}$ & $\underline{\mathrm{Ba}}$ & Ce & $\underline{E u}$ & \\
\hline \multirow[t]{8}{*}{ CN1 } & $106-150$ & 7.05 & 8.93 & 2.10 & 0.99 & 0.75 & 0.78 & 7.94 \\
\hline & & 13.87 & 8.88 & 2.42 & 1.04 & 1.45 & 1.43 & 8.02 \\
\hline & & 27.94 & 8.79 & 2.46 & 1.09 & 1.35 & 1.74 & 8.74 \\
\hline & & 55.80 & 8.60 & 2.33 & 0.99 & 1.39 & 1.45 & \\
\hline & $355-500$ & 7.05 & 8.94 & 1.98 & 0.81 & 0.53 & 0.55 & 8.16 \\
\hline & & 13.86 & 8.93 & 2.50 & 0.96 & 0.77 & 0.79 & 8.59 \\
\hline & & 27.93 & 8.83 & 2.03 & 1.01 & 1.05 & 1.03 & 8.70 \\
\hline & & 55.84 & 8.76 & 2.24 & 1.02 & 1.19 & 1.21 & \\
\hline \multirow[t]{8}{*}{ CN2 } & $106-150$ & 7.01 & 8.90 & 2.12 & 1.14 & 3.81 & 3.92 & 8.12 \\
\hline & & 13.82 & 8.81 & 2.75 & 1.06 & 4.08 & 4.31 & 8.36 \\
\hline & & 27.88 & 8.67 & 2.29 & 1.13 & 3.77 & 3.96 & 8.60 \\
\hline & & 55.80 & 8.50 & 2.24 & 1.04 & 2.35 & 2.37 & \\
\hline & $355-500$ & 7.00 & & 2.02 & 0.59 & 0.52 & 0.55 & 8.08 \\
\hline & & 13.81 & 8.84 & 2.70 & 1.15 & 2.48 & 2.68 & 8.36 \\
\hline & & 27.88 & 8.73 & 2.45 & 1.11 & 1.88 & 1.96 & 3.57 \\
\hline & & 55.80 & 8.56 & 2.58 & 1.13 & 2.46 & 2.60 & \\
\hline \multirow[t]{4}{*}{ CN3 } & Chunk & 8.01 & 8.54 & 2.75 & 1.00 & 1.15 & 1.22 & 8.24 \\
\hline & & 17.82 & 8.42 & 2.69 & 0.93 & 2.75 & $2.5 !$ & 8.28 \\
\hline & & 33.00 & 8.62 & 2.67 & 0.84 & 2.43 & 2.05 & 8.53 \\
\hline & & 59.92 & 8.52 & 2.64 & 0.93 & 3.17 & 2.80 & \\
\hline \multirow[t]{4}{*}{ CN4 } & Chunk & 8.00 & 8.54 & 2.82 & 1.10 & 1.23 & 1.35 & 8.30 \\
\hline & & 17.82 & 8.55 & 2.97 & 1.19 & 5.25 & 4.39 & 8.60 \\
\hline & & 33.00 & 8.77 & 2.84 & 1.09 & 2.18 & 1.97 & 8.57 \\
\hline & & 59.92 & 8.63 & 2.83 & 1.15 & 3.71 & 2.73 & \\
\hline
\end{tabular}


TABLE XVII

PH AND L/S VALUES, <75- $\mu m$ FRACTIONS, AMBIENT TEMPERATURE

\begin{tabular}{|c|c|c|c|c|c|c|}
\hline Core & $\begin{array}{c}\text { Sorption } \\
\text { Time } \\
\text { (days) }\end{array}$ & $\begin{array}{c}\text { Final } \\
\mathrm{pH}\end{array}$ & $\overline{\mathrm{Ba}}$ & $\frac{\mathrm{L} / \mathrm{S}}{\mathrm{Ce}}$ & $\overline{E u}$ & $\begin{array}{c}\text { Final } \\
\text { Desorption } \\
\mathrm{pH}\end{array}$ \\
\hline \multirow[t]{8}{*}{ CN1 } & 7.11 & 8.58 & 1.02 & 1.05 & 1.05 & 8.54 \\
\hline & 7.08 & 8.64 & 1.01 & 1.03 & 1.03 & 8.74 \\
\hline & 13.96 & 8.61 & 0.99 & 1.01 & 1.01 & 8.72 \\
\hline & 13.93 & 8.73 & 0.96 & 0.86 & 0.86 & 8.91 \\
\hline & 27.91 & 8.81 & 0.98 & 0.90 & 0.91 & 8.82 \\
\hline & 27.88 & 8.81 & 1.01 & 0.91 & 0.89 & 8.84 \\
\hline & 56.19 & 8.62 & 1.00 & 0.98 & 0.99 & \\
\hline & 56.17 & 8.71 & 1.00 & 0.99 & 1.00 & \\
\hline \multirow[t]{4}{*}{ CN2 } & 7.10 & 8.62 & 1.07 & 1.24 & 1.27 & 8.65 \\
\hline & 13.95 & 8.65 & 0.93 & 0.74 & 0.73 & 8.86 \\
\hline & 27.90 & 8.82 & 0.91 & 0.93 & 0.95 & 8.85 \\
\hline & 56.19 & 8.72 & 1.01 & 0.98 & 0.98 & \\
\hline \multirow[t]{4}{*}{ CN3 } & 7.10 & 8.62 & 0.99 & 0.96 & 0.97 & 8.66 \\
\hline & 13.95 & 8.59 & 0.94 & 0.67 & 0.66 & 8.83 \\
\hline & 27.90 & 8.81 & 0.98 & 0.87 & 0.87 & 8.83 \\
\hline & 56.18 & 8.69 & 0.97 & 0.91 & 0.91 & \\
\hline \multirow[t]{4}{*}{ CN4 } & 7.09 & 8.61 & 1.10 & 1.30 & 1.33 & 8.72 \\
\hline & 13.94 & 8.66 & 0.96 & 0.83 & 0.81 & 8.89 \\
\hline & 27.90 & 8.77 & 1.00 & 1.05 & 1.06 & 8.86 \\
\hline & 56.18 & 8.71 & 1.01 & 1.03 & 1.03 & \\
\hline
\end{tabular}


TABLE XVIII

pH AND L/S VALUES $<75-\mu m$ FRACTIONS, $70^{\circ} \mathrm{C}$

\begin{tabular}{|c|c|c|c|c|c|c|c|}
\hline \multirow[b]{2}{*}{ Core } & \multirow{2}{*}{$\begin{array}{c}\text { Sorption } \\
\text { Time } \\
\text { (days) }\end{array}$} & \multirow{2}{*}{$\underset{\mathrm{pH}}{\text { Final }}$} & \multicolumn{4}{|c|}{$L / S$} & \multirow{2}{*}{$\begin{array}{c}\text { Fina1 } \\
\text { Desorption } \\
\mathrm{pH}\end{array}$} \\
\hline & & & $\mathrm{Sr}$ & $\mathrm{Bg}$ & $\mathrm{Ce}$ & $\mathrm{Eu}$ & \\
\hline \multirow[t]{4}{*}{ CN1 } & 8.02 & 8.51 & 2.45 & 1.23 & 1.82 & 1.76 & 8.64 \\
\hline & 17.84 & 8.61 & 2.43 & 1.04 & 0.93 & 0.93 & 8.31 \\
\hline & 33.01 & 8.71 & 2.42 & 1.13 & 1.41 & 1.35 & 8.53 \\
\hline & 59.94 & 8.52 & 2.12 & 1.00 & 0.89 & 1.15 & \\
\hline \multirow[t]{4}{*}{$\mathrm{CN} 2$} & 8.02 & 8.54 & 2.47 & 1.00 & 1.34 & 1.32 & 8.47 \\
\hline & 17.84 & 8.52 & 2.52 & 0.86 & 1.19 & 1.17 & 8.35 \\
\hline & 33.01 & 8.87 & 2.44 & 1.08 & 1.49 & 1.47 & 8.44 \\
\hline & 59.94 & 8.52 & 2.43 & 1.08 & 1.17 & 1.19 & \\
\hline \multirow[t]{4}{*}{ CN3 } & 8.02 & 8.49 & 2.71 & 0.69 & 0.77 & 0.72 & 8.39 \\
\hline & 17.83 & 8.44 & 2.49 & 0.81 & 0.62 & 0.64 & 8.26 \\
\hline & 33.01 & 8.64 & 2.48 & 0.95 & 1.24 & 1.24 & 8.36 \\
\hline & 59.93 & 8.43 & 2.34 & 1.16 & 1.93 & 2.56 & \\
\hline \multirow[t]{4}{*}{ CN4 } & 8.01 & 8.61 & 2.56 & 0.94 & 1.24 & 1.22 & 8.26 \\
\hline & 17.83 & 8.61 & 2.57 & 0.78 & 1.07 & 1.06 & 8.08 \\
\hline & 33.01 & 8.78 & 2.50 & 0.88 & 0.98 & 0.97 & 8.38 \\
\hline & 59.93 & 8.48 & 2.36 & 1.25 & 1.63 & 1.68 & \\
\hline
\end{tabular}


TABLE XIX

PERCENT RECOVERY AND PH VALUES FOR CONTROL SAMPLES

\begin{tabular}{|c|c|c|c|c|c|c|c|c|}
\hline \multirow{2}{*}{$\begin{array}{l}\text { Temp. } \\
\left({ }^{\circ} \mathrm{C}\right)\end{array}$} & \multirow{2}{*}{$\begin{array}{l}\text { Batch } \\
\text { Number of } \\
\text { the water* }\end{array}$} & \multirow{2}{*}{$\begin{array}{c}\text { Contact } \\
\text { Time } \\
\text { (days) } \\
\end{array}$} & \multirow{2}{*}{$\begin{array}{l}\text { Final } \\
\mathrm{pH}\end{array}$} & \multicolumn{5}{|c|}{ Percent Remaining in Solution } \\
\hline & & & & Cs & $\underline{S r}$ & $\underline{\mathrm{Ba}}$ & $\mathrm{Ce}$ & $\underline{E u}$ \\
\hline \multirow[t]{8}{*}{20} & 1 & 6.73 & & 102 & 102 & 101 & 8.80 & 71.9 \\
\hline & & 13.73 & 8.91 & 98.6 & 98.6 & 98.3 & 8.39 & 67.3 \\
\hline & & 26.89 & 8.95 & 99.5 & 98.8 & 98.9 & 5.86 & 61.8 \\
\hline & & 55.68 & 9.01 & 97.9 & 98.3 & 96.9 & 4.47 & 48.5 \\
\hline & 2 & 7.11 & & 99.8 & 99.4 & 101 & 51.9 & 82.2 \\
\hline & & 13.86 & & 102 & 93.4 & 89.2 & 5.34 & 6.27 \\
\hline & & 27.82 & 8.81 & 103 & 86.9 & 76.1 & 8.87 & 7.50 \\
\hline & & 56.11 & 8.82 & 106 & 90.2 & 80.7 & 1.54 & 0.24 \\
\hline \multirow[t]{7}{*}{70} & 1 & 7.00 & & 99.9 & 75.8 & 80.0 & 2.50 & 2.21 \\
\hline & & 13.81 & 8.95 & 100 & 56.4 & 62.1 & 5.50 & 11.2 \\
\hline & & 27.88 & 8.97 & 100 & 31.2 & 42.4 & 0.28 & 0.62 \\
\hline & & 55.79 & 8.96 & 97.0 & 22.2 & 33.7 & 0.17 & 0.08 \\
\hline & 2 & 8.00 & 8.59 & 102 & 34.3 & 85.4 & 0.26 & 0.54 \\
\hline & & 17.81 & 8.52 & 99.9 & 61.0 & 70.4 & 0.02 & 0.10 \\
\hline & & 32.99 & 8.72 & 99.8 & 34.6 & 52.1 & & \\
\hline
\end{tabular}

see Table IV. 
also used for strontium under ambient conditions. However, Eq. 3 was used for all other calculations since the container effect on these cations was significant (Table XIX).

Upon examination of Tables VII-XIV one can make several general observations. The scatter in the sorption ratios is sometimes larger than the quoted experimental uncertainties, assuming that one could expect a constant or monotonic behavior with time. This indicates that strictly identical samples or conditions were not always attained. The $R_{d}$ values for most species increase with time. This could be due to alteration of the minerals even at the rather low temperatures involved in these measurements or to relatively slow ion exchange.

Steady state seems to be attained more quickly at the higher temperatures, at least for cesium, strontiums and barium. Essentially the same $R_{d}$ value is obtained at the two temperatures for each of these three cations. The sorption ratios for cerium and europium seem to vary inversely with temperature. Presumably the cerium and europium are more soluble at the higher temperature since they have the tendency to form hydroxides in the $\mathrm{pH} \approx 8$ solutions used.

There does not seem to be a strong correlation between the sorption capability of the material and the depth at which the samples were taken. There are indications that $\mathrm{CN} 1$ is a poorer sorber than $\mathrm{CN} 2$ for the cations studied, but the differences are small. The cation exchange capacity of CN1 is somewhat higher than that of CN2 (see Table II). This indicates that, as expected, the Eleana argillite is rather uniform in its geologic character.

At least qualitatively, an increase in the surface area is accompanied by an increase in the sorption ratio. However, the changes are not very large since the surface area did not change strongly with sieve fraction. Therefore, the differences observed may be due entirely to other factors, such as the differences in the mineral composition of the sieve fractions. Since the permeability of the argillite is low, it is not surprising that the $R_{d}$ values for the chunk samples are significantly different than those obtained from the ground samples.

The agreement between the late time sorption and desorption $R_{d}$ values is usually rather yood. However, some desorption values are significantly greater (see the Ce and Eu data) than those reached by sorption. One can speculate that the observation may be a consequence of the following phenomena. The solution from which sorption takes place may contain different species of the 

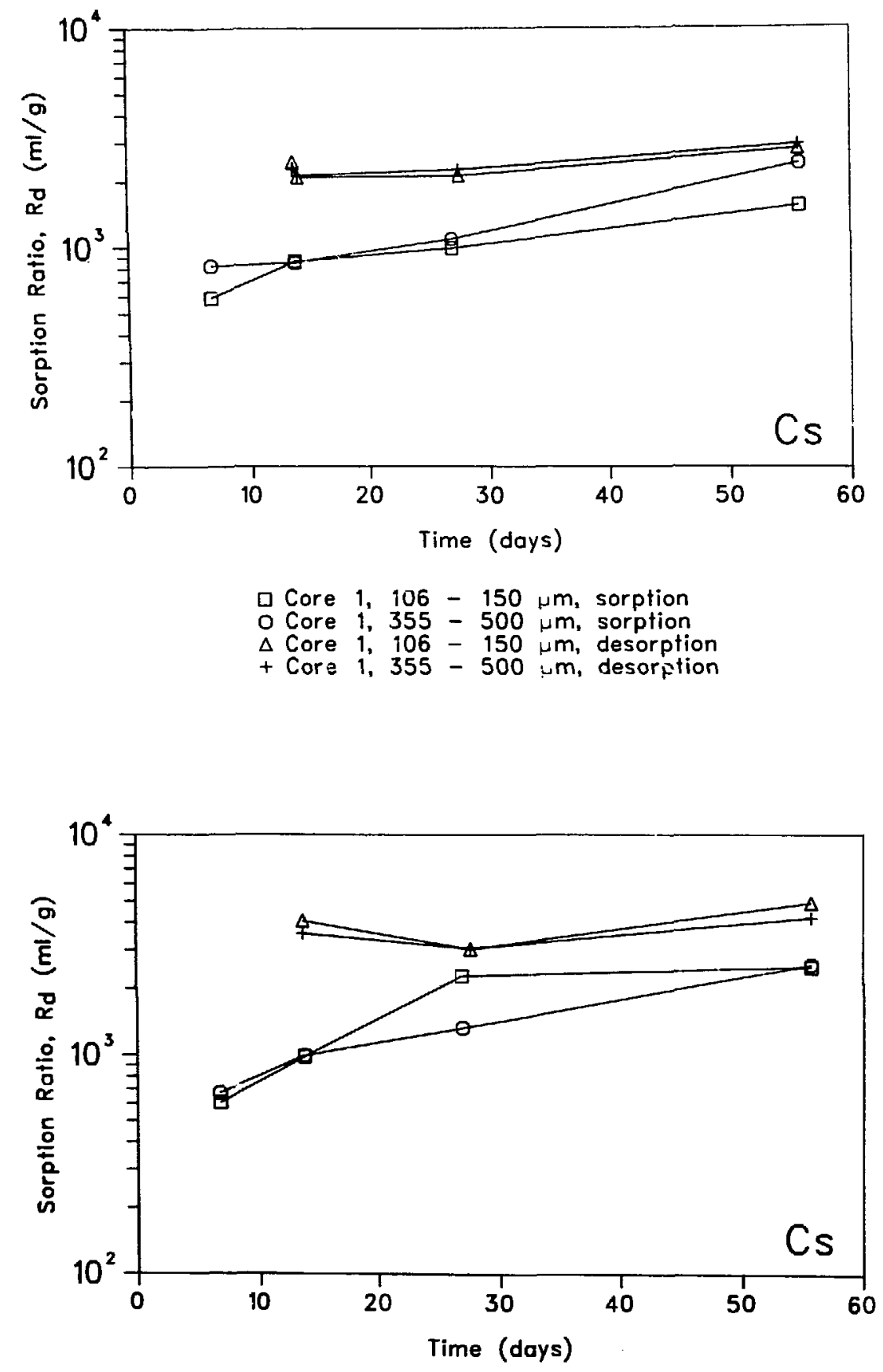

달 2, $106-150 \mu \mathrm{m}$, sorption

o Core 2, 355 - $500 \mu \mathrm{m}$, sorption

$\Delta$ Core 2, 106 - $150 \mu \mathrm{m}$, desorption

+ Core 2, 355 - $500 \mu \mathrm{m}$, desorption

Fig. 1. Cesium sorption-desorption ratio data, selected sieve fractions, ambient temperature. 


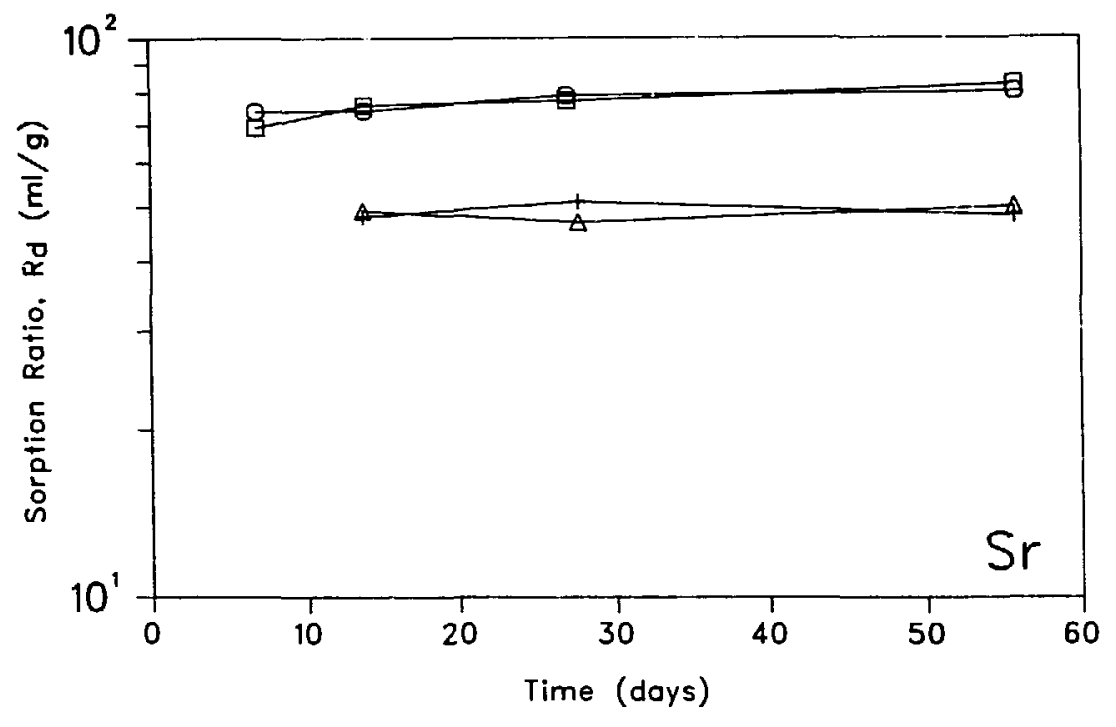

$\square$ Core 1. $106-150 \mathrm{\mu m}$, sorption

o Core 1, 355 - $500 \mathrm{\mu m}$, sorption

$\Delta$ Core 1, $106-150 \mu \mathrm{m}$, Cesorption

+ Core 1, 355 - $500 \mathrm{~mm}$, desorption

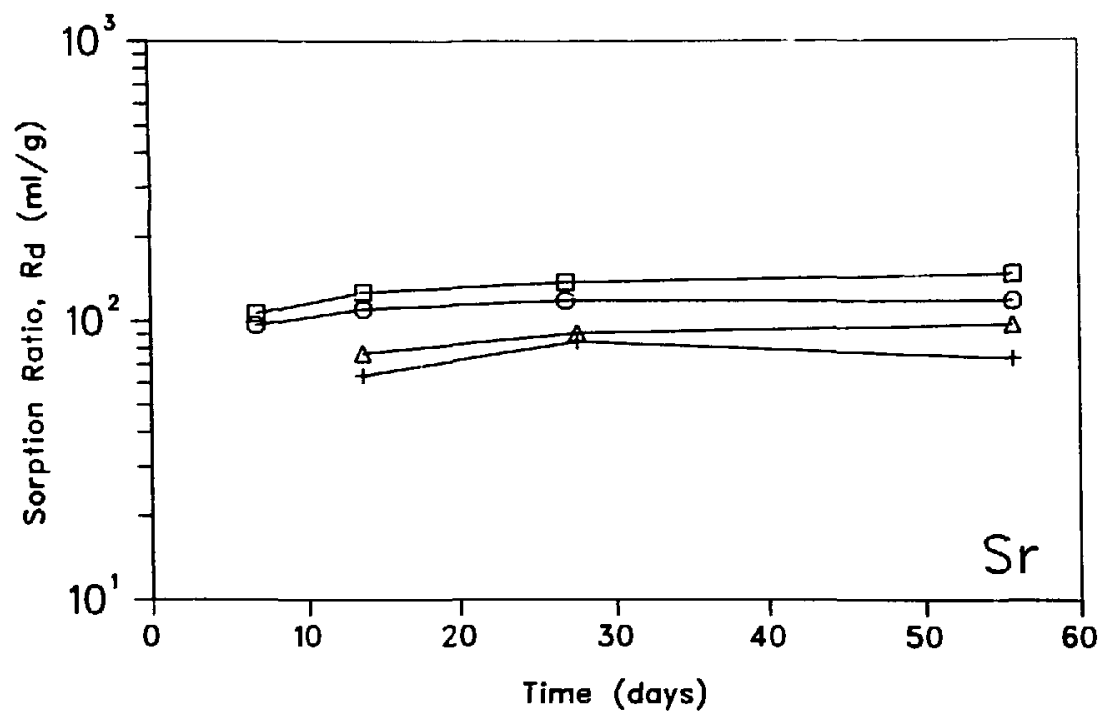

$\square$ Core 2, $106-150 \mu \mathrm{m}$, sorption

O Core 2, 355 - $500 \mathrm{\mu m}$, sorption

$\Delta$ Core 2, $106-150 \mu \mathrm{m}$, desorption

+ Core 2, 355 - $500 \mu \mathrm{m}$, desorption

Fig. 2. Strontium sorption-desorption ratio data, selected sieve fractions, ambient temperature 


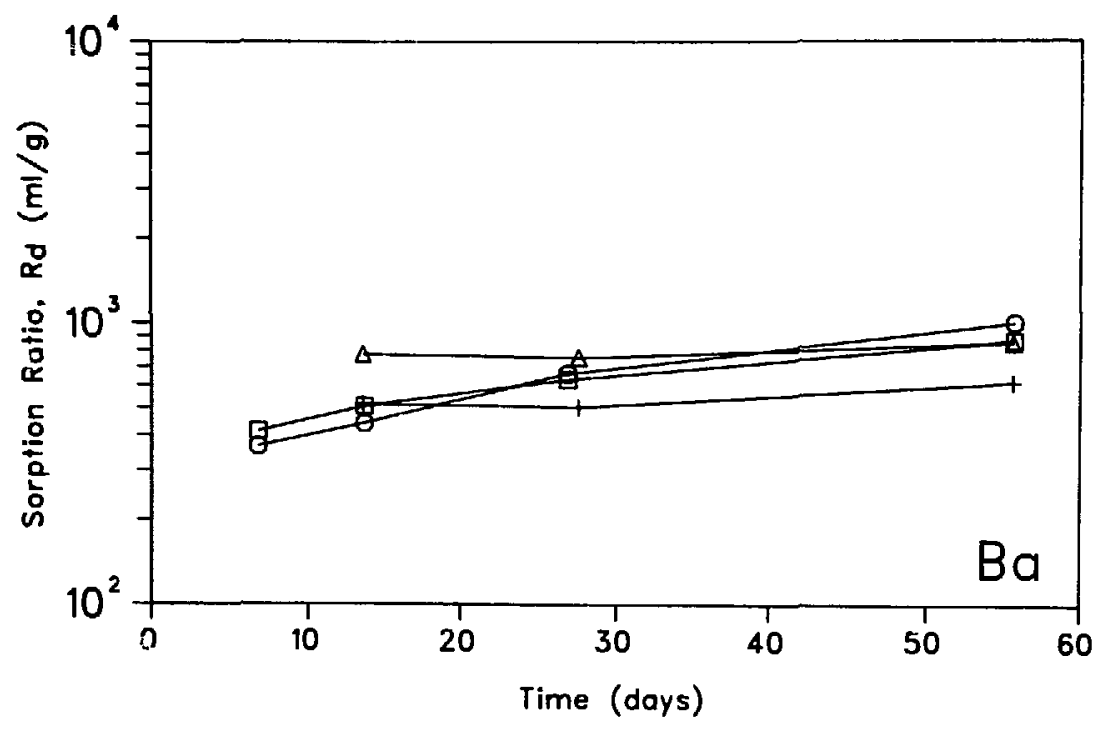

$\square$ Core 1, $106-150 \mu \mathrm{m}$, sorption

o Core 1, 355 - $500 \mathrm{\mu m}$, sorption

$\Delta$ Core 1, $106-150 \mu \mathrm{m}$, desorption

+ Core 1, 355 - $500 \mu \mathrm{m}$, desorption

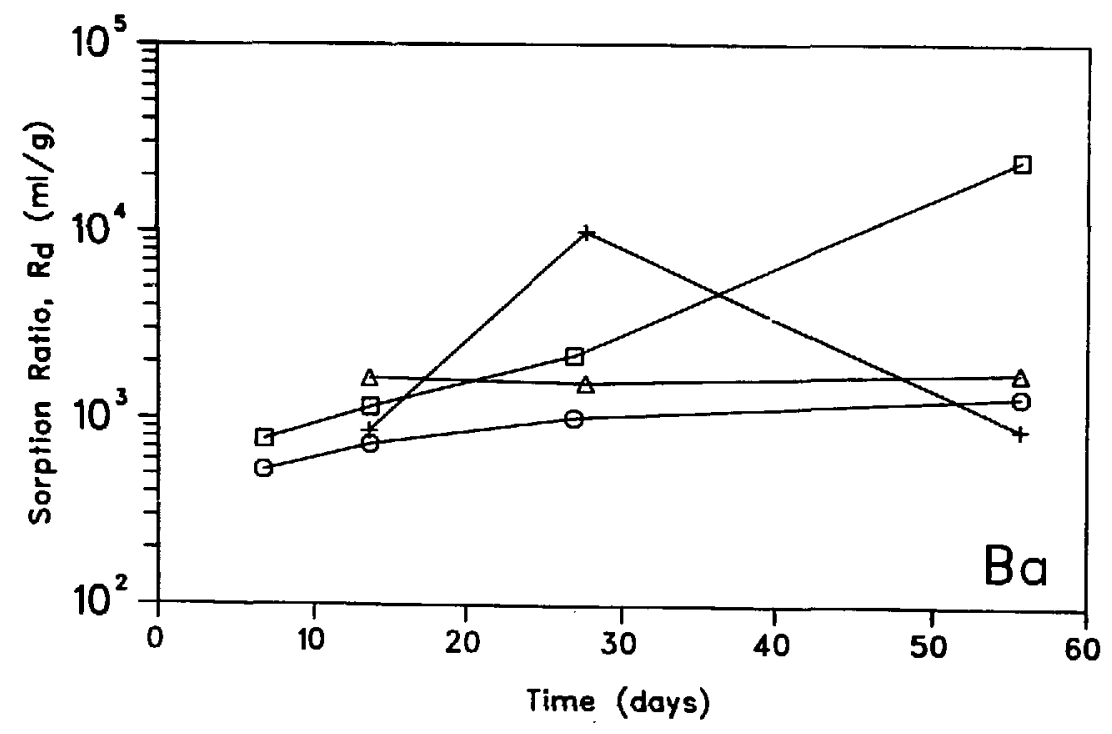

$\square$ Core 2, $106-150 \mu \mathrm{m}$, sorption
$\circ$ Core 2, $355=500 \mu \mathrm{m}$, sorption
$\Delta$ Core 2, $106=150 \mu \mathrm{m}$, desorption
+ Core 2, $355-500 \mu \mathrm{m}$, desorption Fig. 3. Barium sorption-desorption ratio data, selected sieve fractions,
ambient temperature. 

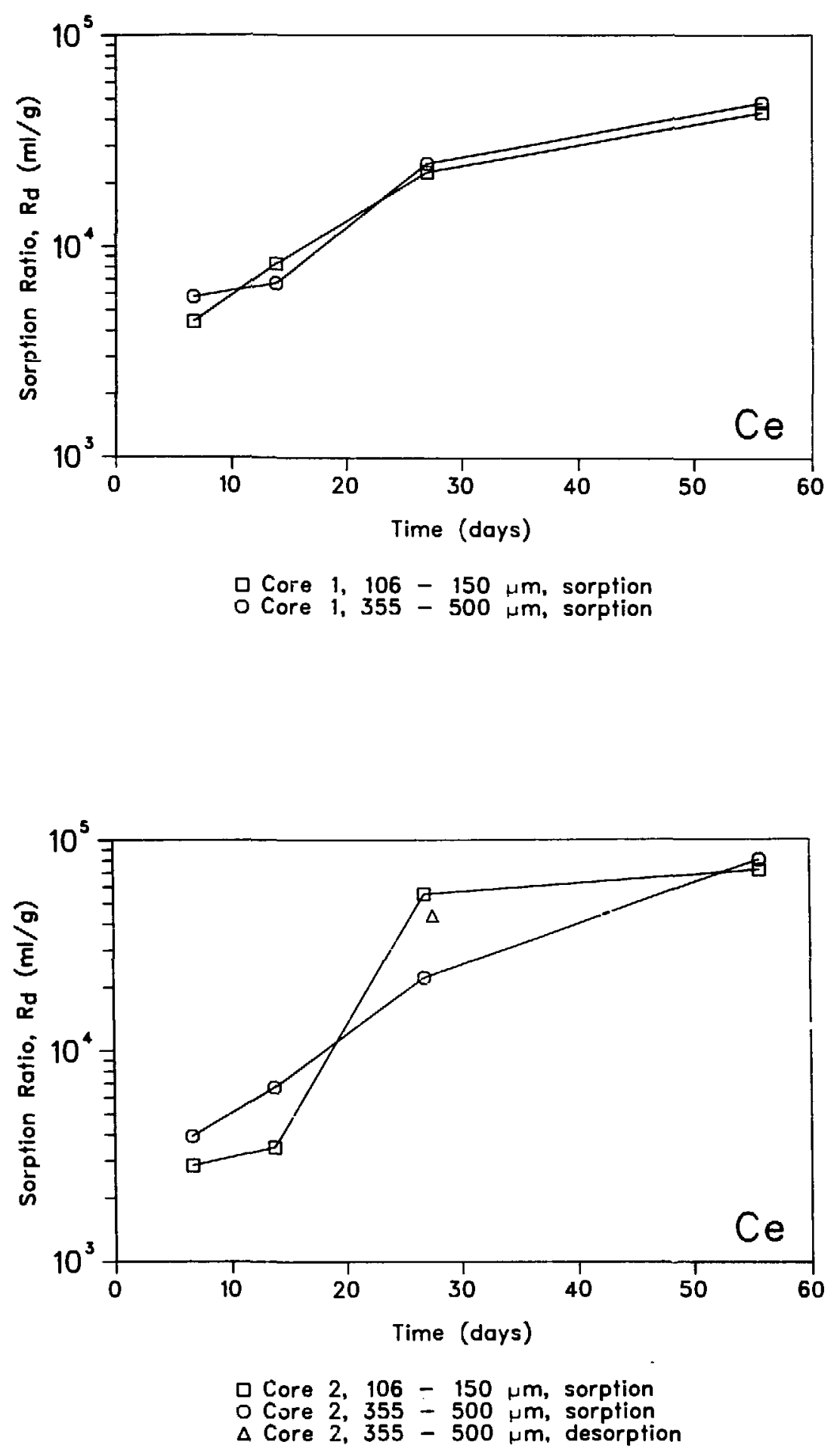

Fig. 4. Cerium sorption-desorption ratio data, selected sieve fractions, ambient temperature. 


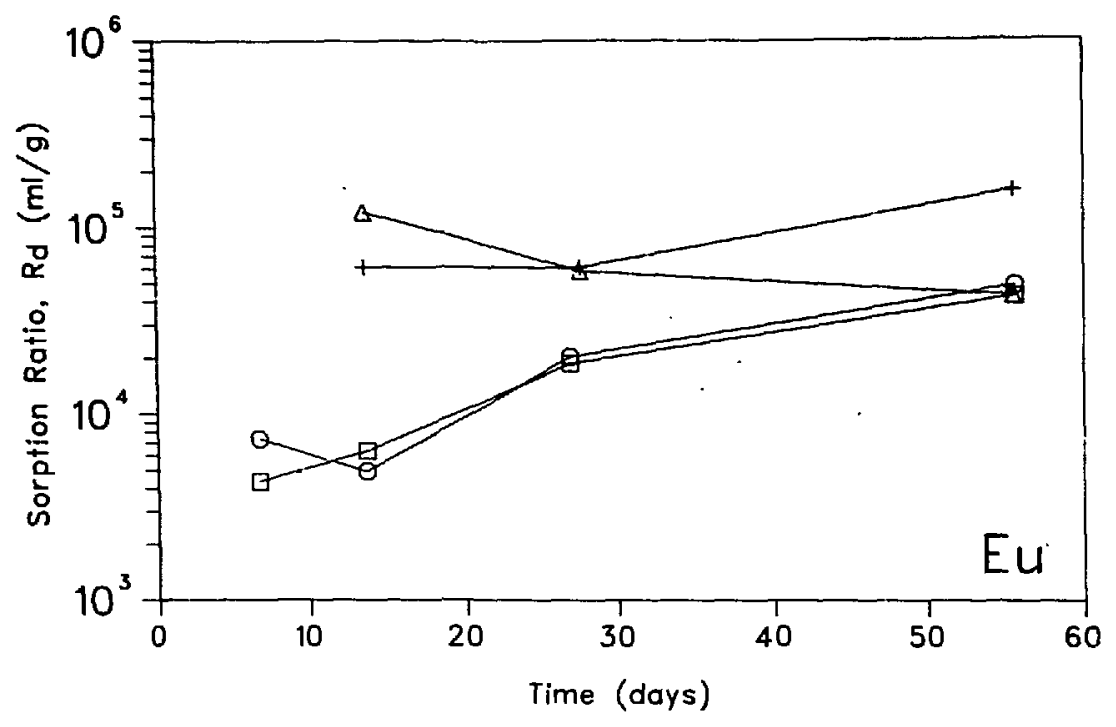

$\square$ Core 1, $106-150 \mu \mathrm{m}$, sorption

o Core 1, 355 - $500 \mu \mathrm{m}$, sorption

$\triangle$ Core 1, 106 - $150 \mathrm{\mu m}$, desorption

+ Core 1, 355 - $500 \mu \mathrm{m}$, desorption

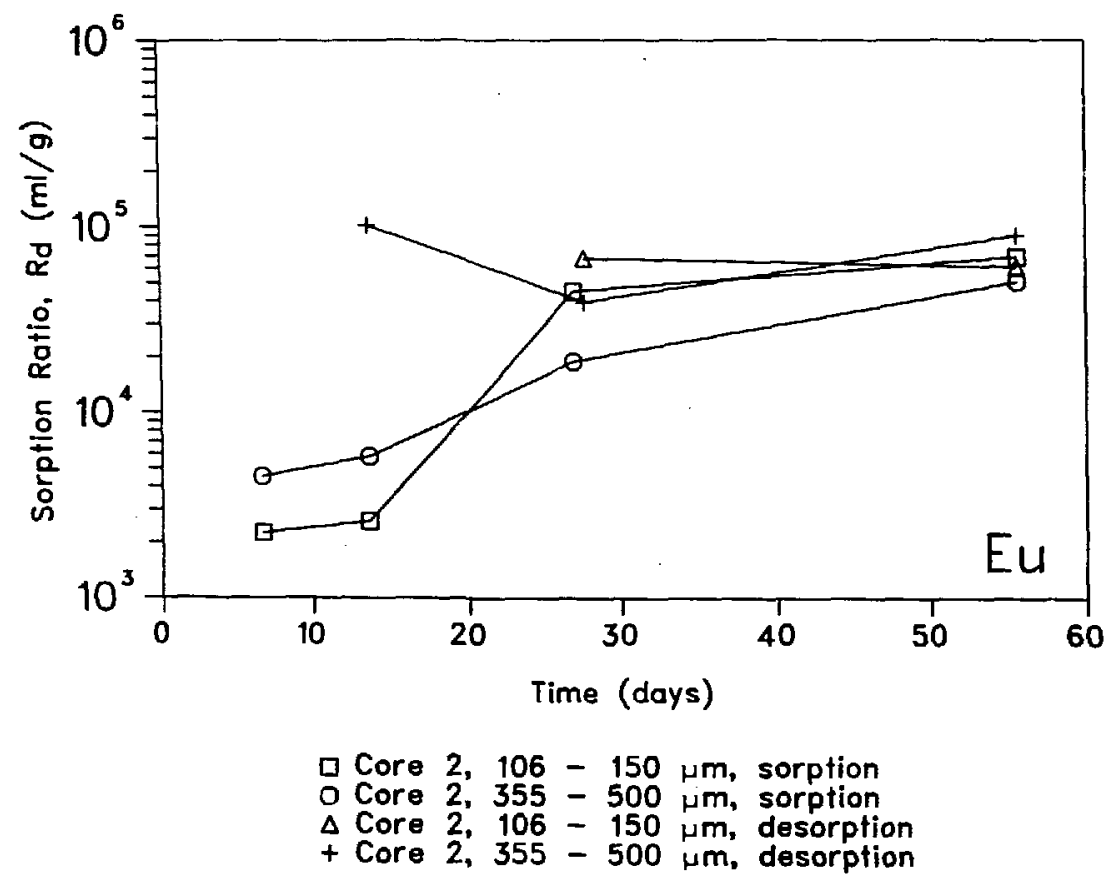

Fig. 5. Europium sorption-desorption ratio data, selected sieve fractions, ambient temperature. 


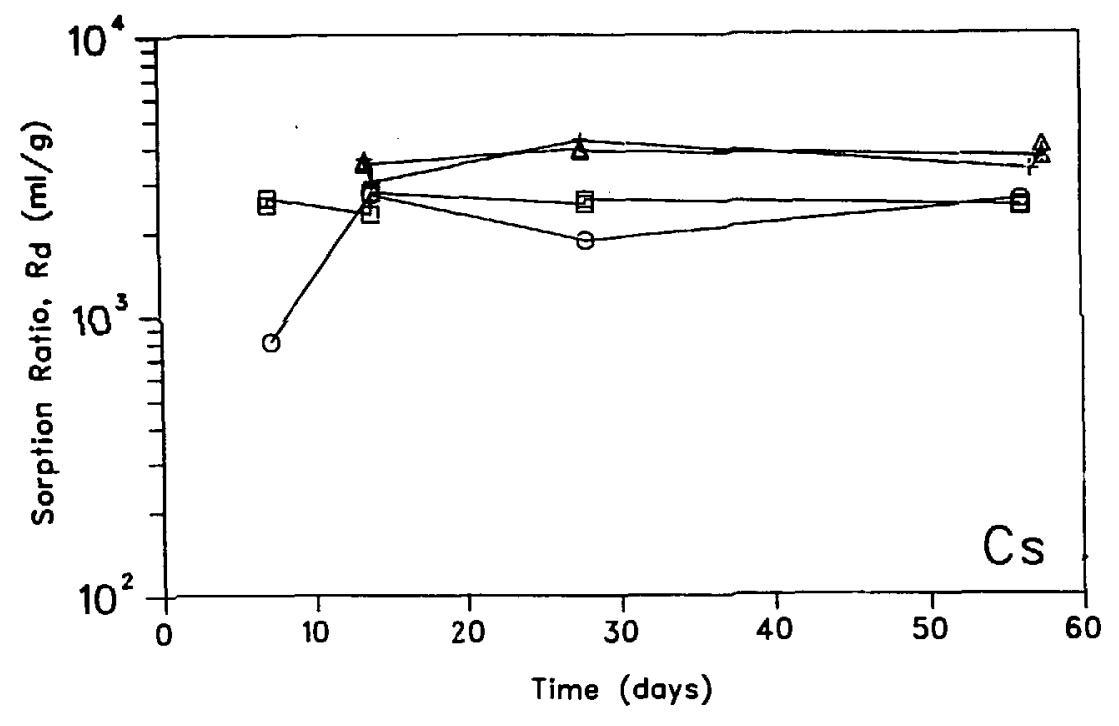

$\square$ Core 1, -75 $\mathrm{mm}$, sorption

0 Core 2, $-75 \mathrm{~km}$, sorption

$\triangle$ Core 1, -75 um, desorption

+ Core 2, -75 $\mathrm{\mu m}$, desorption

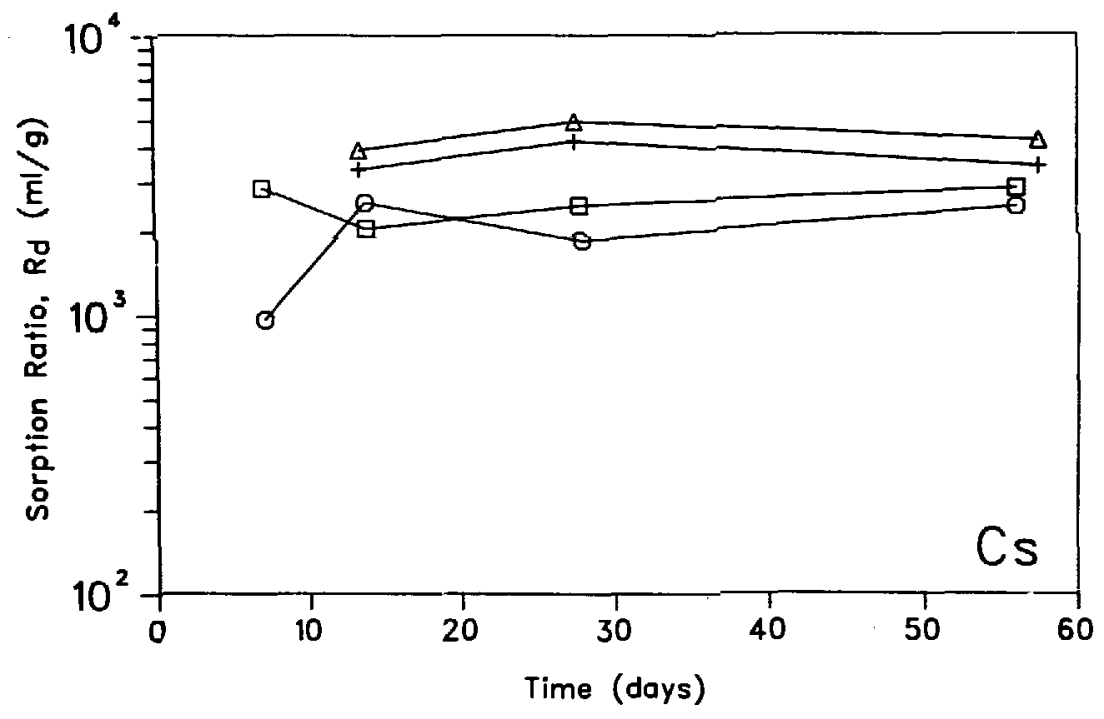

C Core 3, $-75 \mu \mathrm{m}$, sorption

o Core 4, -75 $\mathrm{\mu m}$, sorption

$\Delta$ Core 3, -75 $\mathrm{\mu m}$, desorption

+ Core 4, -75 $\mu \mathrm{m}$, desorption

Fig. 6. Cesium sorption-desorption ratio data, <75- $\mu \mathrm{m}$ fractions, ambiert temperature. 


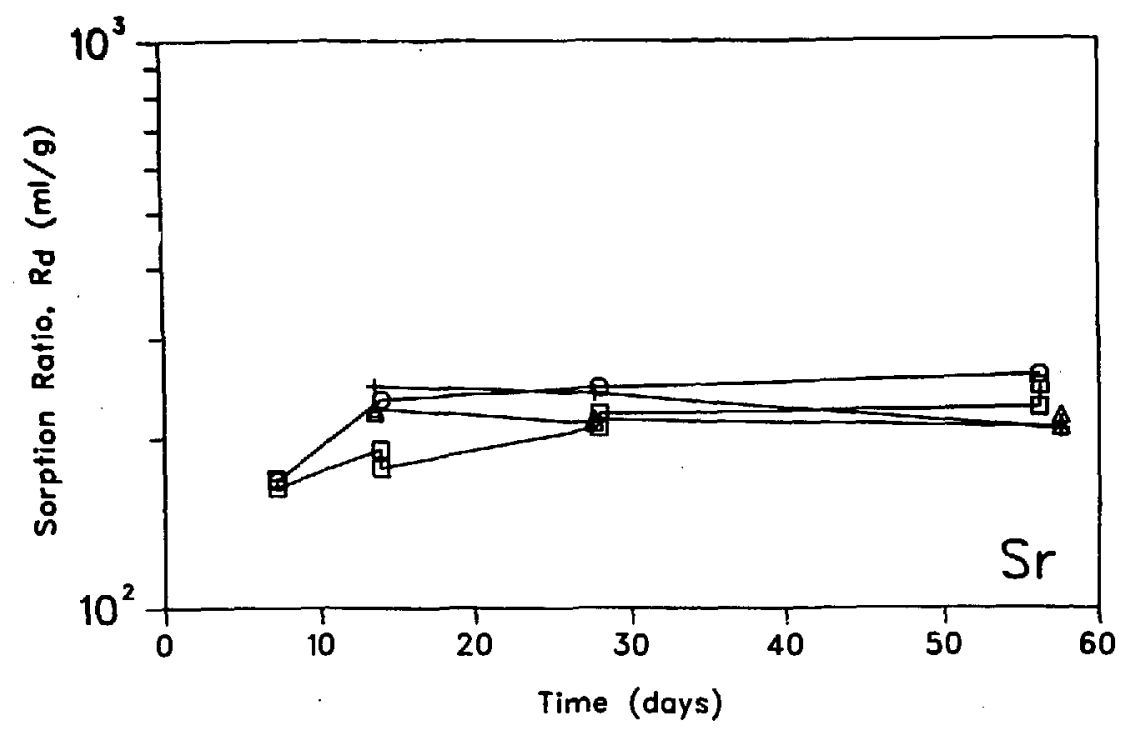

a Core 1, $-75 \mathrm{\mu m}$, sorption

o Core 2, -75 $\mathrm{\mu m}$, sorption

$\Delta$ Core 1, -75 $\mu \mathrm{m}$, desorption

+ Core 2, -75 $\mathrm{\mu m}$, desorption

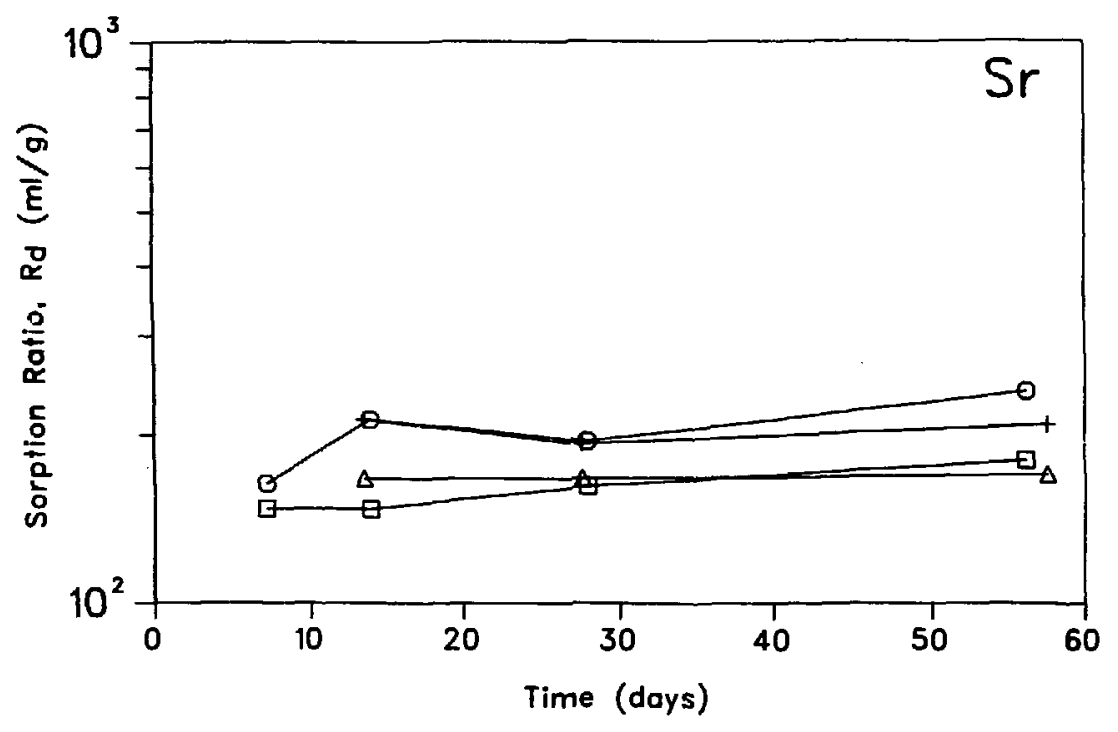

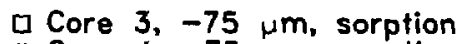

0 Core 4, $-75 \mu \mathrm{m}$, sorption

$\Delta$ Core $3,-75 \mu \mathrm{m}$, desorption

+ Core 4,-75 $\mu \mathrm{m}$, desorption

Fig. 7. Strontium sorption-desorption ratio data, $<75-\mu m$ fractions, ambient temperature. 


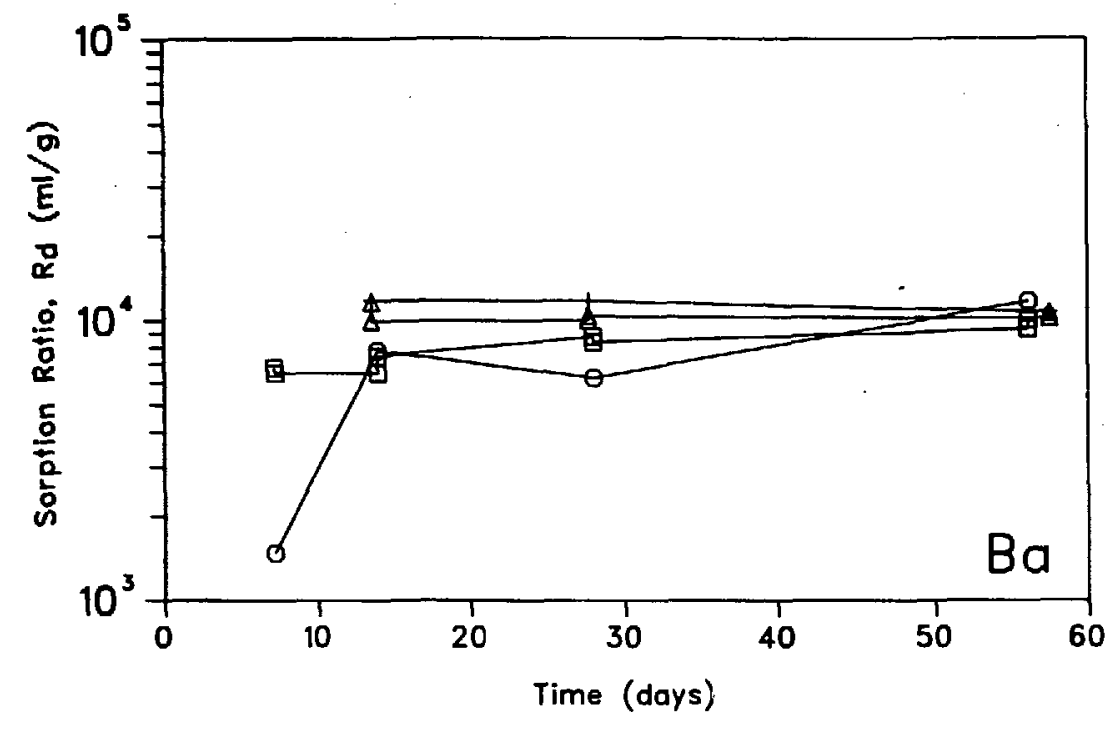

口 Core 1, -75 um, sorption

o Core 2, $-75 \mathrm{\mu m}$, sorption

$\Delta$ Core 1, $-75 \mu \mathrm{m}$, desorption

+ Core 2, $-75 \mu \mathrm{m}$, desorption

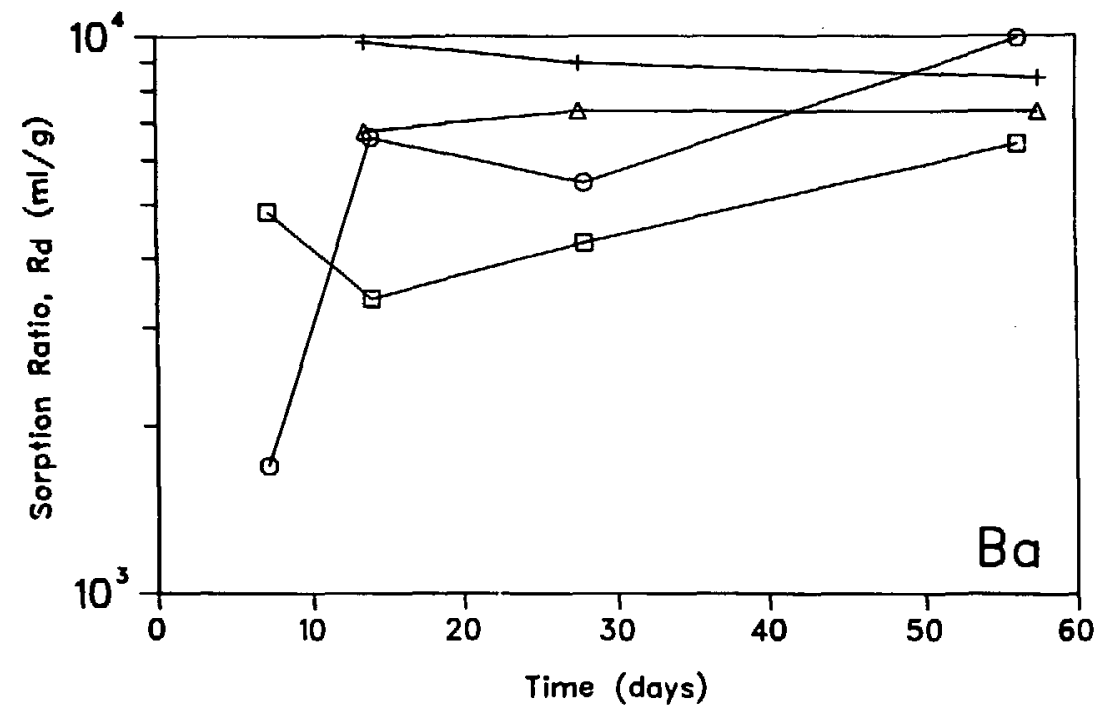

Core 3, $-75 \mathrm{\mu m}$, sorption

Core 4, -75 $\mathrm{\mu m}$, sorption

$\triangle$ Core 3, $-75 \mathrm{\mu m}$, desorption

+ Core 4, -75 $\mathrm{\mu m}$, desorption

Fig. 8. Barium sorption-desorption ratio data $<75-\mu m$ fractions, ambient temperature 

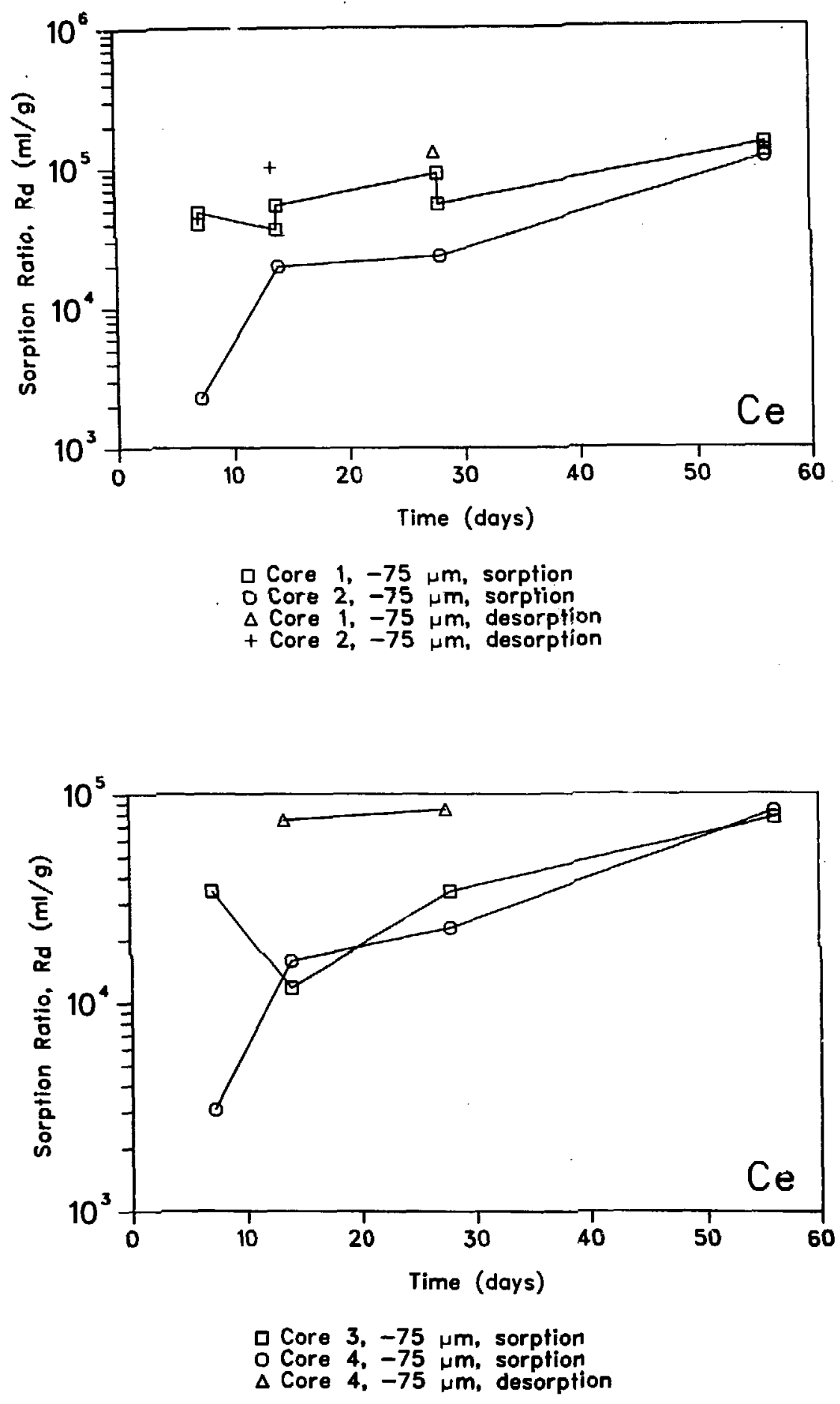

Fig. 9. Cerium sorption-desorption ratio data, $<75 \_$m fractions, ambient temperature. 


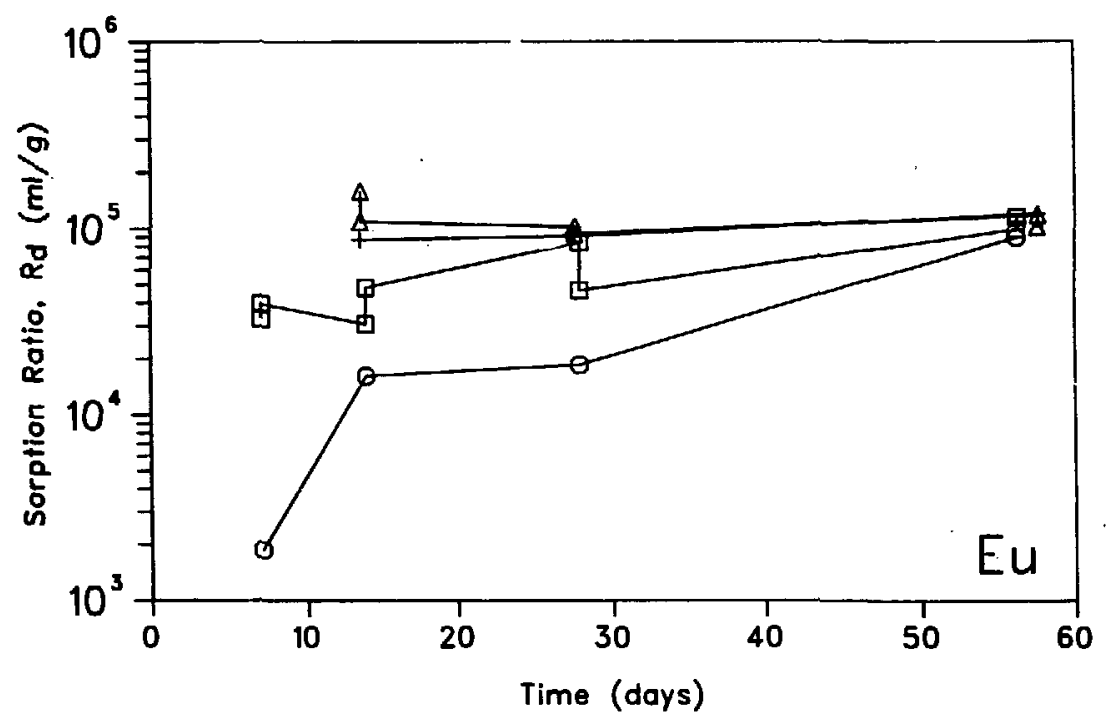

a Core 1, $-75 \mu \mathrm{m}$, sorption

o Core 2, $-75 \mathrm{\mu m}$, sorption

$\Delta$ Core 1, -75 $\mathrm{\mu m}$, desorption

+ Core 2, -75 um, desorption

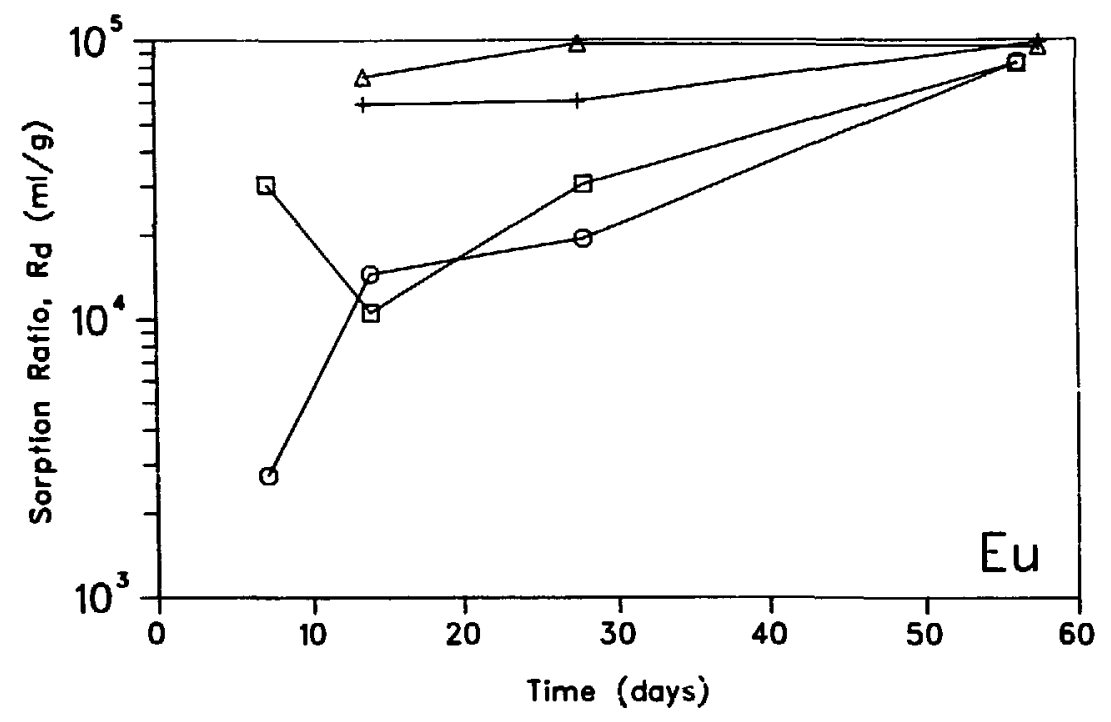

a Core 3, -75 um, sorption

o Core 4, -75 $\mu \mathrm{m}$, sorption

$\Delta$ Core 3, -75 $\mu \mathrm{m}$, desorption

+ Core 4, -75 $\mathrm{\mu m}$, desorption

Fig. 10. Europium sorption-desorption ratio data, $<75-\mu m$ fractions, ambient temperature. 


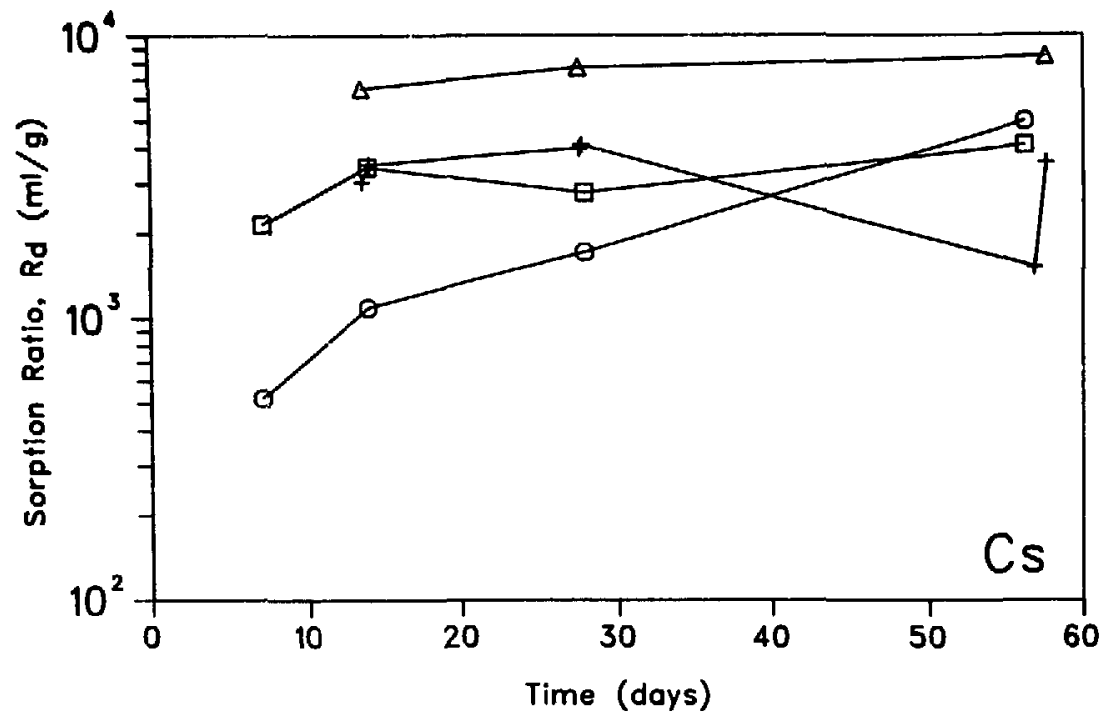

口 Core 3, chunk, sorption

o Core 4, chunk, sorption

$\Delta$ Core 3, chunk, desorption

+ Core 4, chunk, desorption

Fig. 11. Cesium sorption-desorption ratio data, chunk samples, ambient temperature

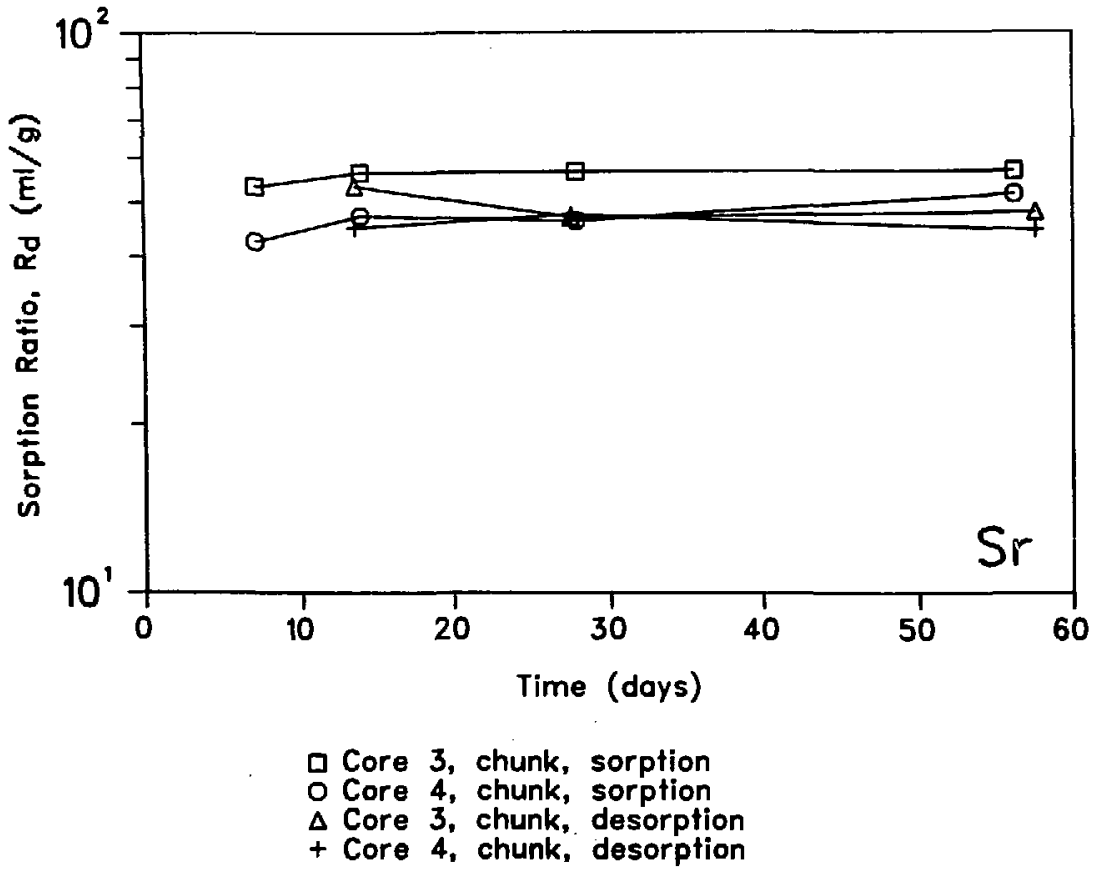

Fig. 12. Strontium sorption-desorption ratio data, chunk samples, ambient temperature. 


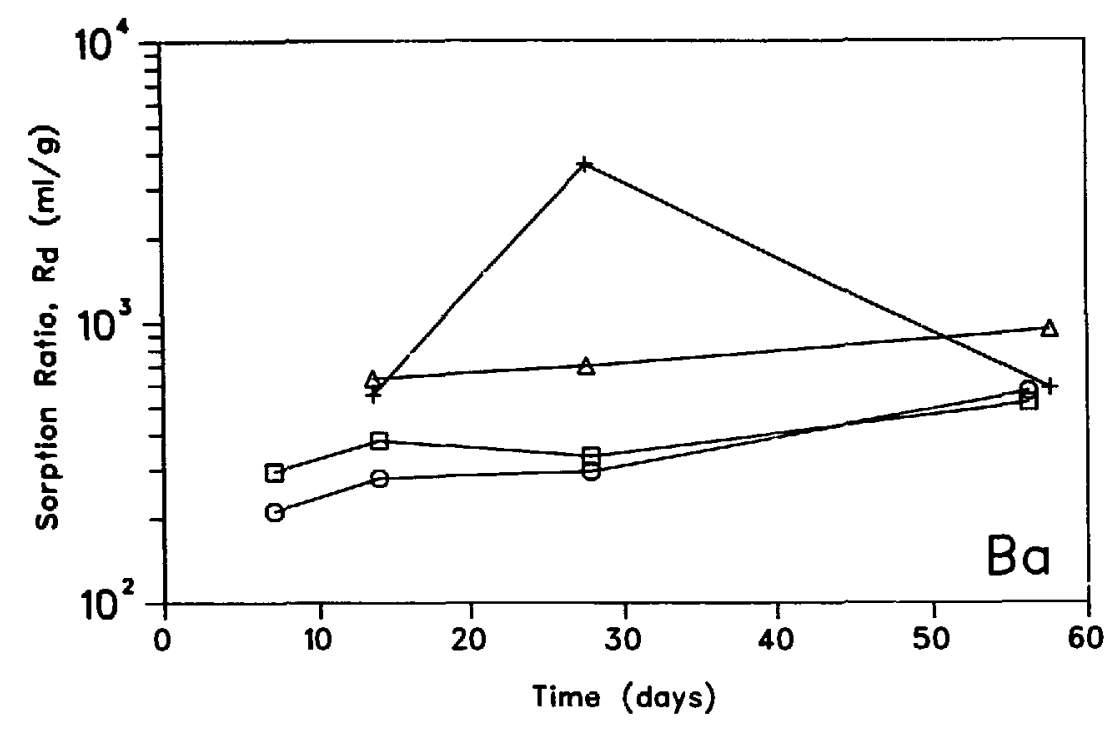

- Core 3, chunk, sorption

o Core 4, chunk, sorption

$\Delta$ Core 3 , chunk, desorption

+ Core 4, chunk, desorption

Fig. 13. Barium sorption-desorption ratio data, chunk samples, ambient temperature.

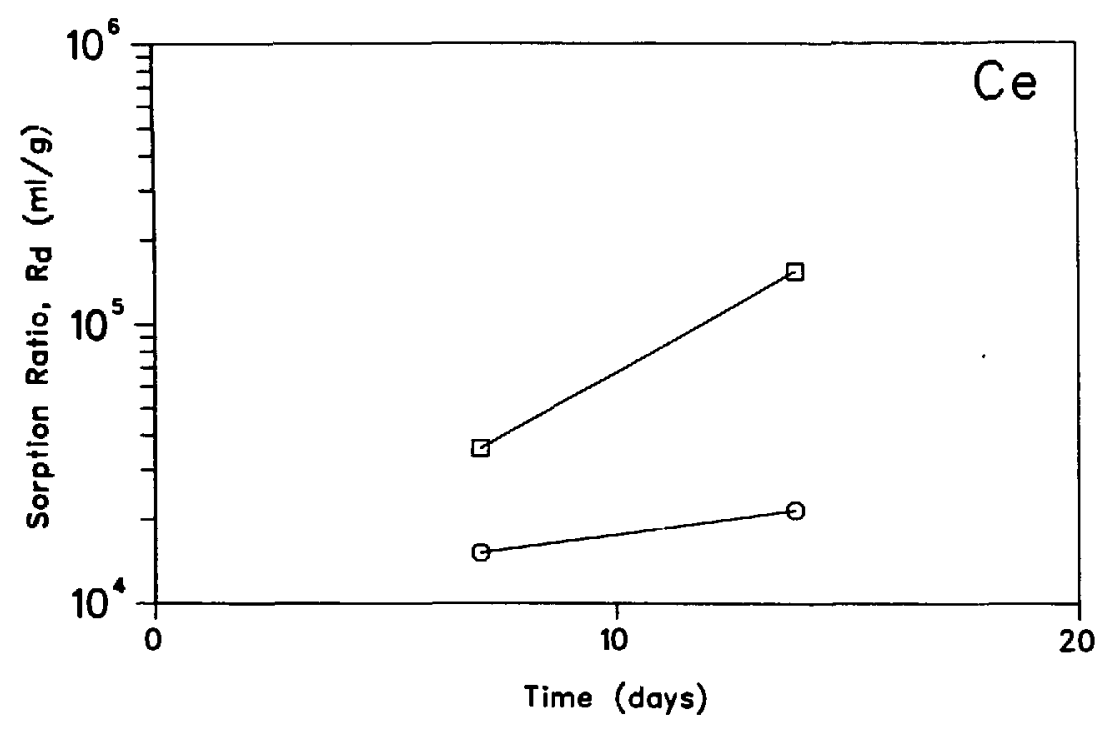

- Core 3, chunk, sorption

o Core 4, chunk, sorption

Fig. 14. Cerium sorption-desorption ratio data, chunk samples, ambient temperature. 


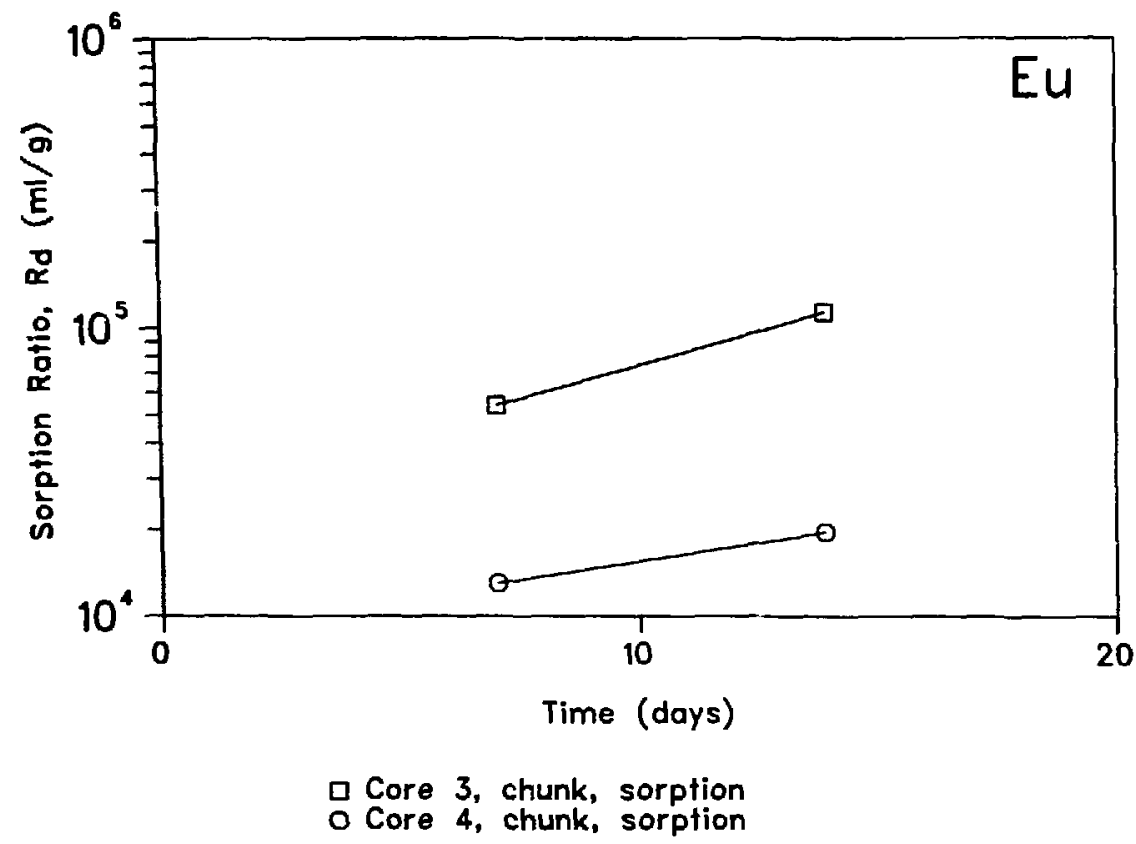

Fig. 15. Europium sorption-desorption ratio data, chunk samples, ambient temperature.

same element (for example, ions of different oxidation states, differently complexed ions, and various degrees of hydration or polymerization). If the exchange between such species is very slow and they exhibit different sorption characteristics, only one species may sorb strongly while the other remains in solution. The nonsorbing species is then absent in the desorption experiment. of course, one could also explain this observation by postulating a significant alteration of the mineralogy in such a manner as to greatiy increase the clay and zeolite fractions on the surface of the solid phase. Since, clays and zeolites have a strong affinity for cations, one would then expect a higher sorption ratio.

The need to sample the solid phase in order to measure the sorption ratio for those species having container problems is very clear. of course, the addition of the solid should reduce the percentage of the activity going to the wall due to the greater surface area of the solid. However, for argillite the magnitude of the effect of the container is sometimes significant, as indicated by the L/S ratio in the tables.

In order to check briefly on the effect of the water and solid pre-equilibration, three measurements were made in which neither the rock nor the 


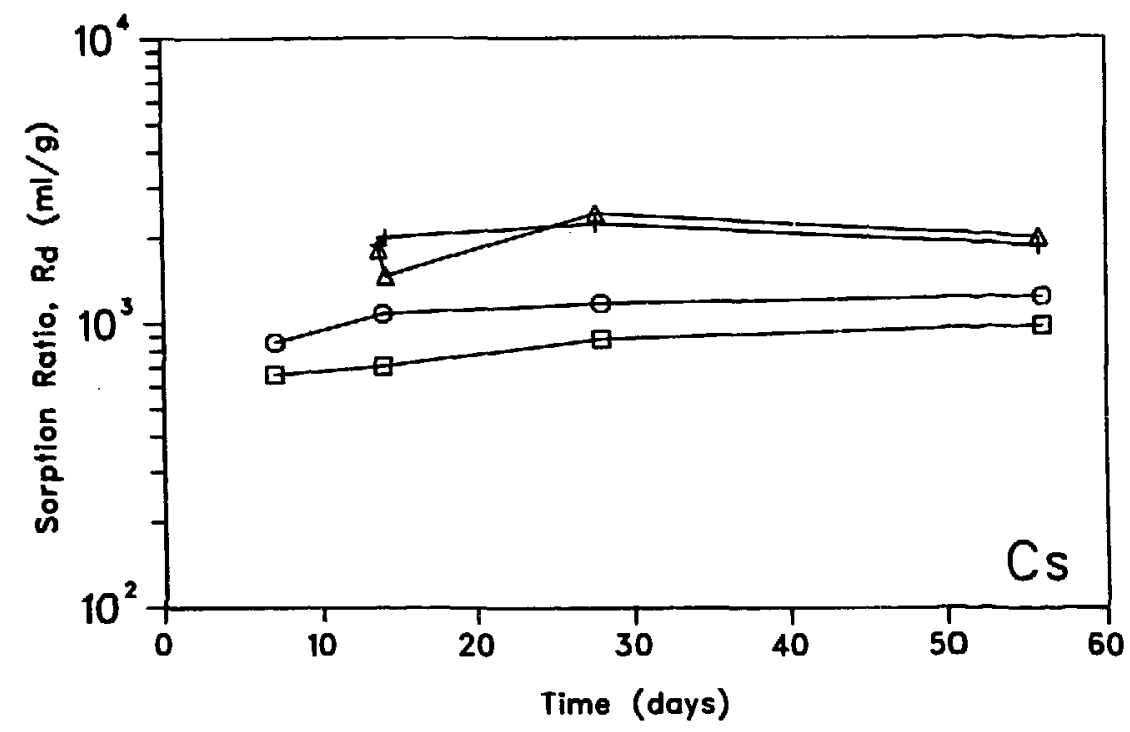

$\square$ Core 1, 106 - $150 \mu \mathrm{m}$, sorption

o Core 1, 355 - $500 \mu \mathrm{m}$, sorption

$\Delta$ Core 1, $106-150 \mu \mathrm{m}$, desorption

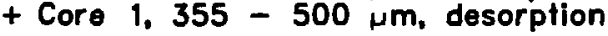

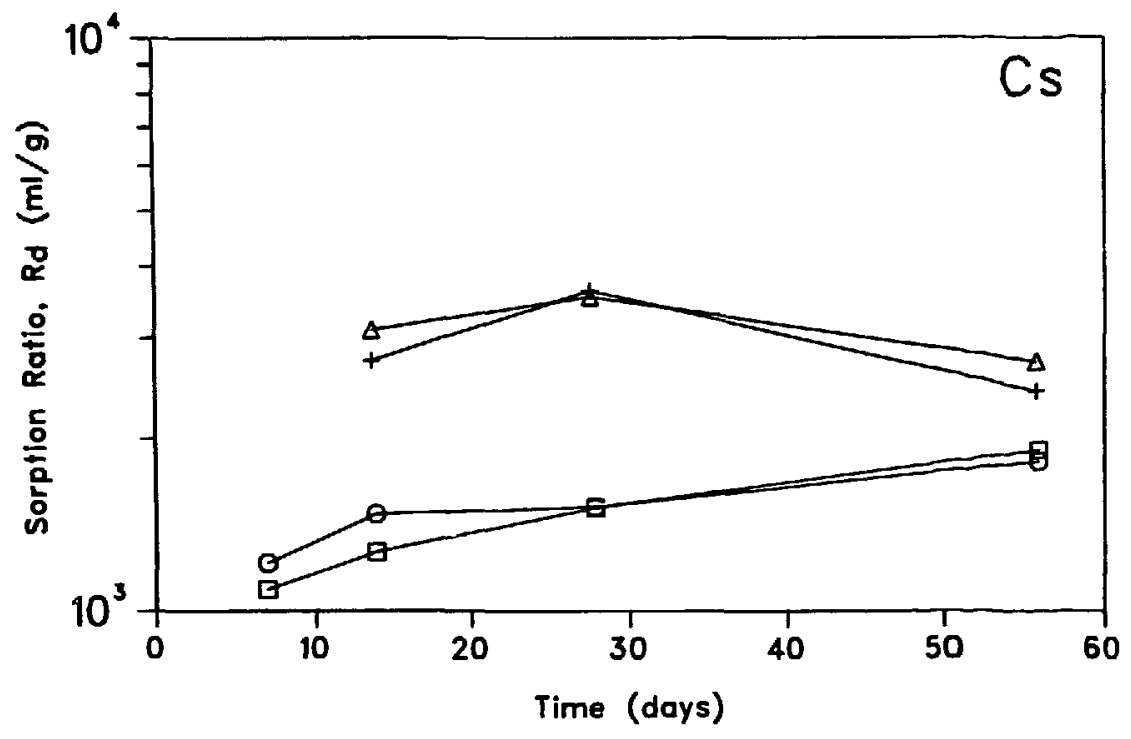

a Core 2, 106 - $150 \mu \mathrm{m}$, sorption

o Core 2, 355 - $500 \mu \mathrm{m}$, sorption

$\Delta$ Core 2, 106 - $150 \mu \mathrm{m}$, desorption

+ Core 2, 355 - $500 \mu \mathrm{m}$, desorption

Fig. 16. Cesium sorption-desorption ratio data, selected sieve fractions, $70^{\circ} \mathrm{C}$. 


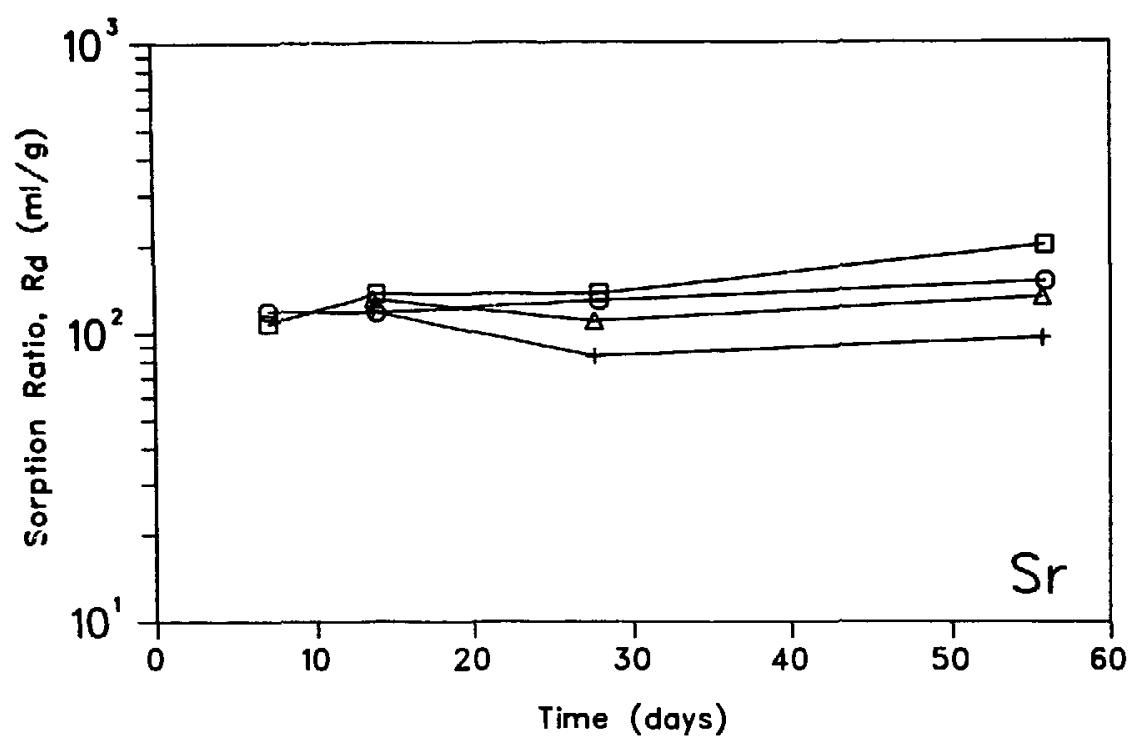

口 Core 1, $106-150 \mu \mathrm{m}$, sorption

o Core 1, 355 - $500 \mu \mathrm{m}$, sorption

$\Delta$ Core 1, $106-150 \mu \mathrm{m}$, desorption

+ Core 1. 355 - $500 \mu \mathrm{m}$, desorption

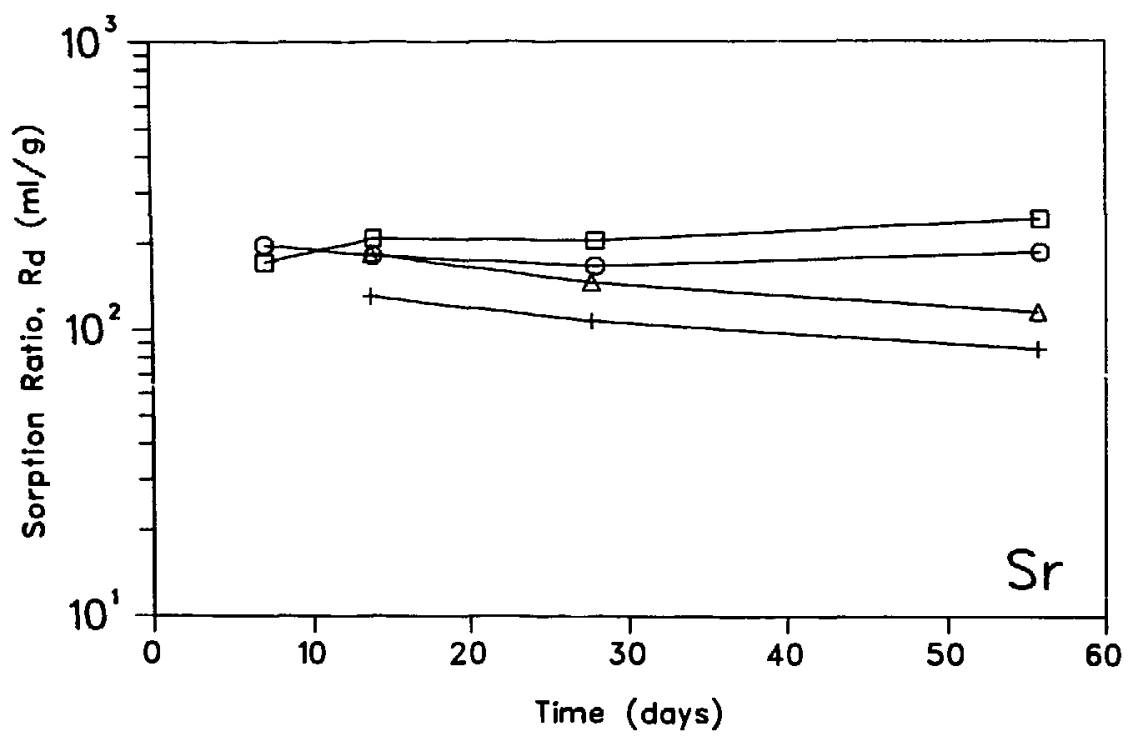

口 Core 2, $106-150 \mu \mathrm{m}$, sorption

o Core 2, 355 - $500 \mu \mathrm{m}$, sorption

$\Delta$ Core 2, $106-150 \mu \mathrm{m}$, desorption

+ Core 2, 355 - $500 \mu \mathrm{m}$, desorption

Fig. 17. Strontium sorption-desorption ratio data, selected sieve fractions, $70^{\circ} \mathrm{C}$. 


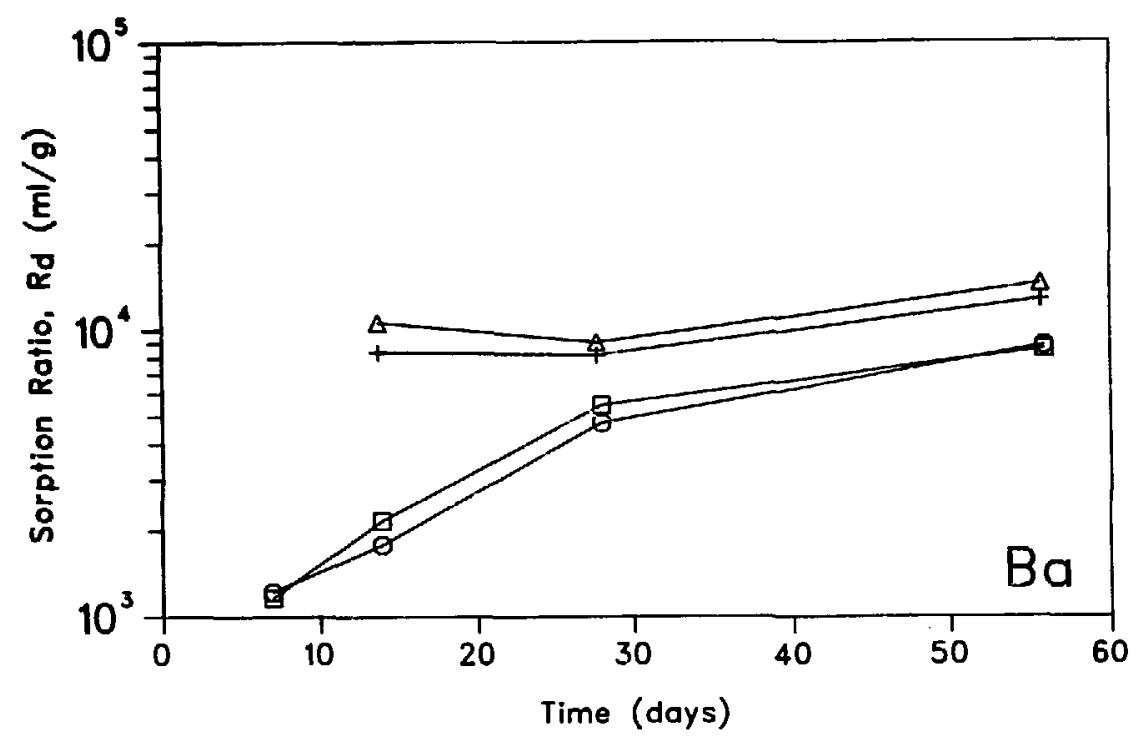

口 Core 1, $106-150 \mu \mathrm{m}$, sorption

o Core 1, 355 - $500 \mathrm{um}$, sorption

$\Delta$ Core $1,106-150 \mu \mathrm{m}$, desorption

+ Core 1, 355 - $500 \mu \mathrm{m}$, desorption

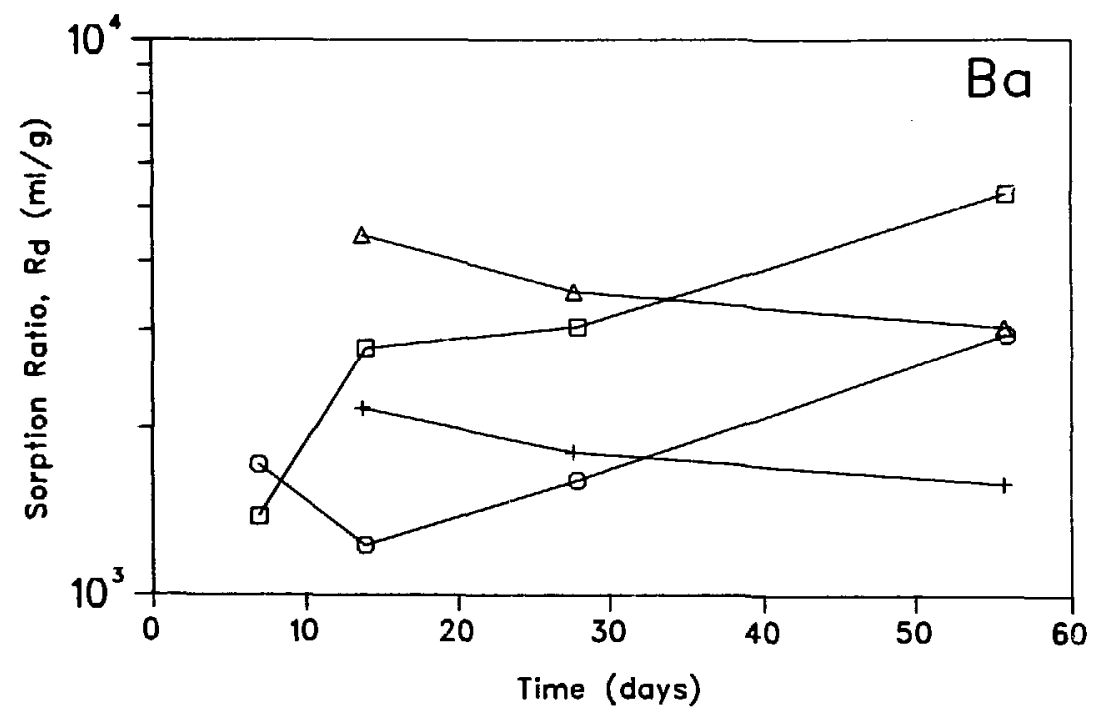

口 Core 2, 106 - $150 \mu \mathrm{m}$, sorption

o Core 2, $355-500 \mathrm{~km}$, sorption

$\Delta$ Core 2, $106-150 \mathrm{\mu m}$, desorption

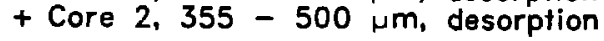

Fig. 18. Barium sorption-desorption ratio data, selected sieve fractions, $70^{\circ} \mathrm{C}$. 


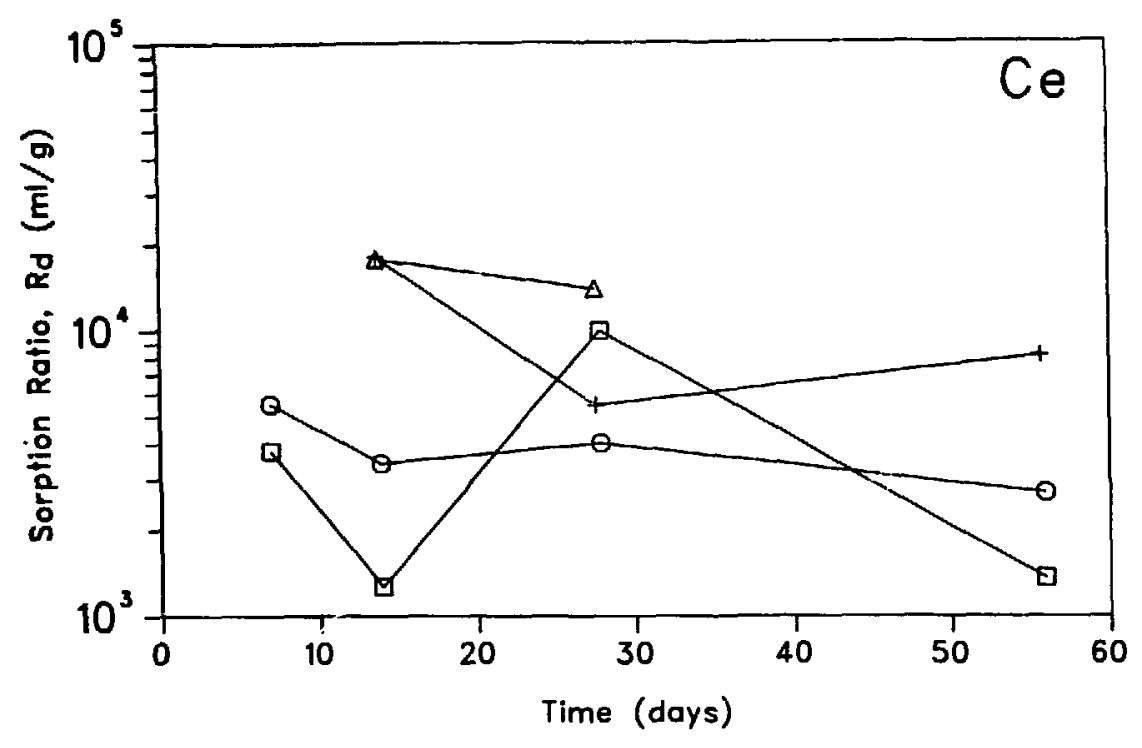

달 1, $106-150 \mu \mathrm{m}$, sorption

o Core 1, 355 - $500 \mu \mathrm{m}$, sorption

$\Delta$ Core 1, $106-150 \mathrm{\mu m}$, desorption

+ Core 1, 355 - $500 \mu \mathrm{m}$, desorption

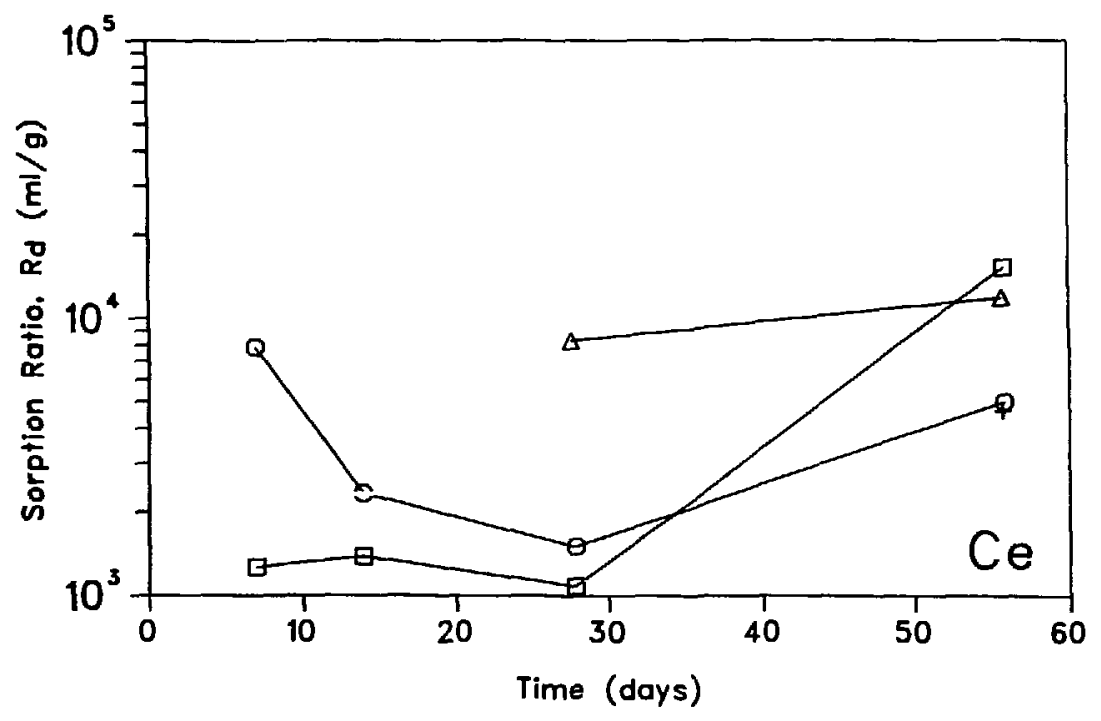

口 Core 2, 106 - $150 \mathrm{\mu m}$, sorption

o Core 2, 355 - $500 \mathrm{\mu m}$, sorption

$\Delta$ Core 2, $106-150 \mathrm{\mu m}$, desorption

+ Core 2, 355 - $500 \mu \mathrm{m}$, desorption

Fig. 19. Cerium sorption-desorption ratio data, selected sieve fractions, $70^{\circ} \mathrm{C}$. 


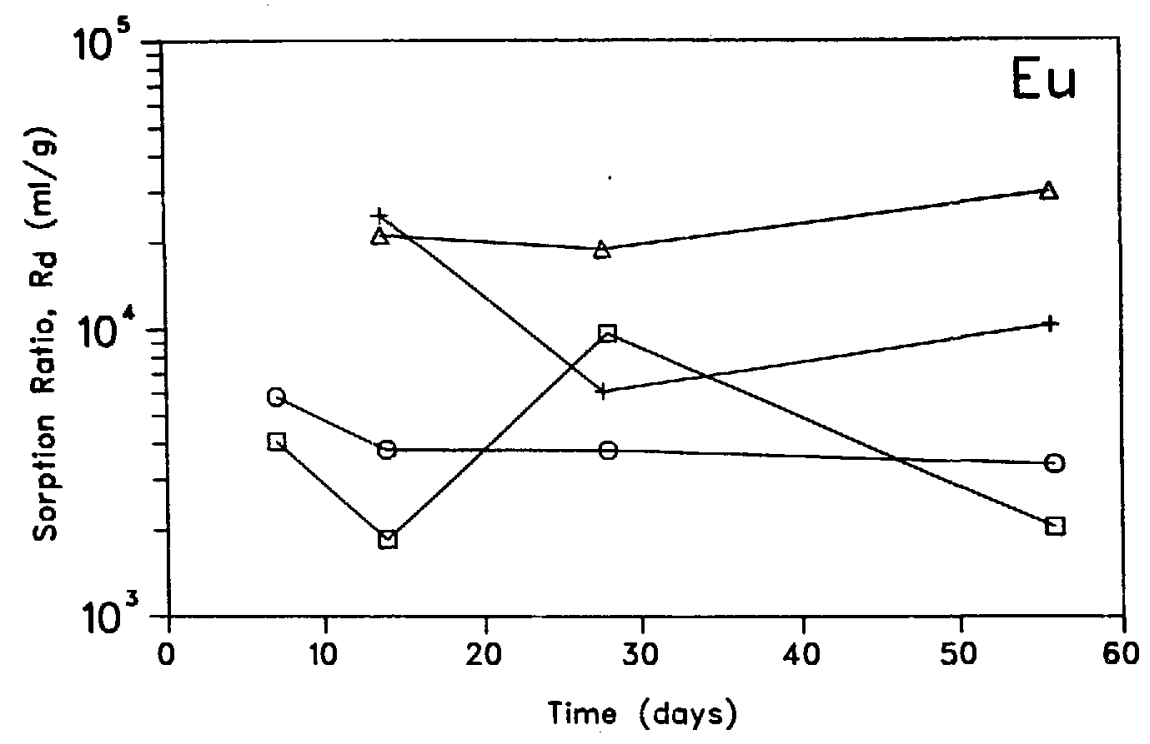

$\square$ Core 1, $106-150 \mu \mathrm{m}$, sorption

o Core 1, 355 - $500 \mu \mathrm{m}$, sorption

$\Delta$ Core 1, $106-150 \mu \mathrm{m}$, desorption

+ Core 1, 355 - $500 \mu \mathrm{m}$, desorption

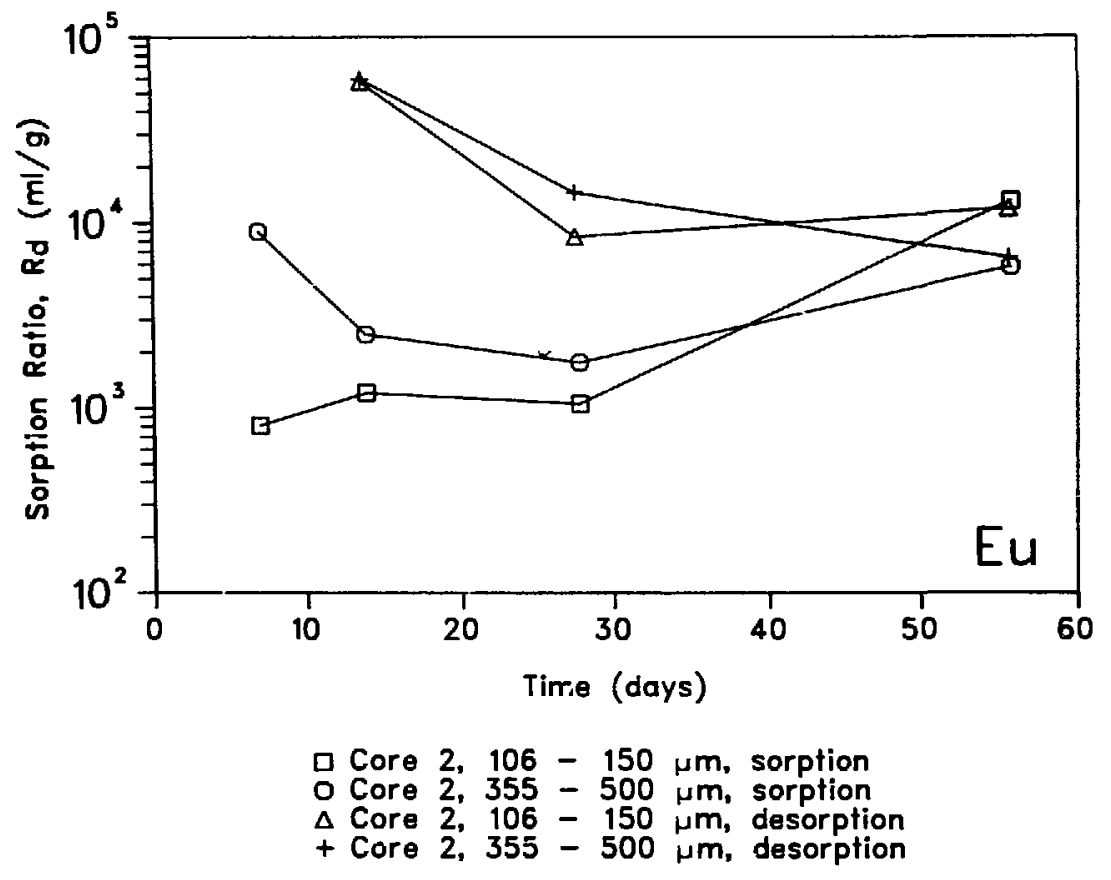

Fig. 20. Europium sorption-desorption ratio data, selected sieve fractions, $70^{\circ} \mathrm{C}$. 


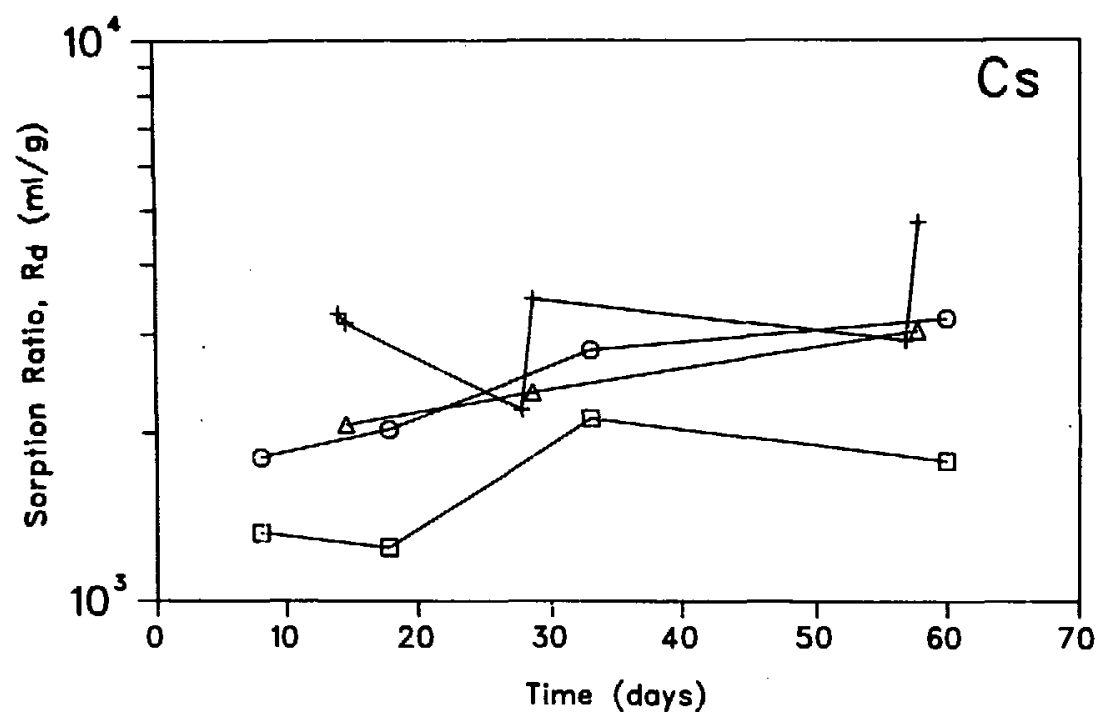

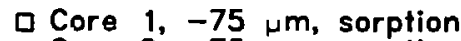

o Core 2, $-75 \mu \mathrm{m}$, sorption

$\Delta$ Core 1, $-75 \mu \mathrm{m}$, desorption

+ Core 2, -75 $\mathrm{\mu m}$, desorption

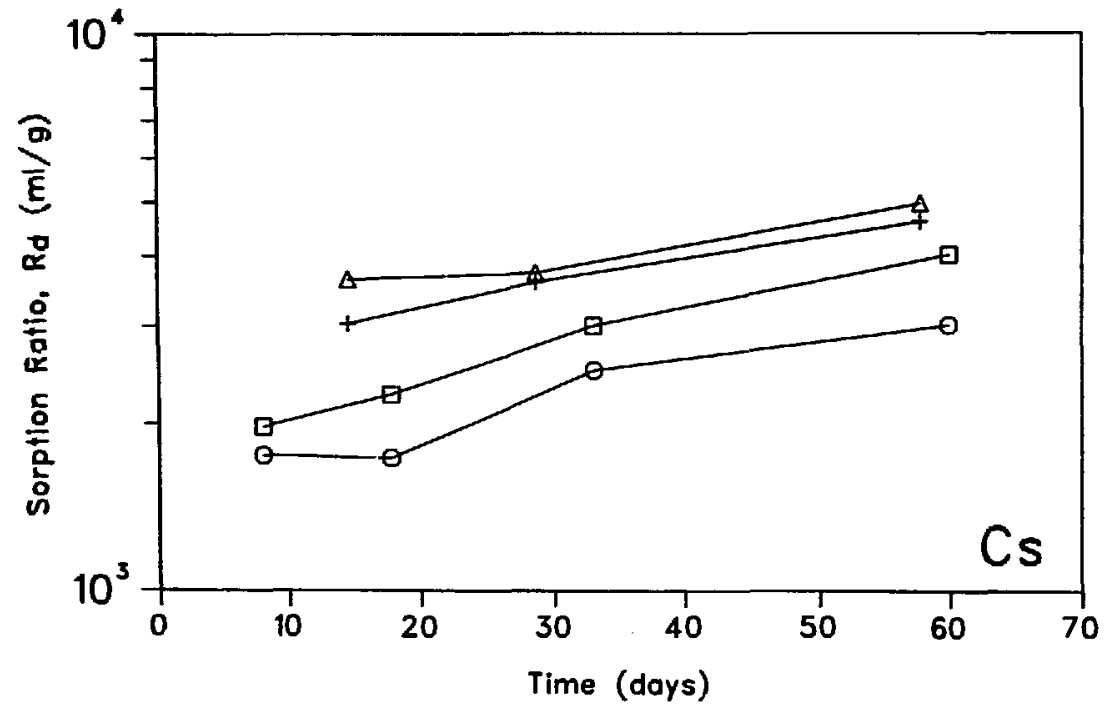

$\square$ Core 3, $-75 \mathrm{\mu m}$, sorption

o Core 4, $-75 \mu \mathrm{m}$, sorption

$\Delta$ Core 3, $-75 \mu \mathrm{m}$, desorption

+ Core 4, -75 um, desorption

Fig. 21. Cesium sorption-desorption ratio data, $\varangle 5-\mu m$ fractions, $70^{\circ} \mathrm{C}$. 


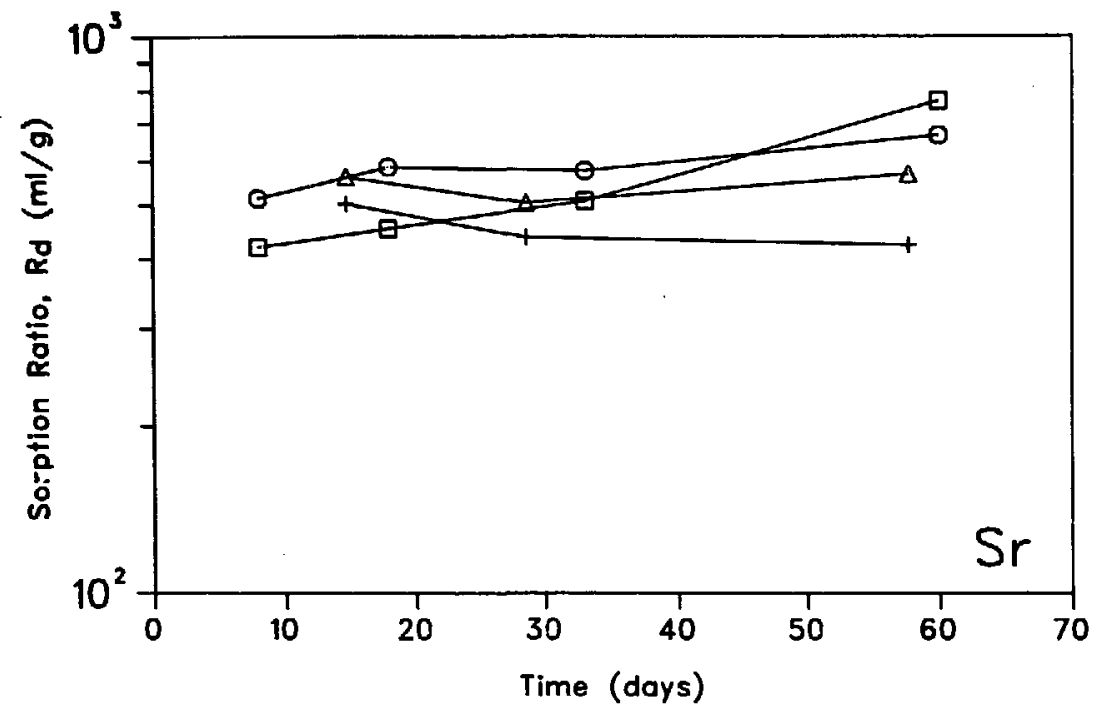

a Core 1, $-75 \mu \mathrm{m}$, sorption

o Core 2,-75 um, sorption

$\Delta$ Core 1, $-75 \mu \mathrm{m}$, desorption

+ Core 2, $-75 \mu \mathrm{m}$, desorption

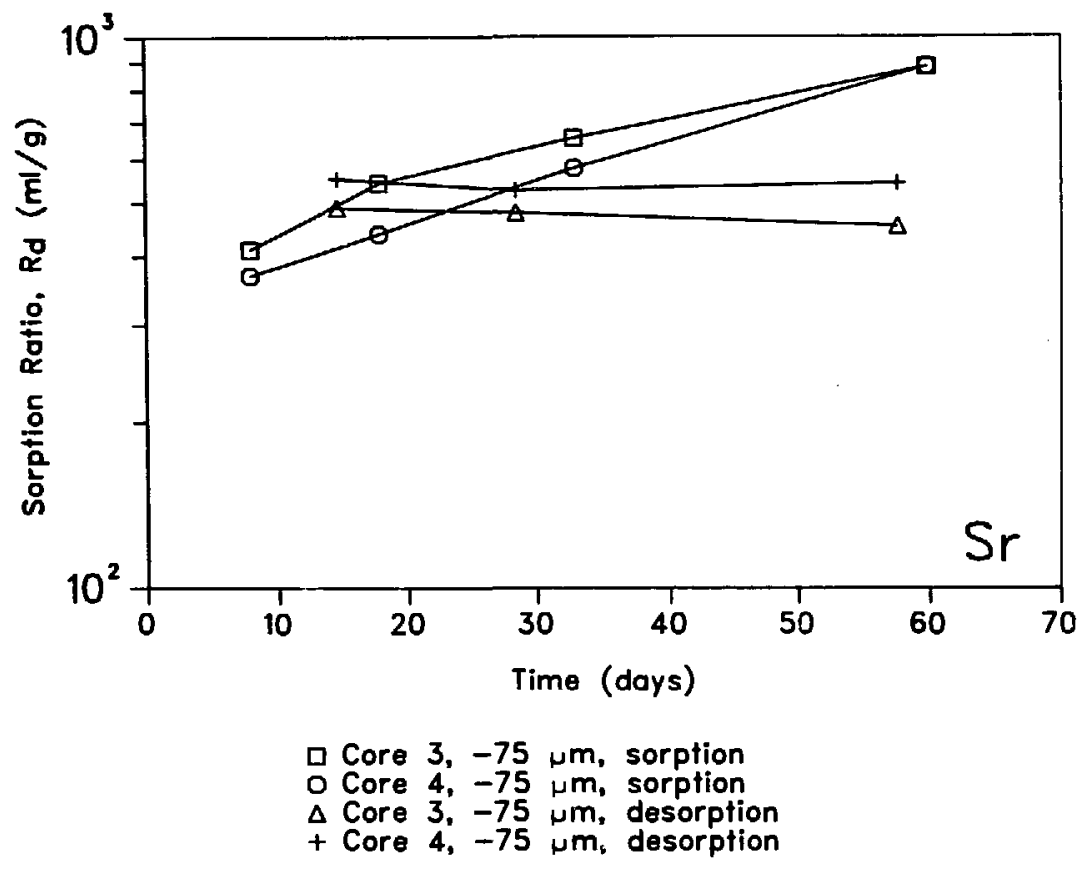

Fig. 22. Strontium sorption-desorption ratio data, $\nabla 5-\mu \mathrm{m}$ fractions, $70^{\circ} \mathrm{C}$. 


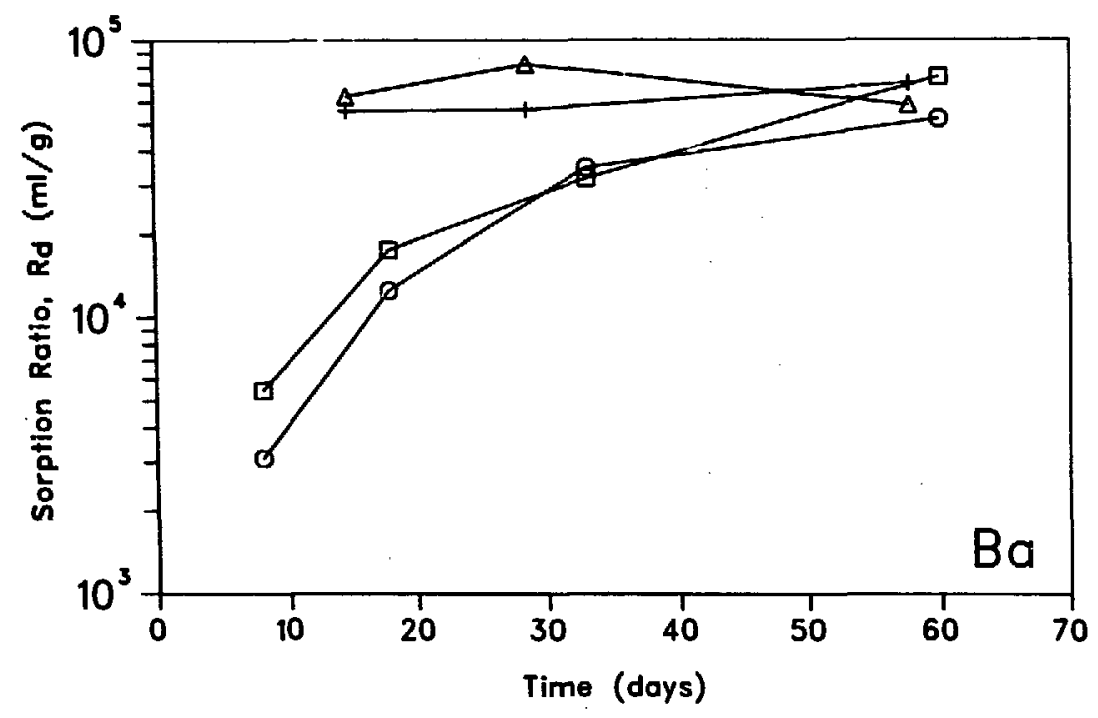

- Core 1, $-75 \mu \mathrm{m}$, sorption

o Core 2, -75 $\mathrm{\mu m}$, sorption

$\Delta$ Core $1,-75 \mathrm{\mu m}$, desorption

+ Core 2, $-75 \mathrm{\mu m}$, desorption

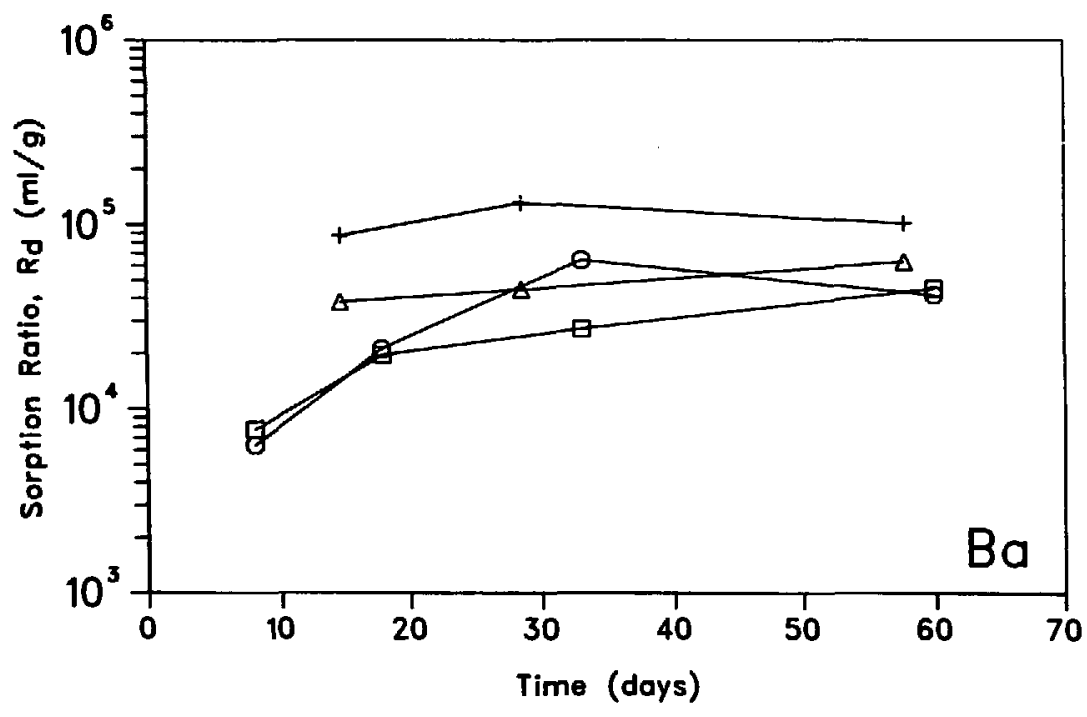

C Core 3, -75 um, sorption

o Core 4, -75 $\mathrm{\mu m}$, sorption

$\Delta$ Core 3, $-75 \mu \mathrm{m}$, desorption

+ Core 4, -75 jm, desorption

Fig. 23. Barium sorption-desorption ratio data, $\nabla 5-\mu m$ fractions, 


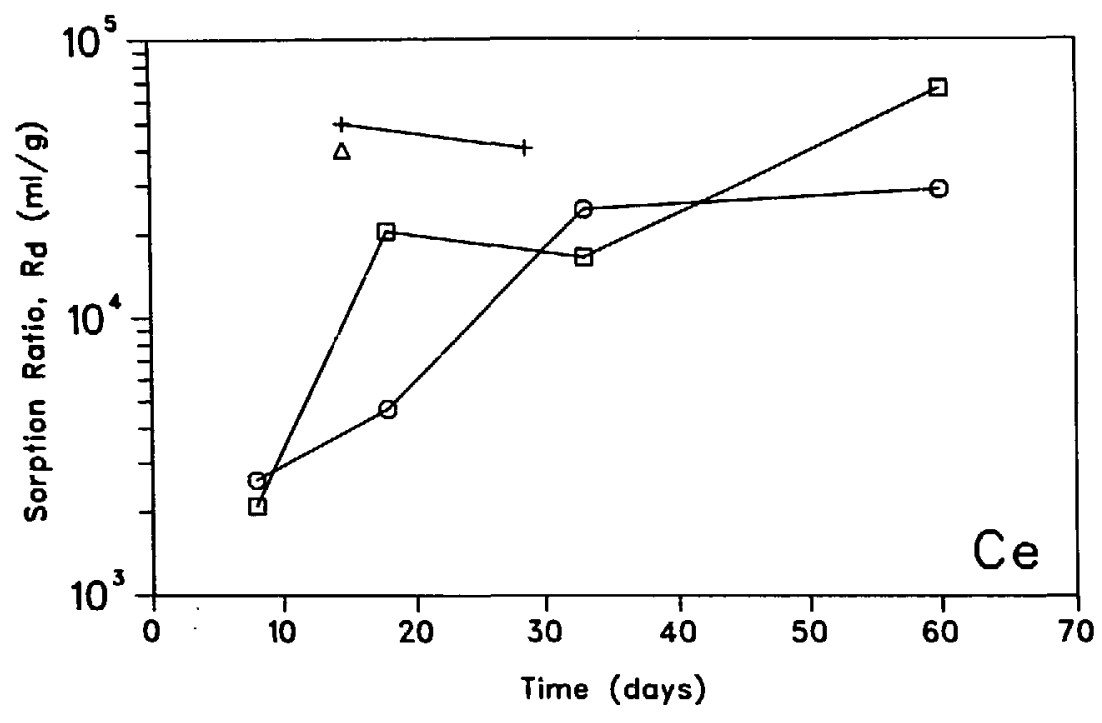

a Core 1, $-75 \mu \mathrm{m}$, sorption

o Core 2, $-75 \mathrm{\mu m}$, sorption

$\Delta$ Core 1, $-75 \mu \mathrm{m}$, desorption

+ Core 2, -75 $\mathrm{\mu m}$, desorption

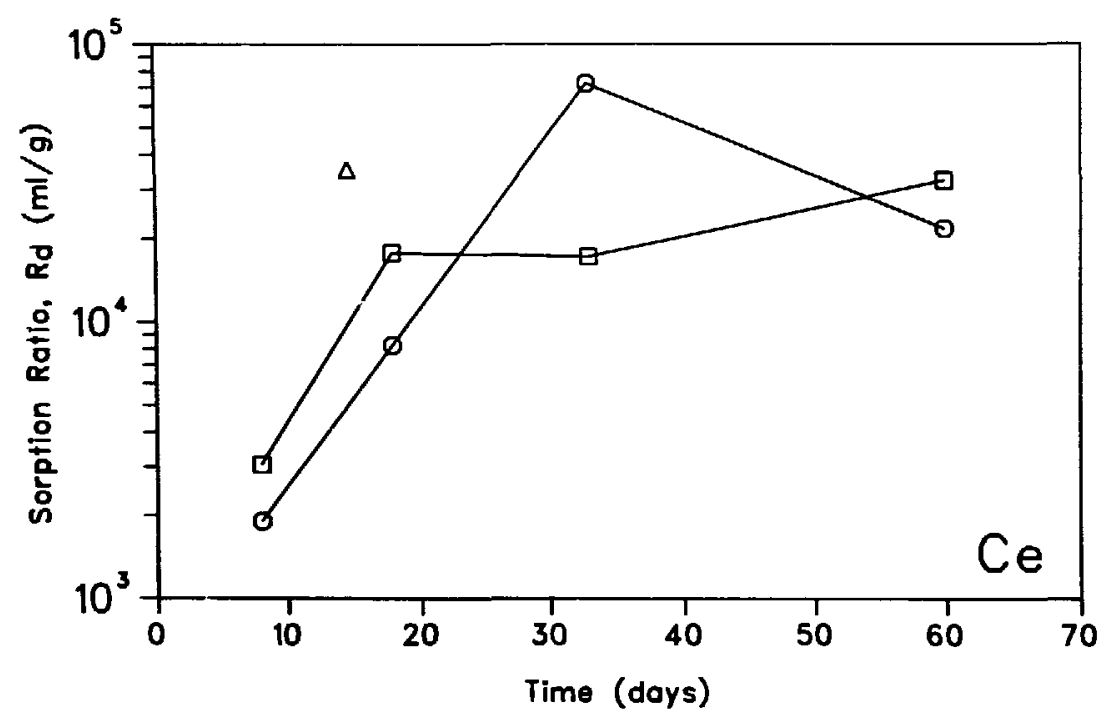

c Core 3, $-75 \mathrm{\mu m}$, sorption

O Core 4, $-75 \mu \mathrm{m}$, sorption

$\Delta$ Core 3, $-75 \mu \mathrm{m}$, desorption

Fig. 24. Cerium sorption-desorption ratio data, $>5-\mu m$ fractions, $70^{\circ} \mathrm{C}$. 

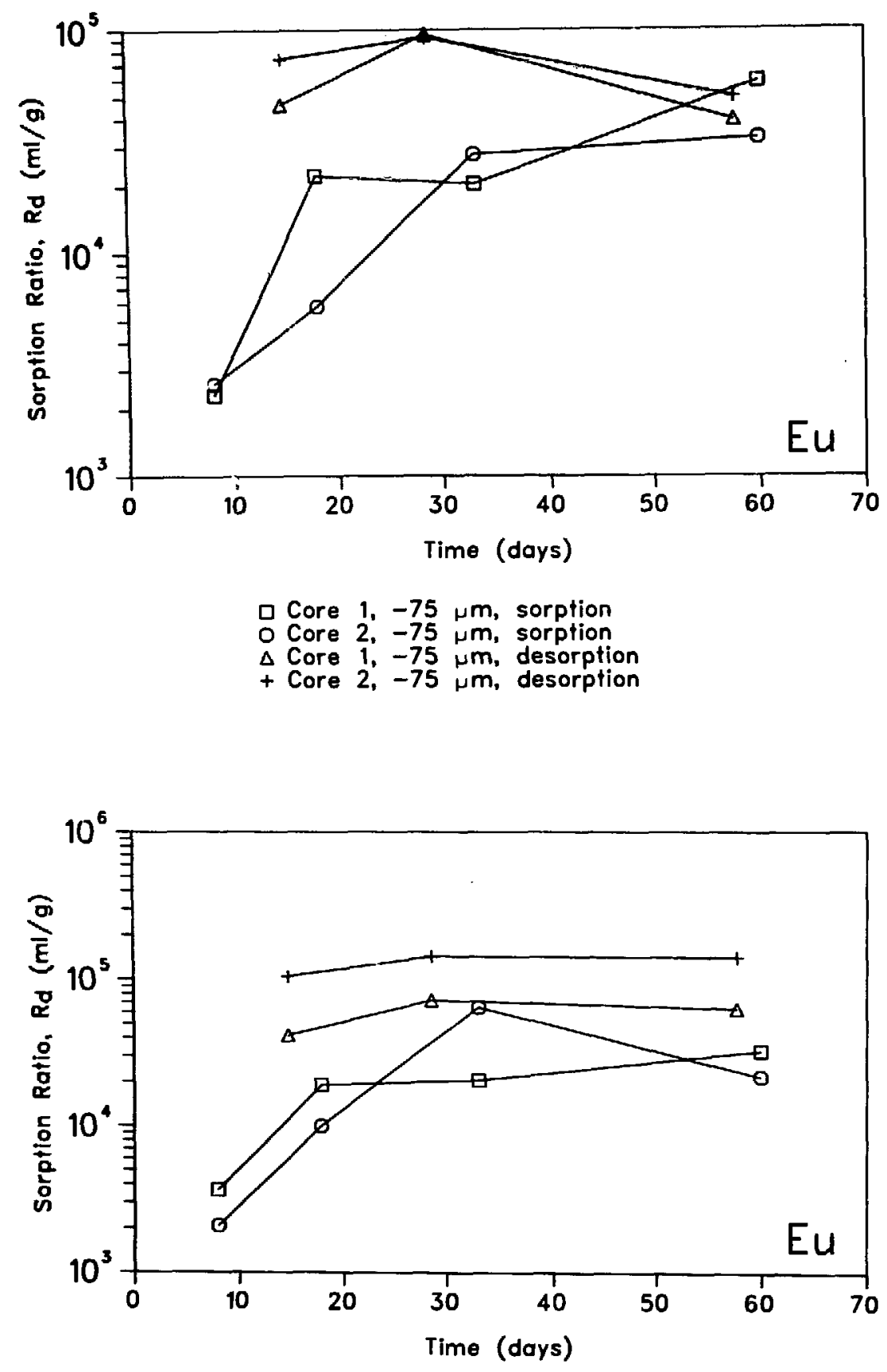

당 3, $-75 \mu \mathrm{m}$, sorption

o Core 4, $-75 \mu \mathrm{m}$, sorption

$\Delta$ Core 3, $-75 \mathrm{\mu m}$, desorption

+ Core 4, $-75 \mu \mathrm{m}$, desorption

Fig. 25. Europium sorption-desorption ratio data, $\nabla 5-\mu \mathrm{m}$ fractions, $70^{\circ} \mathrm{C}$. 


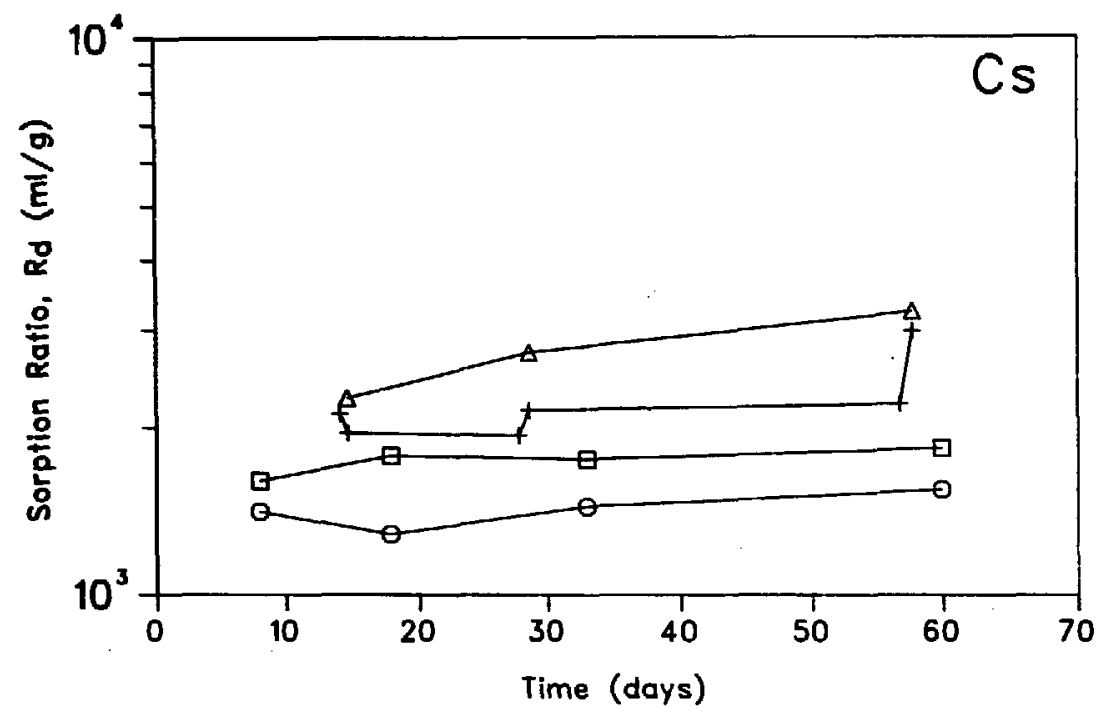

口 Core 3, chunk, sorption

O Core 4, chunk, sorption

$\triangle$ Core 3, chunk, desorption

+ Core 4, chunk, desorption

Fig. 26. Cesium sorption-desorption ratio data, chunk samples, $70^{\circ} \mathrm{C}$.

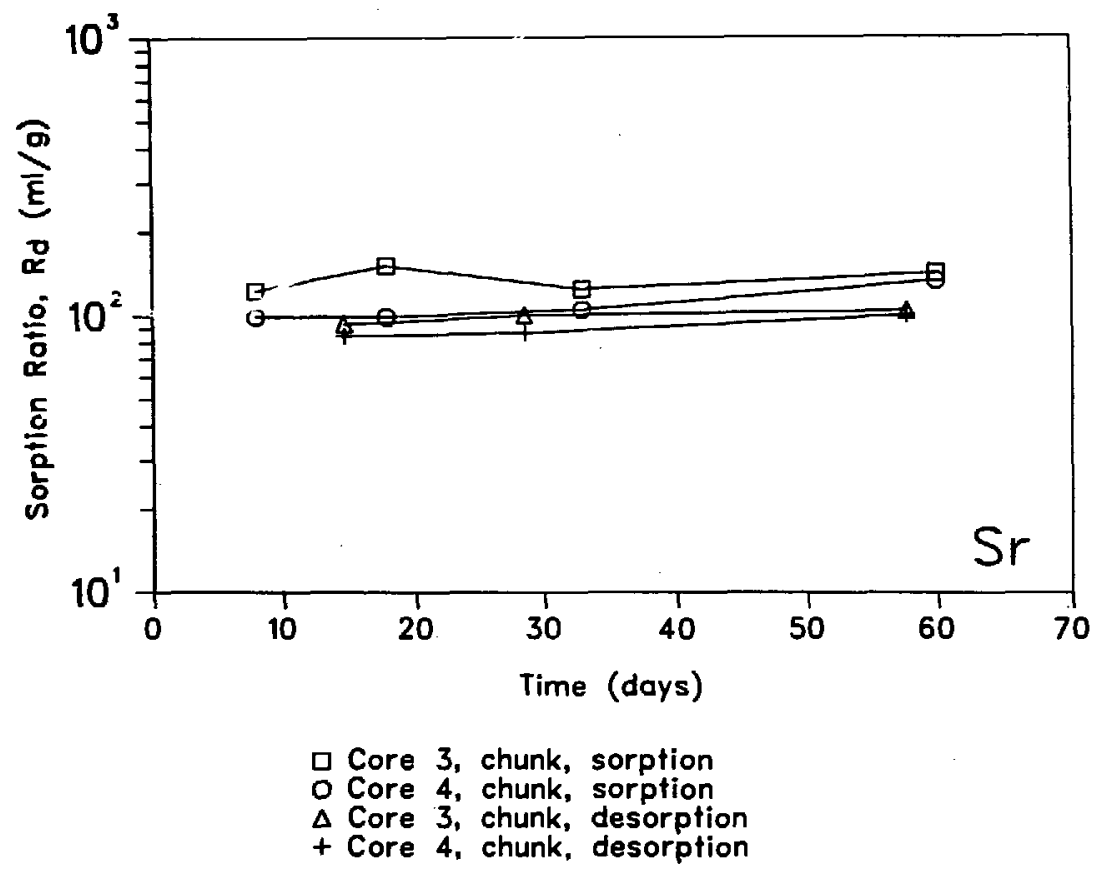

Fig. 27. Strontium sorption-desorption ratio data, chunk samples, $70^{\circ} \mathrm{C}$. 


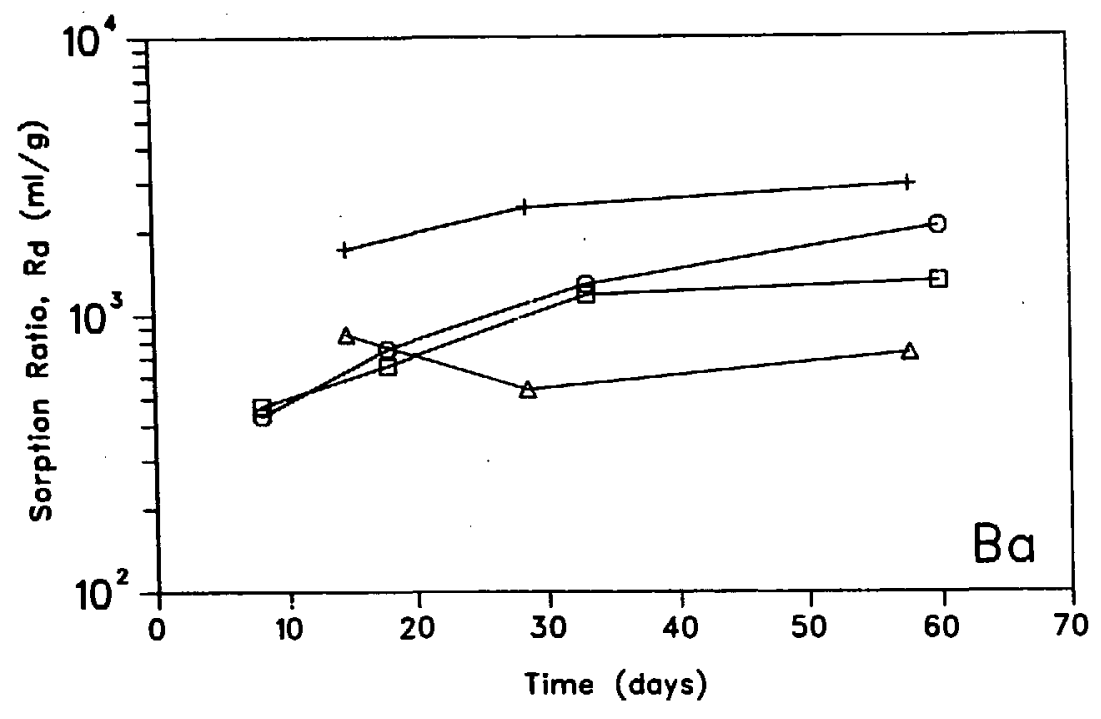

口 Core 3, chunk, sorption

O Core 4, chunk, sorption

$\triangle$ Core 3, chunk, desorption

+ Core 4, chunk, desorption

Fig. 28. Barium sorption-desorption ratio data, chunk samples, $70^{\circ} \mathrm{C}$.

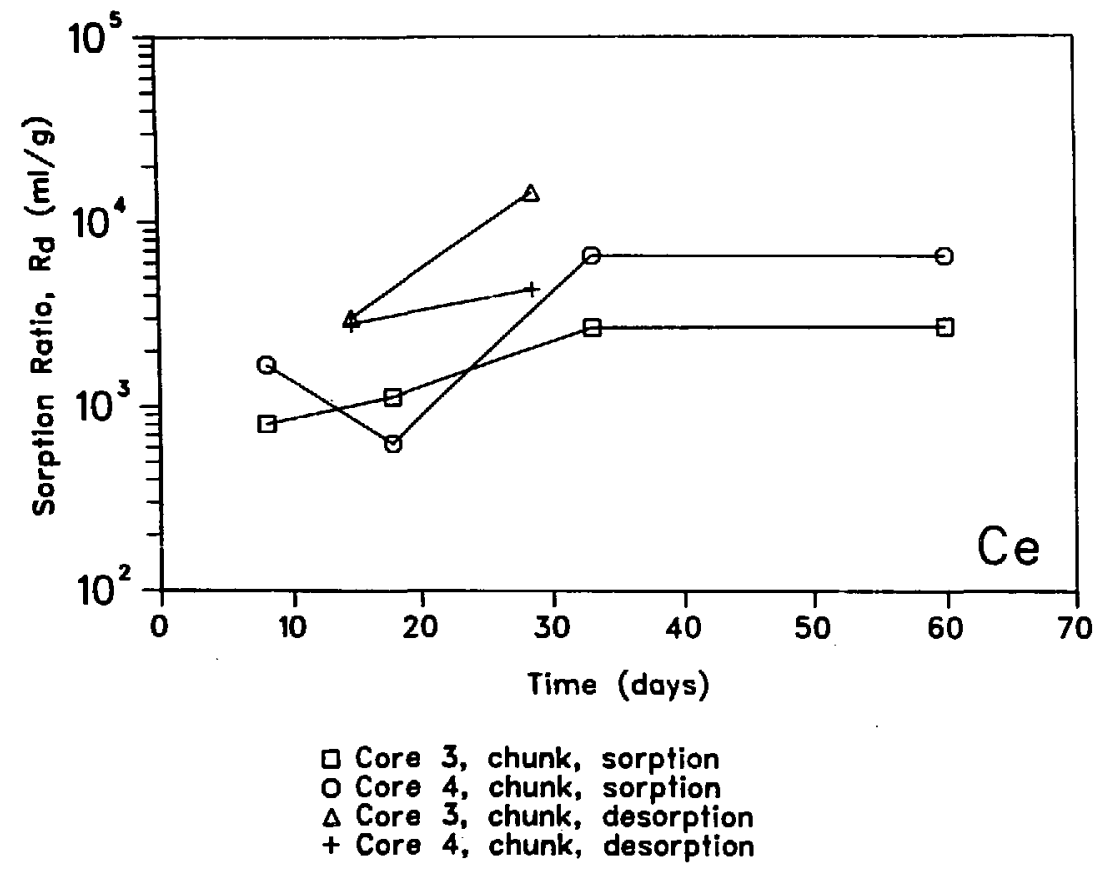

Fig. 29. Cerium sorption-desorption ratio data, chunk samples, $70^{\circ} \mathrm{C}$. 


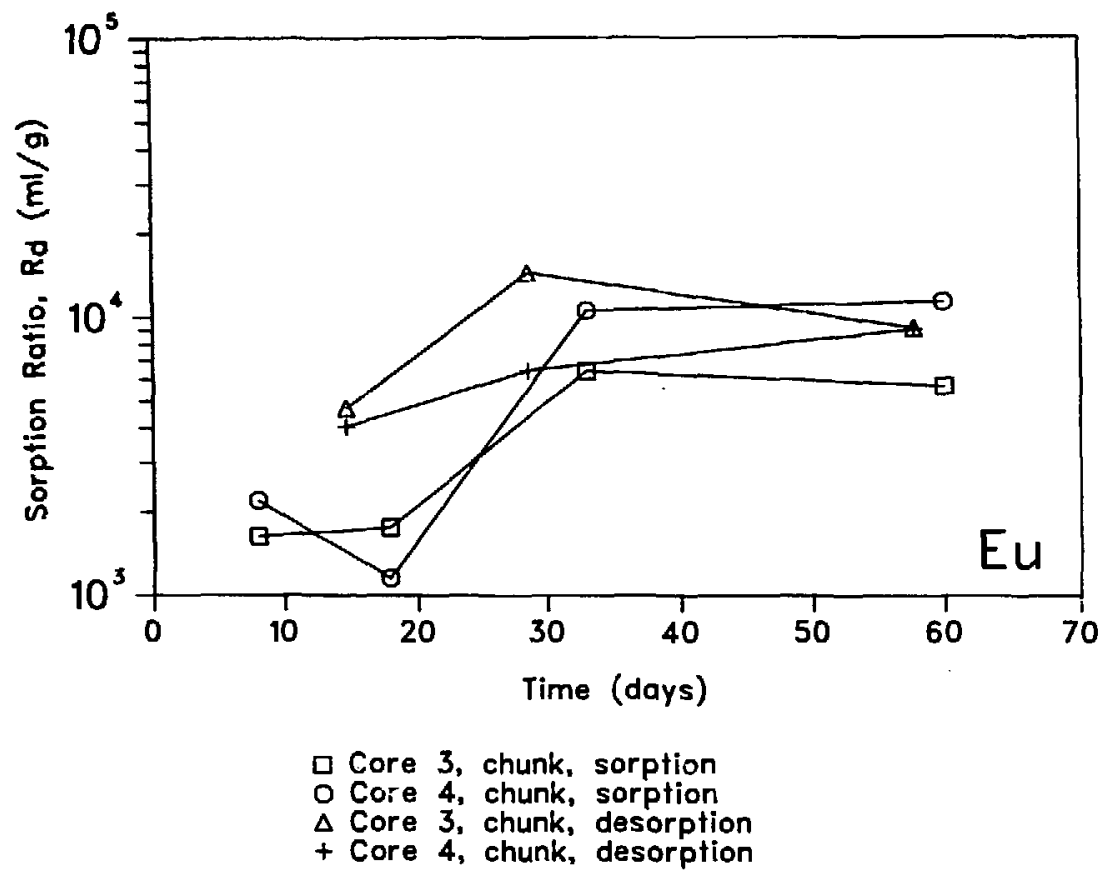

Fig. 30. Europium sorption-desorption ratio data, chunk samples, $70^{\circ} \mathrm{C}$.

water was pre-equilibrated. Otherwise, exactly the same procedure as described previously was used. The contact times were 1,2 and 4 weeks and the $<75-\mu \mathrm{m}$ material prepared from $\mathrm{CN} 1$ was used. The measurements were run at ambient temperatures. The sorption ratios and associated data are given in Table $X X$ and $X X I$. The measured $R_{d}$ values are somewhat higher than those given in Table IX for the study on the same material with pre-equilibrated waters. This may be due to entrapment of the cations during the mass transfer processes that are occurring as the system approaches "equilibrium."

Table XXII gives the mean $R_{d}$ values for the sorption measurements for each of the core samples at the two different temperatures. Even though there are some particle size effects on the sorption ratio, and also an increase in sorption with time, it is felt that a simple average is reasonably justified. These average values indicate that the elements arranged in the order of increasing sorption ratio at ambient and at $70^{\circ} \mathrm{C}$ is: $\mathrm{Sr}, \mathrm{Cs}, \mathrm{Ba}, \mathrm{Ce}, \mathrm{Eu}$. The sorption of cerium and europium is about equal in magnitude.

IV. SORPTION OF TECHNETIUM

A. Measurement Technique

Measurements of the sorption behavior of technetium, under atmospheric 
TABLE XX

SORPTION RATIOS, CNI, < $75 \mu \mathrm{m}$ FRACTION,

AMBIENT TEMPERATURE, NO PRE-EQUILIBRATION

Contact

Time

(days)

6.91

13.83

$(2.8)$

Sorption Ratio, $R_{d}(m \ell / g)^{\star}$

27.85

$3840(3.0)$

$(2.2)$

$472(2.1)$

$15900(6.1)$

487 (2.5)

$15900(6.1)$
$18300(7.8)$

\begin{tabular}{rr} 
Ce(III) & Eu(III) \\
\cline { 1 - 2 } $94100(8.8)$ & $76100(10)$ \\
$162000(11)$ & $131000(12)$ \\
$171000(21)$ & $148000(15)$
\end{tabular}

* See the footnote to Table VII.

TABLE XXI

pH AND L/S VALUES FOR MEASUREMENTS IN TABLE XX

\section{Contact}

Time

(days)

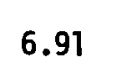

$6.91^{\star *}$

13.83

$13.83^{\star \star}$

27.85

$27.85 * \star$

Final

$\mathrm{pH}^{*}$

8.83

8.85

9.07

9.01

9.45

9.26

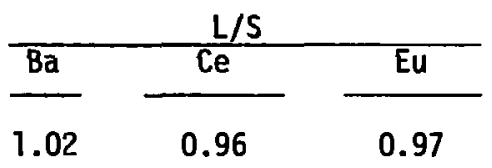

0.95

1.03

1.02

0.96

0.97

0.95

0.97

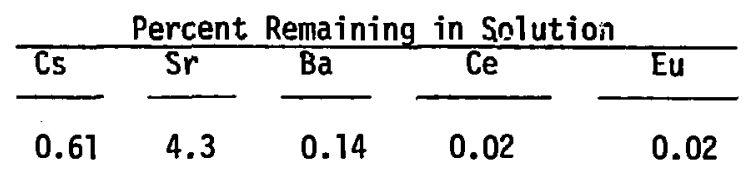

$\begin{array}{llll}99.2 & 101 & 95.9 & 72.03\end{array}$

85.6
0.01

$0.54 \quad 4.25$

0.13

62.25

$92.3 \quad 93.9$

89.1

0.11

0.01

$92.3 \quad 53.86$

0.02

78.3

0.01

$94.6 \quad 97.4$

77.4

\footnotetext{
* The initial pH was 8.46
}

${ }^{\star \star *}$ Control samples 
TABLE XXII

MEAN SORPTION RATIOS

Sorption Ratio, $R_{d}(m \ell / g)$

Element

Cs

Sr

$\mathrm{Ba}$

Ce

Eu $22^{\circ} \mathrm{C}$

\begin{tabular}{|c|c|c|c|c|}
\hline \multirow[b]{2}{*}{ Core } & & \\
\hline & Sorption & Desorption & Sorption & Desorption \\
\hline CNI & $1830 \pm 200$ & $3110 \pm 710$ & $1200 \pm 120$ & $1980 \pm 610$ \\
\hline CN2 & $1580 \pm 200$ & $3810 \pm 610$ & $1881 \pm 150$ & $3280+630$ \\
\hline CN3* & $2540 \pm 190$ & $4340 \pm 530$ & $2810 \pm 460$ & $4110 \pm 740$ \\
\hline $\operatorname{con} 4 *$ & $1940 \pm 360$ & $3630 \pm 480$ & $2240 \pm 310$ & $3740 \pm 810$ \\
\hline CN1 & $138 \pm 14$ & $133 \pm 88$ & $265 \pm 57$ & $256 \pm 218$ \\
\hline CN2 & $156 \pm 17$ & $131 \pm 76$ & $335 \pm 61$ & $236 \pm 166$ \\
\hline CN3* & $159 \pm 77$ & $168 \pm 7$ & $622 \pm 100$ & $508 \pm 40$ \\
\hline CN4* & $202 \pm 16$ & $204 \pm 11$ & $567 \pm 110$ & $541 \pm 13$ \\
\hline CN1 & $4270 \pm 970$ & $5530 \pm 5100$ & $12700 \pm 5600$ & $29600 \pm 29300$ \\
\hline $\mathrm{CN} 2$ & $4900 \pm 2000$ & $5650 \pm 5140$ & $10900 \pm 5100$ & $22030 \pm 29300$ \\
\hline CN3* & $4730 \pm 640$ & $7140 \pm 330$ & $24900 \pm 7800$ & $48600 \pm 13100$ \\
\hline $\mathrm{CN} 4 *$ & $5920 \pm 1690$ & $9050 \pm 680$ & $33400 \pm 12600$ & $36800 \pm 43600$ \\
\hline CN1 & $47400 \pm 10400$ & $>100000$ & $10700 \pm 5000$ & $17200 \pm 12300$ \\
\hline CN2 & $34000 \pm 11000$ & $72000 \pm 40000$ & $8660 \pm 2990$ & $26000 \pm 19800$ \\
\hline CN3* & $39300 \pm 13600$ & & $17600 \pm 6000$ & $26600 \pm 12400$ \\
\hline CN4* & $31200 \pm 17700$ & $79600 \pm 6600$ & $26000 \pm 15900$ & \\
\hline CN1 & $40300 \pm 800$ & $89800 \pm 45000$ & $10700 \pm 4400$ & $32500 \pm 26900$ \\
\hline $\mathrm{CN} 2$ & $26800 \pm 8400$ & $81600 \pm 25000$ & $9360 \pm 3330$ & $41700 \pm 32200$ \\
\hline $\mathrm{CN}_{3}$ * & $38500 \pm 15400$ & $88600 \pm 12800$ & $18900 \pm 5900$ & $58800 \pm 15700$ \\
\hline CN4* & $30000 \pm 18000$ & $72600 \pm 22100$ & $24500 \pm 13900$ & $98200 \pm 75900$ \\
\hline
\end{tabular}

*The results obtained using the chunk samples were not included in the average. 
oxygen conditions, have been made following exactly the same procedures as described earlier in this report (see section III.A). The measurements were made using the ${ }^{95 m_{T}}$ suppl ied by Argonne National Laboratory under contract with Batteile Pacific Northwest Laboratory. The fourth batch (see Table IV) of pre-equilibrated water was used. The initial pH values were 8.32 and 8.38 for the ambient and $70^{\circ} \mathrm{C}$ measurements, respectively. Since the container sorption problems for technetium were unknown, ${ }^{137} \mathrm{Cs}$ was also added to the water $\left(17 \mu \mathrm{Ci}{ }^{137} \mathrm{Cs} / \mathrm{l}\right.$ final solution $\left.\left(1.4 \times 10^{-9} \mathrm{M}\right)\right)$ using the evaporation procedure previously described. However, the ${ }^{95 \mathrm{~m}} \mathrm{Tc}$ was added by simply pipetting a fraction of the diluted tracer into the appropriate water prior to filtration. The $\mathrm{pH}$ did not require adjusting after this addition. The final concentration was $4.1 \mu \mathrm{Ci}{ }^{95 \mathrm{~m}_{\mathrm{Tc}} / \ell \text { solution }}$ $\left(1.9 \times 10^{-9} \mathrm{M}\right)$. The $106-150 \mu \mathrm{m}$ and $355-500 \mu \mathrm{m}$ fractions from $\mathrm{CN} 1$, the $<75-\mu \mathrm{m}$ material from $\mathrm{CN} 2$, and the chunk samples from $\mathrm{CN} 4$ were used in the measurements which were performed at $22 \pm 2^{\circ} \mathrm{C}$ and $70 \pm 1{ }^{\circ} \mathrm{C}$.

B. Results and Conclusions

The results for the $R_{d}$ measurements for the ambient and elevated temperature conditions are given in Tables XXIII and XXIV, respectively. The sorption ratios for technetium were calculated using Eq. 1 since no container sorption was found for ${ }^{95 m_{T}}$. The initial $\mathrm{pH}$ values of the solutions were 8.32 and 8.38 , for the $20^{\circ} \mathrm{C}$ and $70^{\circ} \mathrm{C}$ experiments, respectively. The final $\mathrm{pH}$ values and the percentages of the activities remaining in solution after the appropriate contact time are given in Table XXV. The sorption ratio results are shown graphically in Figs. 31-34.

As expected there seems to be a correlation between the surface area and the technetium sorption ratio for the ground samples. However, the highest $R_{d}$ values were observed for the chunk sample, which should have the lowest surface area. This may be due ${ }^{11}$ to the presence of organic matter in the argillite.

The technetium sorption ratio decreases dramatically when the temperature is raised to $70^{\circ} \mathrm{C}$. This may be due to increased solubility at the higher temperature.

The cesium sorption ratios obtained in this set of measurements are in reasonable agreement with those given earlier (Tables VII-XIV) for the same materials. The $R_{d}$ values for the 106-150 $\mu \mathrm{m}$ fractions from CN1 are higher, 
TABLE XXIII

Cs AND TC SORPTION RATIOS, AMBIENT TEMPERATURE

\begin{tabular}{|c|c|c|c|c|c|}
\hline \multirow[b]{2}{*}{ Core } & \multirow{2}{*}{$\begin{array}{l}\text { Fraction } \\
(\mu \mathrm{m})\end{array}$} & \multirow{2}{*}{$\begin{array}{c}\text { Sorption } \\
\text { Time } \\
\text { (days) } \\
\end{array}$} & \multirow{2}{*}{$\begin{array}{c}\text { Desorption } \\
\text { Time } \\
\text { (days) } \\
\end{array}$} & \multicolumn{2}{|c|}{ Sorption Ratio, $R_{d}(m \ell / g)^{\star}$} \\
\hline & & & & $\underline{\underline{C}}$ & Tc(VII) \\
\hline \multirow[t]{14}{*}{ CN1 } & $106-150$ & 6.75 & & $1320(2.0)$ & $11.8(5.1)$ \\
\hline & & & 56.81 & $1970(11)$ & $126(13)$ \\
\hline & & 16.76 & & $1370(1.6)$ & $11.9(4.0)$ \\
\hline & & & 27.74 & $2810(11)$ & 110 (13) \\
\hline & & 27.77 & & $2350(1.9)$ & $15.9(3.9)$ \\
\hline & & & 14.03 & $2090(11)$ & $95.4(12)$ \\
\hline & & 58.77 & & $2740(1.9)$ & $16.2(3.9)$ \\
\hline & $355-500$ & 6.74 & & $1070(1.3)$ & $15.4(4.0)$ \\
\hline & & & 56.81 & $1570(11)$ & $165(15)$ \\
\hline & & 16.76 & & $1930(1.6)$ & $21.5(3.4)$ \\
\hline & & & 27.74 & $4030(12)$ & $181 \quad(13)$ \\
\hline & & 27.76 & & $2490(2.6)$ & $22.1(3.6)$ \\
\hline & & & 14.03 & $2120(10)$ & $143(13)$ \\
\hline & & 58.76 & & $3850(2.1)$ & $31.0(3.0)$ \\
\hline \multirow[t]{7}{*}{$\mathrm{CN} 2$} & $<75$ & 6.73 & & $1030(12)$ & $18.3(3.9)$ \\
\hline & & & 56.81 & $3270(11)$ & $222 \quad(14)$ \\
\hline & & 16.75 & & $1230(1.5)$ & $29.1(3.0)$ \\
\hline & & & 27.73 & & $204(13)$ \\
\hline & & 27.76 & & $1600(1.8)$ & $34.7(2.9)$ \\
\hline & & & 14.03 & $3000(11)$ & $193(13)$ \\
\hline & & 58.75 & & $1830(1.8)$ & $39.8(3.0)$ \\
\hline \multirow[t]{7}{*}{ CN4 } & Chunk & 6.73 & & $865(1.2)$ & $18.8(3.6)$ \\
\hline & & & 56.81 & $1520(9.6)$ & $511 \quad(21)$ \\
\hline & & 16.74 & & $1930(1.8)$ & $111(2.3)$ \\
\hline & & & 27.73 & $4100(12)$ & $693 \quad(17)$ \\
\hline & & 27.75 & & $3040(1.6)$ & $136(2.1)$ \\
\hline & & & 14.03 & $3490(11)$ & $489 \quad(14)$ \\
\hline & & 58.75 & & $2770(1.9)$ & $(2.4)$ \\
\hline
\end{tabular}

* See the footnote to Table VII. 
TABLE XXIV

CS AND TC SORPTION RATIOS, $70^{\circ} \mathrm{C}$

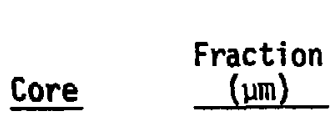

CN1 106-150

$355-500$

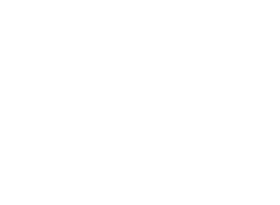

CN2

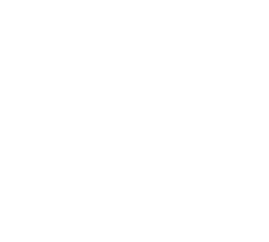

$\begin{array}{rr} & 59.73 \\ \text { CN4 } & \text { Chunk } \quad 6.70\end{array}$

59.72
13.71

27.71

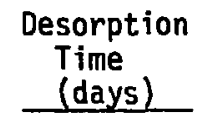

56.80

13.72

27.77

59.74

6.71

13.72

27.72

59.73

6.69

13.71

27.72
14.05

27.73

14.05

56.80

27.73

14.05

56.80

27.73

1.4 .05

56.80

27.71

(4.05

\begin{tabular}{|c|c|}
\hline \multicolumn{2}{|c|}{ Sorption Ratio, $R_{d}(m \ell / g){ }^{*}$} \\
\hline$\underline{\mathrm{CS}}$ & Ic(VI) \\
\hline $620(1.1)$ & $1.24(29)$ \\
\hline $1380(10)$ & $-3.98(28)$ \\
\hline $640(1.1)$ & $1.44(25)$ \\
\hline $1340(10)$ & $-2.43(48)$ \\
\hline $662(1.5)$ & $1.57(23)$ \\
\hline $1460(9.9)$ & $-1.75(70)$ \\
\hline $765(1.5)$ & $1.06(34)$ \\
\hline $972(1.3)$ & $1.72(22)$ \\
\hline $1930(10)$ & $-1.77(67)$ \\
\hline $983(1.5)$ & $2.23(16)$ \\
\hline $1890(11)$ & $1.57(94)$ \\
\hline $1110(1.5)$ & $2.03(18)$ \\
\hline $2000(11)$ & 0.04 \\
\hline $1150(1.6)$ & $1.61(23)$ \\
\hline $1930(1.5)$ & $0.94(42)$ \\
\hline $2930(11)$ & $-8.86(10)$ \\
\hline $1950(1.6)$ & $1.90(21)$ \\
\hline $2200(11)$ & $-4.38(25)$ \\
\hline $2060(1.9)$ & $3.14(14)$ \\
\hline $3260(11)$ & $5.81(35)$ \\
\hline $2340(1.8)$ & $2.15(20)$ \\
\hline $1050(1.3)$ & $5.36(7.9)$ \\
\hline $2200(11)$ & $17.8(18)$ \\
\hline $1020(1.4)$ & $6.70(6.8)$ \\
\hline $1930(11)$ & $33.5(11)$ \\
\hline $1130(1.7)$ & $9.56(5.2)$ \\
\hline $2120(11)$ & $45.3(13)$ \\
\hline T2.20 (1.7) & $12.4 \quad(4.6)$ \\
\hline
\end{tabular}

* See the footnote to Table VII. 
TABLE XXV

FINAL pH AND PERCENT REMAINING IN SOLUTION

\begin{tabular}{|c|c|c|c|c|c|c|}
\hline \multirow[b]{2}{*}{ Core } & \multirow{2}{*}{$\begin{array}{c}\text { Fraction } \\
\text { (um) } \\
\end{array}$} & \multirow{2}{*}{$\begin{array}{l}\text { Contact } \\
\text { Time } \\
\text { (days) } \\
\end{array}$} & \multirow{2}{*}{$\begin{array}{c}\text { Temperature } \\
\left({ }^{\circ} \mathrm{C}\right) \\
\end{array}$} & \multirow{2}{*}{$\begin{array}{c}\text { Final } \\
\mathrm{pH}\end{array}$} & \multicolumn{2}{|c|}{$\begin{array}{l}\text { Percent Remaining } \\
\text { in Solution }\end{array}$} \\
\hline & & & & & $\underline{C s}$ & Tc \\
\hline \multirow[t]{8}{*}{ CN1 } & $106-150$ & 6.75 & 20 & 8.75 & 1.52 & 63.3 \\
\hline & & 16.76 & & 8.78 & 1.48 & 63.4 \\
\hline & & 27.77 & & 8.46 & 0.85 & 55.9 \\
\hline & & 58.77 & & 8.20 & 0.73 & $55 . j$ \\
\hline & $355-500$ & 6.74 & 20 & 8.62 & 1.85 & 56.8 \\
\hline & & 16.76 & & 8.66 & 1.03 & 48.2 \\
\hline & & 27.76 & & 8.41 & 0.80 & 47.5 \\
\hline & & 58.76 & & 8.36 & 0.52 & 39.4 \\
\hline \multirow[t]{4}{*}{ CN2 } & $<75$ & 6.73 & 20 & 8.88 & 2.16 & 55.4 \\
\hline & & 16.75 & & 8.76 & 1.84 & 44.2 \\
\hline & & 27.76 & & 8.53 & 1.40 & 39.6 \\
\hline & & 58.75 & & 8.47 & 1.24 & 36.7 \\
\hline \multirow[t]{4}{*}{ CN4 } & Chunk & 5.73 & 20 & 8.72 & 2.22 & 51.1 \\
\hline & & 16.74 & & 8.70 & 1.01 & 15.0 \\
\hline & & 27.75 & & 8.54 & 0.65 & 12.8 \\
\hline & & 58.75 & & 8.44 & 0.71 & 8.1 \\
\hline \multirow[t]{8}{*}{ CN1 } & $106-150$ & 6.72 & 70 & 8.87 & 3.17 & 94.3 \\
\hline & & 13.72 & & 8.67 & 3.09 & 93.4 \\
\hline & & 27.72 & & 8.00 & 2.96 & 92.8 \\
\hline & & 59.73 & & 8.65 & 2.62 & 95.1 \\
\hline & $355-500$ & 6.71 & 70 & 8.82 & 2.04 & 92.2 \\
\hline & & 13.72 & & 8.75 & 1.94 & 89.7 \\
\hline & & 27.72 & & 8.20 & 1.79 & 90.8 \\
\hline & & 59.73 & & 8.64 & 1.74 & 92.7 \\
\hline \multirow[t]{4}{*}{$\mathrm{CN} 2$} & $<75$ & 6.69 & 70 & 8.78 & 1.16 & $96 . \hat{0}$ \\
\hline & & 13.71 & & 8.02 & 1.16 & 92.3 \\
\hline & & 27.72 & & 8.26 & 1.10 & 88.0 \\
\hline & & 59.73 & & 8.46 & 0.98 & 91.5 \\
\hline \multirow[t]{4}{*}{$\mathrm{CN} 4$} & Chunk & 6.70 & 70 & 8.75 & 1.87 & 78.9 \\
\hline & & 13.71 & & 8.25 & 1.96 & 75.2 \\
\hline & & 27.71 & & 8.21 & 1.72 & 67.4 \\
\hline & & 59.72 & & 8.56 & 1.65 & 62.2 \\
\hline
\end{tabular}



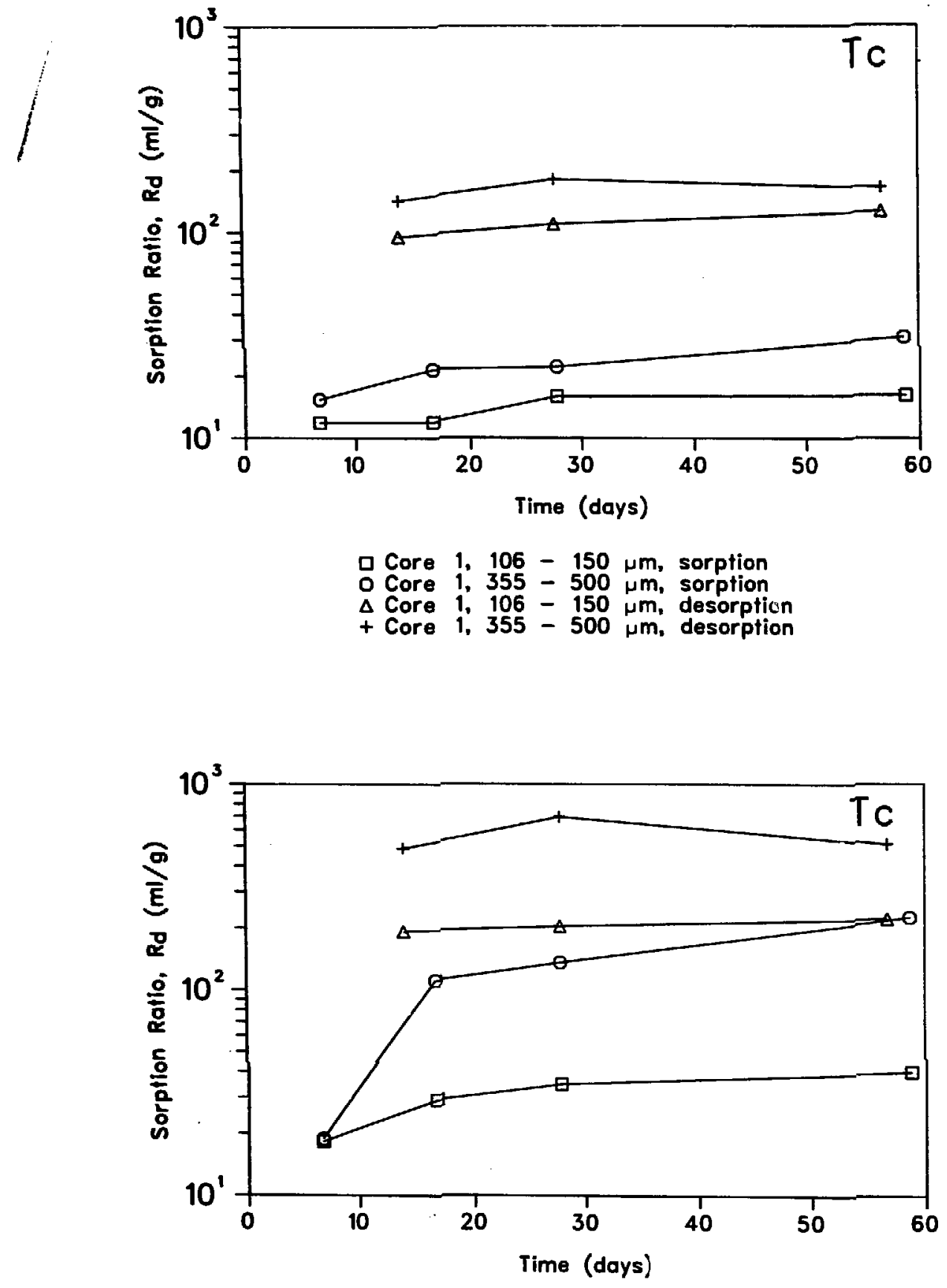

口 Core 2, $-75 . \mu \mathrm{m}$, sorption

o Core 4, chunk, sorption

$\Delta$ Core 2, $-75 \mathrm{~mm}$, desorption

+ Core 4, chunk, desorption

Fig. 31. Technetium sorption-desorption ratio data, ambient temperature. 


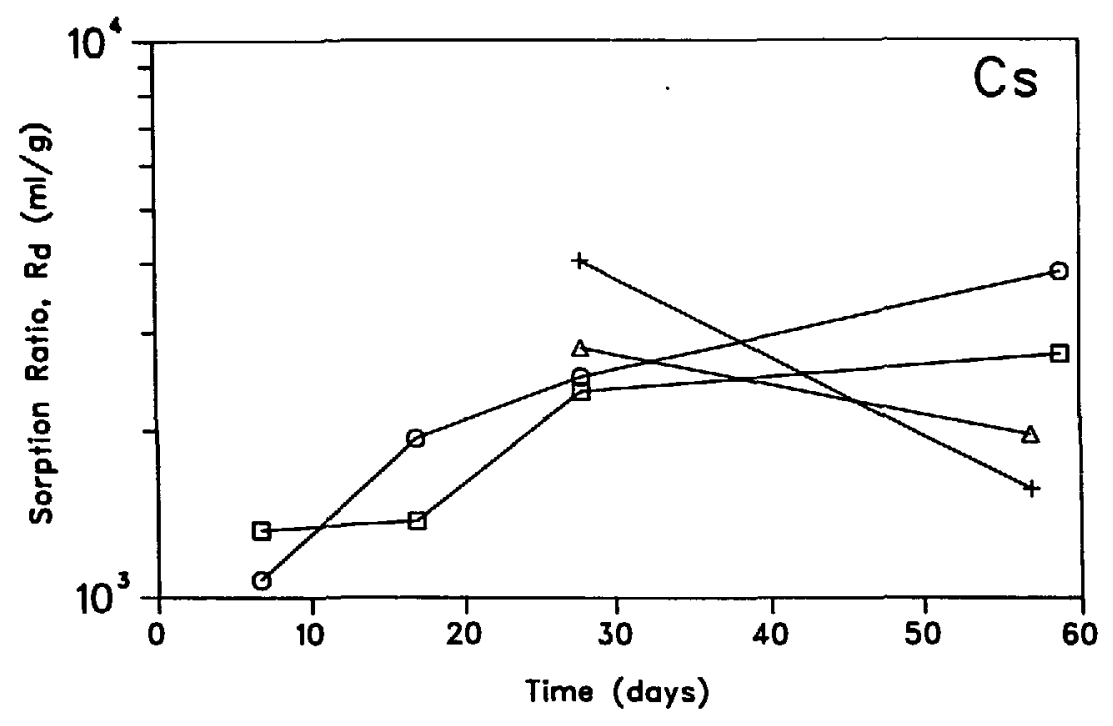

D Core 1, 106 - $150 \mu \mathrm{m}$, sorption

O Core 1, 355 - $500 \mathrm{\mu m}$, sorption

$\Delta$ Core 1, 106 - $150 \mu \mathrm{m}$, desorption

+ Core 1, 355 - $500 \mu \mathrm{m}$, desorption

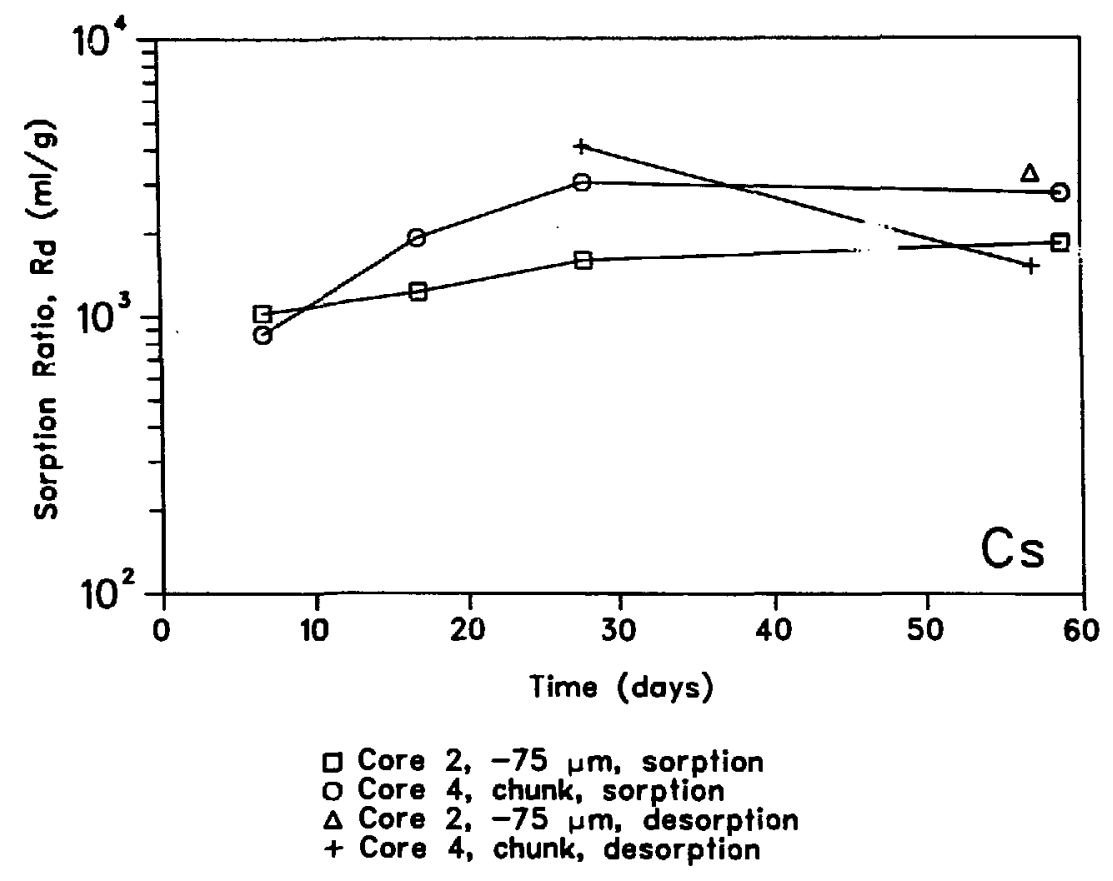

Fig. 32. Cesium sorption-desorption ratio data, ambient temperature. 

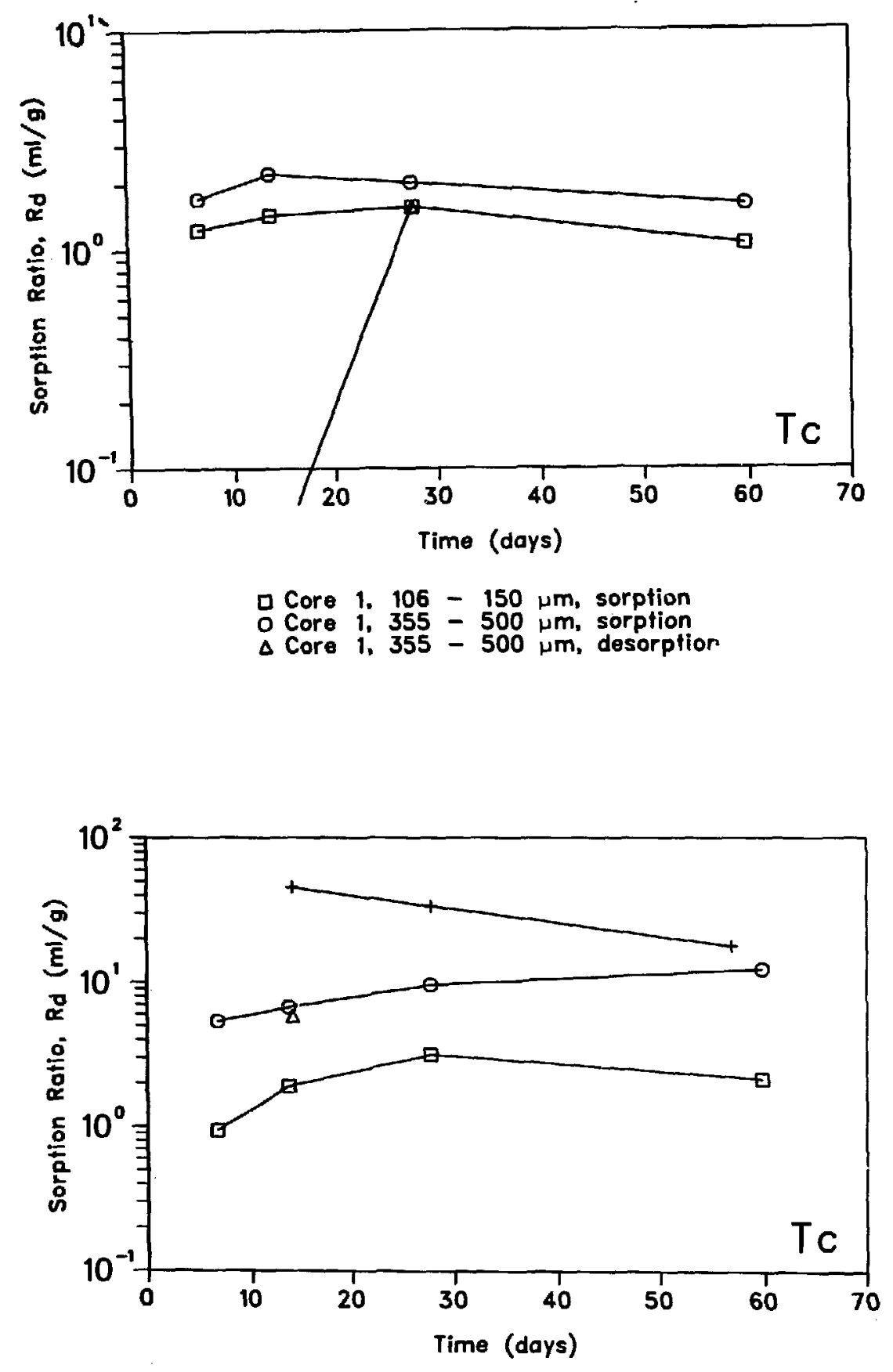

$a$ Core 2, $-75 \mathrm{um}$, sorption

o Core 4, chunk, sorption

$\triangle$ Core 2, $-75 \mathrm{\mu m}$, desorption

+ Core 4, chunk, desorption

Fig. 33. Technetium sorption-desorption ratio data, $70^{\circ} \mathrm{C}$. 


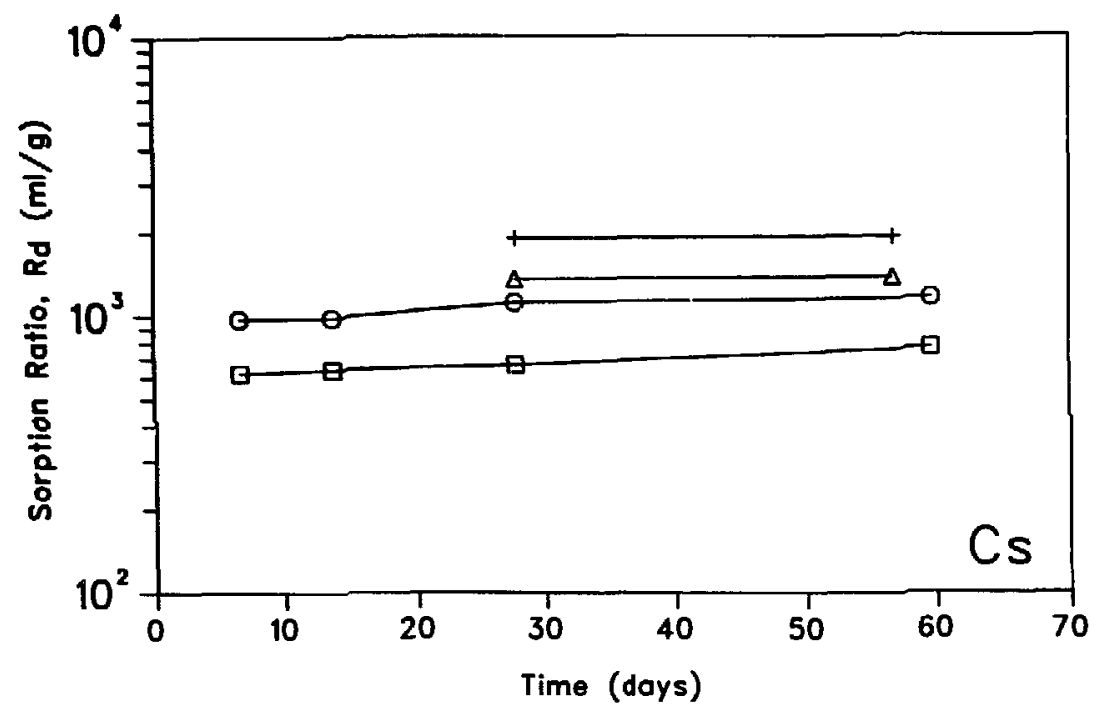

口 Core 1, 106 - $150 \mu \mathrm{m}$, sorption

o Core 1, 355 - $500 \mu \mathrm{m}$, sorption

$\Delta$ Core 1, 106 - $150 \mathrm{\mu m}$, desorption

+ Core 1, 355 - 500 нm, desorption

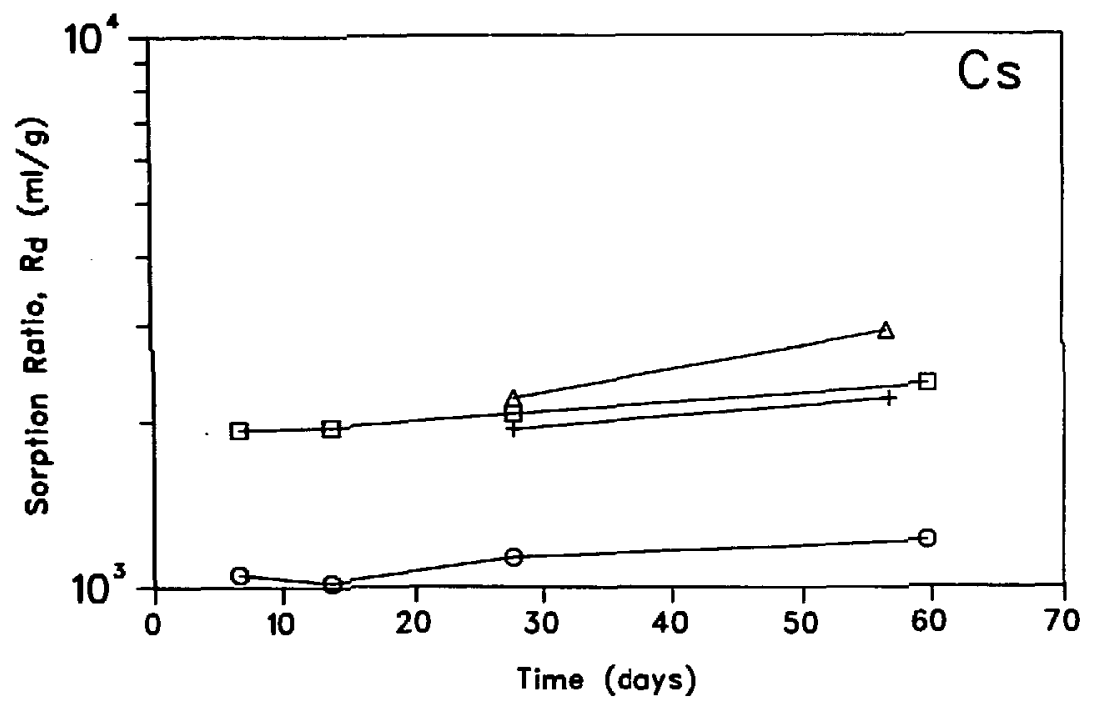

口 Core 2, $-75 \mu \mathrm{m}$, sorption

o Core 4, chunk, sorption

$\Delta$ Core 2, $-75 \mathrm{\mu m}$, desorption

+ Core 4, chunk, desorption

Fig. 34. Cesium sorption-desorption ratio data, $70^{\circ} \mathrm{C}$. 
however, than the earlier results. The agreement between the sets is encouraging since a different batch of water was used and the sieved fractions had been stored for several months between the two sets of experiments. One could expect some dehydration of the samples with time that could lead to changes in the mineralogy.

The mean sorption ratios for technetium for all measurements are $47 \pm 15$ $\mathrm{m} / \mathrm{g}$ and $3.4 \pm 0.8 \mathrm{ml} / \mathrm{g}$ for the ambient and $70^{\circ} \mathrm{C}$ conditions, respectively. Similarly, the mean sorption ratios for cesium for these experiments are $2270 \pm 940 \mathrm{ml} / \mathrm{g}$ and $1580 \pm 690 \mathrm{ml} / \mathrm{g}$ for the two temperature conditions.

\section{SUMMARY}

Table XXVI summarizes representative sorption ratios for each of the elements studied at ambient $\left(22 \pm 2^{\circ} \mathrm{C}\right)$ and elevated $\left(70 \pm 1^{\circ} \mathrm{C}\right)$ temperature. ACKNOWLEDGMENTS

The authors wish to thank A. R. Lappin and R. G. Dosch of the Sandia Laboratories for providing the Eleana argillite cores and for the water analysis and formulation.

Similarly, we wish to acknowledge R. J. Serne (Battelle Pacific Northwest Laboratory) and J. J. Hines (Argonne National Laboratory) who provided the ${ }^{95 m_{T C}}$ utilized in this study.

The authors wish to thank D. C. Hoffman for many fruitful discussions and valuable advice. The authors also wish to acknowledge the following Los Alamos Scientific Laboratory personnel for the efforts mentioned: J. R. Smyth and R. M. Vidale (petrography), R. E. Honnell (size distribution analyses and BET surface area measurements), P. A. Elder and M. E. Lark (sample counting and $\gamma$-spectral analyses), A. E. Norris and R. E. Honnell (BET surface area and particle size analyses), and E. F. Willow and L. M. Wagoner (typing of drafis and final manuscript). 
TABLE XXVI

REPRESENTATIVE SORPTION RATIOS (m//g)

\begin{tabular}{|c|c|c|c|c|}
\hline \multirow[b]{2}{*}{ Element } & \multicolumn{2}{|c|}{$22 \pm 2^{\circ} \mathrm{C}$} & \multicolumn{2}{|c|}{$70 \pm 1{ }^{\circ} \mathrm{C}$} \\
\hline & Sorption & Desorption & Sorption & Desorption \\
\hline Sr & $135 \pm 10$ & $126 \pm 14$ & $322 \pm 37$ & $268 \pm 36$ \\
\hline $\operatorname{Tc}(V I I)$ & $47 \pm 15$ & & $3.4 \pm 0.8$ & $17 \pm 8$ \\
\hline Cs & $1990 \pm 120$ & $3610 \pm 210$ & $1580 \pm 90$ & $2680 \pm 140$ \\
\hline $\mathrm{Ba}$ & $3920 \pm 710$ & $5240 \pm 790$ & $13200 \pm 3000$ & $31300 \pm 6700$ \\
\hline $\mathrm{Ce}$ (III) & $41900 \pm 6400$ & $86400 \pm 14000$ & $10800 \pm 2500$ & $17400 \pm 3900$ \\
\hline$E($ III $)$ & $36000 \pm 5100$ & $89200 \pm 6000$ & $11400 \pm 2300$ & $42700 \pm 7400$ \\
\hline
\end{tabular}

\section{REFERENCES}

1. E. R. Thomkins and S. W. Mayer, "Ion Exchange as a Separations Method III. Equilibrium Studies of the Reactions of Rare Earth Complexes with Synthetic Ion Exchange Resins," J. Am. Chem. Soc. 69, 2859 (1947); "Ion Exchange as a Separations Method IV. Theoretical Analys is of The Column Separations Process," J. Am. Chem. Soc. 69, 2866 (1947).

2. J. F. Relyea, Di Rai, and R. J. Serne, "Interaction of Waste Radionuclide with Geomedia: Program, Approach, and Progress," Proceedings of the Symposium on Science Underlying Radionuclide Waste Management, Materials Research Society, Boston, Massachusetts, November 28-December 1, 1978.

3. G. H. Higgins, "Evaluation of the Ground-Water Contaminants Hazard from Underground Nuclear Explosions," J. Geophys. Res. 64, 1509 (1959).

4. D. H. Lester, G. Jansen, and H. C. Burkholder, "Migration of Radionuclide Chains Through an Absorbing Medium," in Adsorption and Ion Exchange, I. Zwiebel and N. H. Sweed, Eds. (AIChE Symposium Series 152, No. 71, New York, 1975) 202-213.

5. K. Wolfsberg, "Sorption-Desorption Studies of Nevada Test Site Alluvium and Leaching Studies of Nuclear Test Debris," Los Alamos Scientific Laboratory report LA-7216-MS (1978).

6. H. Cramer, Mathematical Methods of Statistics (Princeton University Press, 1946), p. 187.

7. S. Brunauer, P. H. Emmett, and R. Teller, "Adsorption of Gases in Multimolecular Layers," J. Am. Chem. Soc. 60, 309 (1938).

8. R. S. Dyal and S. B. Hendricks, "Total Surface of Clays in Polar Liquids as

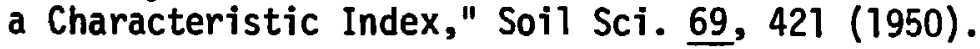


9. C. A. Bower and J. 0. Goertzen, "Surface Area of Soils and Clays by an Equilibrium Ethylene Glycol Method," Soil Sci. 87, 289 (1959).

10. B. L. McNeal, "Effect of Exchangeable Cations on Glycol Retention by Clay minerals," Soil Sci. 97, 96 (1964).

11. D. Rhai and R. J. Serne, "Solid Phases and Solution Species of Different Elements in Geologic Environments," Battelle Pacific Northwest Laboratory report PNL-2651 (March 1978). 